Claudio Eduardo Goes

\title{
RECONSTRUÇÃO TRI-DIMENSIONAL DE IMAGENS OBSTÉTRICAS DE ULTRA-SOM UTILIZANDO LINGUAGEM COMPUTACIONAL JAVA E OPENGL
}

Tese apresentada à Escola de Engenharia de São Carlos da Universidade de São Paulo, como parte dos requisitos para obtenção do Título de Doutor em Engenharia Elétrica.

Orientador: Prof. Dr. Homero Schiabel 
AUTORIZO A REPRODUÇÃO E DIVULGAÇÃO TOTAL OU PARCIAL DESTE TRABALHO, POR QUALQUER MEIO CONVENCIONAL OU ELETRÔNICO, PARA FINS DE ESTUDO E PESQUISA, DESDE QUE CITADA A FONTE.

Ficha catalográfica preparada pela Seção de Tratamento

da Informação do Serviço de Biblioteca - EESC/USP

Goes, Claudio Eduardo

G598r Reconstrução tri-dimensional de imagens obstétricas de ultra-som utilizando linguagem computacional JAVA e OPENGL / Claudio Eduardo Goes ; orientador Prof. Dr. Homero Schiabel. -- São Carlos, 2007.

Tese (Doutorado-Programa de Pós-Graduação em Engenharia Elétrica. Área de Concentração: Processamento de Sinais e Instrumentação) -- Escola de Engenharia de São Carlos da Universidade de São Paulo, 2007.

1. Ultra-som. 2. Reconstrução de volume. 3. Imagem tridimensional. 4. Feto. 5. JAVA. 6. OpenGL. I. Título. 
Dedico...

A minha mãe pelo exemplo de vida e por seu amor incondicional Ao meu pai cuja perseverança me mostrou como conseguir um sonho Aos meus avós pelo carinho e amor que sempre me trataram A minha esposa Giovana pelo amor e amizade 



\section{Agradecimentos}

Gostaria de antes de todos agradecer principalmente ao Prof. Dr. Homero Schiabel, pela orientação neste trabalho e principalmente, por ter me ensinado como professor sobre o universo acadêmico sempre com muita seriedade, inteligência e profissionalismo. Espero ter atingido suas expectativas durante os 8 anos que trabalhamos juntos desde o Mestrado até agora. Obrigado Professor.

Aos meus pais, Odete Rosa Escanuela Góes e Cláudio Góes por terem contribuído para a formação do meu caráter e minha educação, fatores estes que me ajudaram muito em minha vida.

À minha irmãzinha Caroline Escanhuela Góes ao João Felipe Góes Aranha e ao Luis Henrique por terem feito meus finais de semana melhores.

Aos meus avós Francisco Fernandes e Rosa Escanhuela pela eterna preocupação demonstrada e por serem sempre maravilhosos para mim.

À minha querida e amada esposa Giovana Tonon Góes por ter me amado, compreendido e me ajudado, em tudo o que foi necessário, durante todos esses anos e por fazer meus dias mais felizes.

À grande amiga e Prof Dr $^{a}$ Fátima de Lourdes dos Santos Nunes Marques, pelas longas discussões e auxílio no que diz respeito desde os tempos da graduação, até o presente momento. Agradeço a Deus por ter colocado uma pessoa iluminada e inteligente como você na minha vida.

Ao amigo e agora Prof. Dr. Peter Par..., digo, Marcelo Andrade da Costa Vieira por todos os momentos que convivemos juntos, mesmos os mais difíceis você sempre encontrou um jeito de inverter a situação, muito obrigado. 
Aos amigos Dr. Mauricio Cunha Escarpinatti e Ms. Ana Cláudia Martinez pelo convívio diário e por tornar o ambiente do laboratório mais alegre.

Ao Prof. Dr. Aderson Tadeu Beresowski por ter me auxiliado na captura da maior parte das imagens contidas neste trabalho. Pela sua alegria e disposição em me atender, mesmo sendo uma pessoa muito ocupada.

Aos amigos Ismar Spina e Alessandra Spina pela amizade e pelo excelente acolhimento em São Carlos, durante as últimas fases da elaboração deste trabalho.

Ao primo Francisco José Conti Escanhuela pela grande amizade e por ser aquele irmão que não cheguei a ter.

Aos Tios Francisco Escanhuela Fernandes e Antônio Escanhuela Fernandes, e as Tias Ivete Luzia Escanhuela Fernandes, Neuza Conti Escanhuela e Maria José Escanhuela pela preocupação carinho e apoio demonstrado durante a elaboração deste trabalho.

Ao médico João Paulo Issa, por ter me auxiliado na coleta de algumas imagens deste trabalho e mais importante, por ter tratado minha esposa quando ela precisou.

À minha cunhada Renata Tonon pela ajuda na captura de algumas imagens de ultrasom.

À Renata Góis, Patrícia Berlinni, Michele Fúlvia, Eveline Rodrigues, Paulo Domingues, Leandro Freitas, Paula Zítico, Luciana Guimarães e a todos os outros colegas do Laboratório de Análise e Processamento de Imagens Médicas e Odontológicas (LAPIMO), pelo companheirismo, carinho, e pelos excelentes momentos que passamos juntos ao longo dessa jornada.

A todos os professores e funcionários do Departamento de Engenharia Elétrica, principalmente à Marisa, Denise, Roseli, Jussara, Gerson, Dona Cida e Ruiberto pelo auxílio nas tarefas burocráticas e pela excelente convivência durante todos esses 9 anos.

Aos amigos, Fabio Roberval Rossi e Alessandra pela grande amizade que sempre mantivemos. 
À Bianca em memória, por ter feito a minha vida mais feliz por quase 12 anos. Aos amigos e colegas de trabalho Ronaldo Martins da Costa, Kelton Augusto Pontara, Luciene Cristina Rinaldi, Élvio Gilberto da Silva, Luiz Alexandre da Silva, Tânia Ferreira, Maria José de Almeida Tamamati e Renata Caversan pela constante preocupação a respeito deste trabalho.

A todas as pessoas que me ajudaram de alguma maneira para a realização deste trabalho e de maneira injusta não foram aqui citados peço perdão e ofereço um muito obrigado de todo meu coração.

Ao CNPQ e à CAPES por terem confiado a mim a bolsa de estudos atualmente muito concorrida, e que foi imprescindível para a realização deste projeto.

Finalmente, ao mais importante de todos, agradeço à Deus pela proteção me dada todo esse tempo, principalmente nas viagens pelas estradas e nos momentos mais difíceis que passei durante toda minha vida e não sabia a quem recorrer. 



\section{RESUMO}

Este projeto de pesquisa trata da elaboração de um sistema de reconstrução de imagens obstétricas de fetos, em aparelhos de ultra-som convencionais, para a visualização dessas imagens em três dimensões utilizando a Internet como meio de utilização do sistema, com o principal objetivo de proporcionar aos médicos ginecologistas melhor visualização do formato e das estruturas internas, e em especial da face do feto, através do processo de reconstrução tridimensional feito a partir de um conjunto de imagens bidimensionais capturadas em aparelhos convencionais de ultra-som. O uso clínico deste projeto está previsto para o setor de Obstetrícia do Hospital das Clínicas de Ribeirão Preto.

Palavras-chave: ultra-som, reconstrução de volume, tridimensional, feto, Java, OpenGL. 



\begin{abstract}
This project of research deals with the elaboration of a reconstruction system of obstetrics images of embryos in devices of ultrasound will be conventional the visualization of these images in three dimensions using the Internet half of uses of the system, with the main objective provides to the medical gynecologists a better visualization of the format and the internal structures and in special the face of the embryo through the made process of threedimensional reconstruction from a dataset of captured bi-dimensional images in conventional devices of ultrasound. The clinical uses of this project is foreseen will be the sector of Obstetrics of the Hospital of the Clinics of Ribeirão Preto.
\end{abstract}

Key-words: ultrasound, volume rendering, three-dimensional, fetus, Java, OpenGL. 



\section{SUMÁRIO}

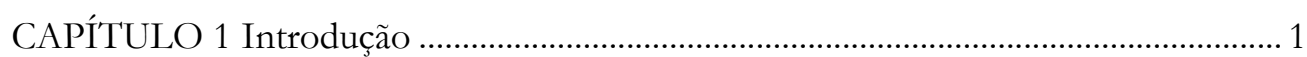

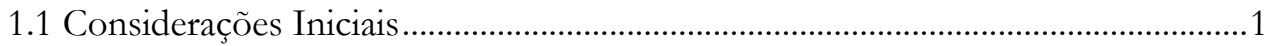

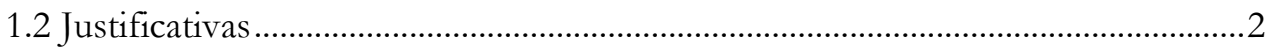

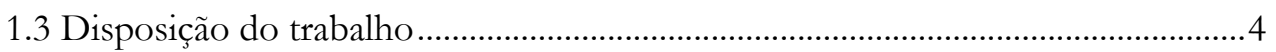

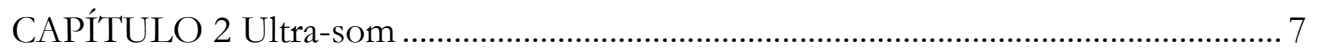

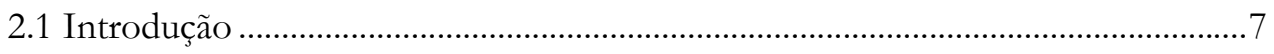

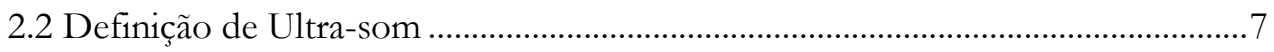

2.3 Componentes Básicos de um Aparelho de Ultra-som Convencional .................. 9

2.4 Esquema de um Transdutor ..............................................................................12

2.5 Funcionamento do Aparelho de Ultra-som.............................................................13

2.6 Diagnóstico de Imagens pelo Ultra-som..............................................................15

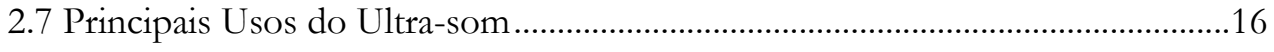

2.8 Riscos da Utilização do Ultra-som..........................................................................17

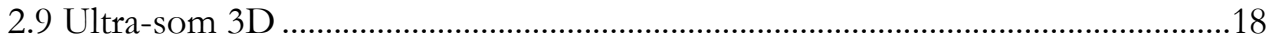

CAPÍTULO 3 Reconstrução de Volume em Imagens Digitais ...................................2 27

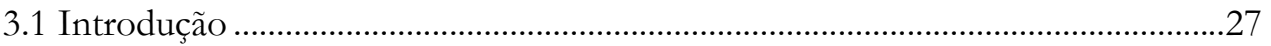

3.2 Métodos para Visualização de Volumes.......................................................................30

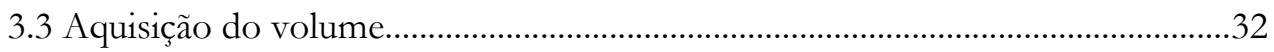

3.4 Reconstrução de Volume por Ray-casting e Ray-tracing ...........................................33

3.5 Diagrama da Reconstrução de Volume......................................................................36

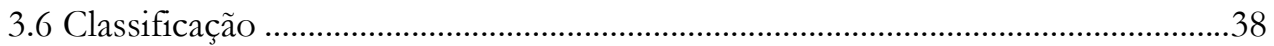

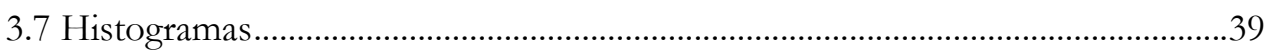

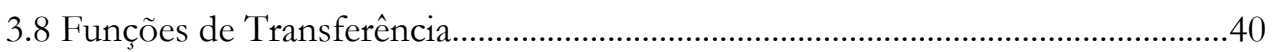

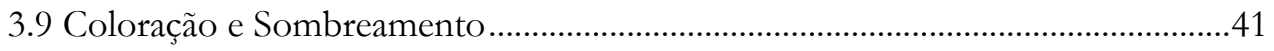

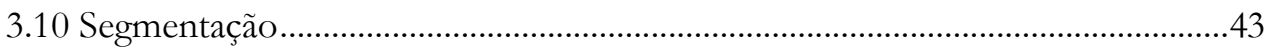

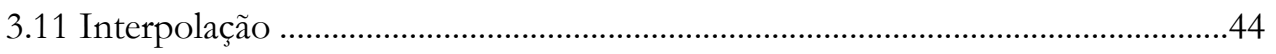

3.11.1 Núcleos de Interpolação.....................................................................................45

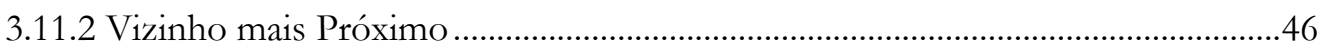

3.12 OpenGL (Open Graphics Library) .....................................................................4

3.13 A Linguagem Computacional Java.......................................................................48

CAPÍTULO 4 Formas de Aquisição de Imagens 3D em Aparelhos de Ultra-som ... 53

4.1 Introdução 


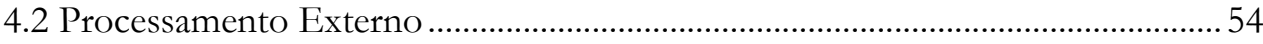

4.3 Sensores Mecânicos Provendo Varredura Volumétrica .......................................... 55

4.4 Transdutores Convencionais Conectados a Sensores Espaciais .......................... 57

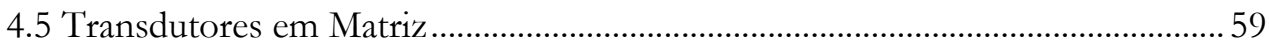

CAPÍTULO 5 Materiais e Métodos..............................................................................61

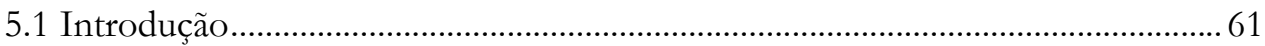

5.2 Rastreador Magnético Polhemus Patriot ................................................................. 62

5.2.1 Console do Equipamento Polhemus Patriot .............................................................63

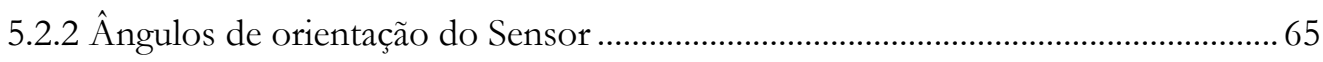

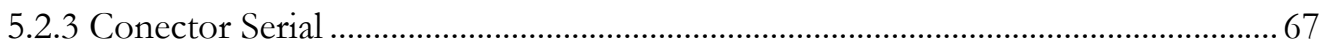

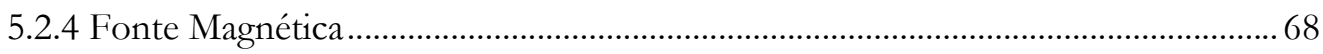

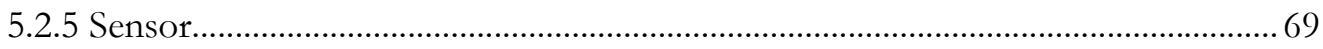

5.3 Comunicação dos Dados do Sensor Patriot com o Computador ........................ 71

5.4 Esquema de Desenvolvimento do Sistema Proposto.............................................. 71

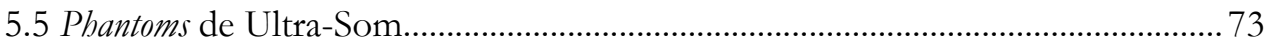

5.6 Captura de Imagens Ultra-sônicas de Fetos............................................................... 79

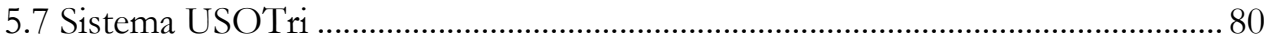

5.7.1 Diagrama de Fluxo de Funcionamento do Sistema USOTri..................................... 81

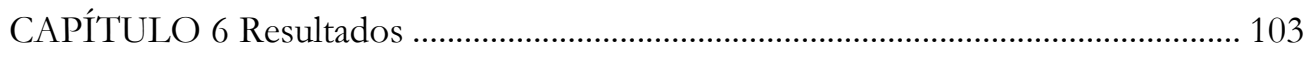

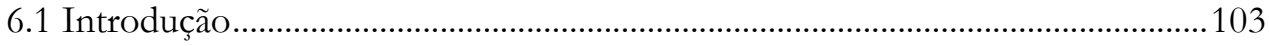

6.2 Phantom Computacional....................................................................................... 104

6.3 Testes Práticos com Phantoms Físicos....................................................................... 108

6.4 Testes com Imagens Reais de Feto in vivo ……………………........................117

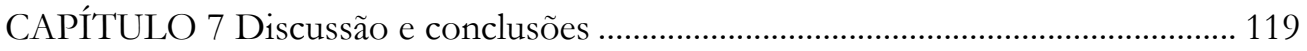

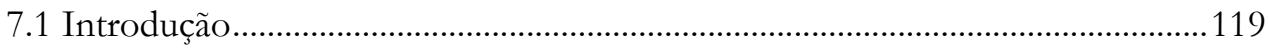

7.2 Manipulação da Informação do Volume 3D ...................................................... 121

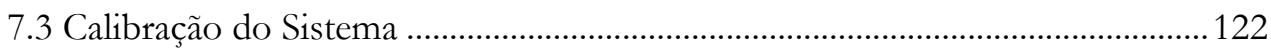

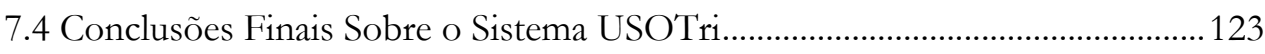

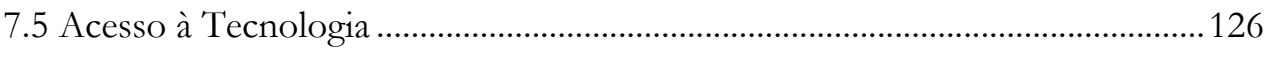

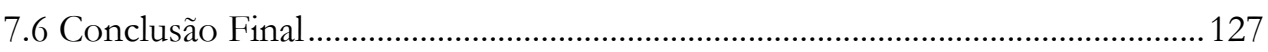

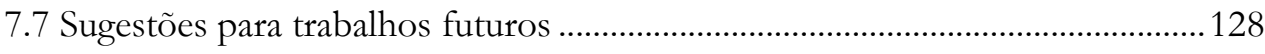

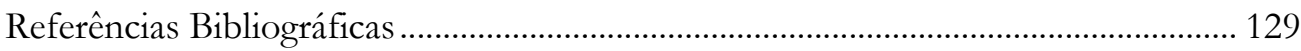




\section{LISTA DE FIGURAS}

Figura 2.1 - Principais partes de um equipamento de Ultra-som convencional. 9

Figura 2.2 - Diferentes tipos de transdutores utilizados em exames por equipamentos de Ultra-som. a) Convexos; b) Endocavitários ou Transvaginais; c) Transrectal; d) Setoriais. (Fonte: Shimadzu do Brasil) 11

Figura 2.3 - Esquema interno de um transdutor. Fonte: HEDRICK et al. (1995). .13

Figura 2.4 - Esquema de funcionamento de um aparelho de ultra-som. Fonte: HEDRICK et al. (1995) 14

Figura 2.5 - Exame de ultra-som obstétrico sendo realizado em uma paciente (Fonte:

Philips Research) 16

Figura 2.6 - Diferença visual nos modos de ultra-som 2D para o ultra-som 3D: a) Imagem de um bebe após o parto; b) Imagem do bebe com o ultra-som 2D; c) Imagem do bebe em um ultra-som 3D. Fonte: www.gemedicalsystems.com. 22

Figura 2.7 - Imagem de ultra-som ilustrando o crescimento do feto com aproximadamente 20 semanas de idade dentro do útero da mãe: a) Imagem de uma criança em um ultrasom 2D; b) Imagem de uma criança em um ultra-som 3D. Fonte: www.pregnancyweekly.com 22

Figura 2.8 - Visualização do ultra-som 3D: a) Antes da 26ª semana de gestação; b) Após a $26^{a}$ semana de gestação. Fonte: GHI T. et al. (2000). .24

Figura 2.9 - Aspecto de meningomielocele: a) Ultra-som convencional 2D; b) Ultra-som 3D. Fonte: CHMAIT et al. (2001) 25

Figura 3.1 - Exemplo da reconstrução de alguns objetos em uma cena. Fonte: WOO et al. (1999). 29

Figura 3.2 - Reconstrução de volume a partir de seções planares adquiridas por tomografia computadorizada de uma cabeça humana de um cadáver. Fonte: LEVOY (1988b)... 30

Figura 3.3 - Ilustração da representação de uma matriz de: (a) Pixels; (b) Voxels. ..................33

Figura 3.4 - Raio percorrendo um volume de dados para formar um único pixel no

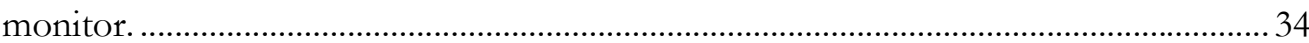

Figura 3.5 - Composição final da cor do voxel. Fonte: FOLEY et al. (1990)........................... 35

Figura 3.6 - Diagrama da reconstrução de volume. Fonte: LICHTENBELT et al. (1998).. 37

Figura 3.7 - Exemplo de um volume reconstruído e seu histograma: a) Volume reconstruído; b) Histograma obtido do conjunto de dados do volume..... 40 
Figura 3.8 - Galeria contendo diferentes níveis de funções de transferência de cores e opacidades. Fonte: MARKS et al. (1997)

Figura 3.9 - Galeria contendo diferentes níveis de função de transferência de opacidades.

Fonte: MARKS et al. (1997). .43

Figura 3.10 - Divisão do raio dentro de um volume por passos de incrementos. .44

Figura 3.11 - Passos ao longo de um raio. .45

Figura 3.12 - Diferentes núcleos de interpolação: a) Vizinho mais Próximo; b) Linear; c) Convolução Cúbica; d) B-spline.

Figura 3.13 - Ilustração do procedimento de interpolação..........................................................46

Figura 3.14 - Núcleo de interpolação do Vizinho mais Próximo. ..............................................47

Figura 3.15 - Exemplo de um código fonte de um programa em linguagem Java. .................51

Figura 4.1 - Direção e sentido do transdutor para a captura das imagens em uma gestante geralmente utilizado em sistemas de processamento externo............................................55

Figura 4.2 - Imagem de um sensor mecânico acoplado a um transdutor sobre o corpo do

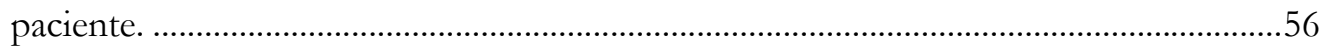

Figura 4.3 - Esquema interno de um transdutor 3D mecânico moderno. ................................57

Figura 4.4 - Sensores de rastreamento de posição magnéticos comercializados pela empresa Polhemus: a) Modelo Fastrak; b) Modelo Patriot.. .59

Figura 4.5 - Diferença entre a posição e o encadeamento de cristais piezelétricos em transdutores e o formato da onda ultra-sônica em transdutores: a) Convencionais; b) Matriz. Fonte: STETTEN et al. (1999).

Figura 5.1 - Dispositivos pertencentes ao rastreador magnético Polhemus Patriot.............63

Figura 5.2 - Vista lateral direita do console "Polhemus Patriot". .64

Figura 5.3 - "Vista" lateral esquerda do console "Polhemus Patriot". .64

Figura 5.4 Ângulos de Euler utilizados no equipamento "Polhemus Patriot".

Figura 5.5 - a) Fonte magnética do equipamento Polhemus Patriot. b) Esquema das dimensões da Fonte magnética.

Figura 5.6 - Sensor magnético do equipamento Polhemus Patriot. ......................................... 70

Figura 5.7 - Esquema mostrando as dimensões do sensor......................................................... 71

Figura 5.8 - Esquema de visualização 3D proposto por DETMER et al. (1994) e KELLEY et al. (1994).

Figura 5.9 - Imagem indicando o posicionamento do sensor de coordenadas 3D em um transdutor de um equipamento de ultra-som.....................................................................73

Figura 5.10 - Phantom fetal Modelo CIRS 065-36......................................................................74 
Figura 5.11 - Phantoms utilizados para os testes de reconstrução tridimensional deste sistema: a) Boneca de Brinquedo; b) Preservativo com água; c) Luva com água; d) Mini-salsicha; e) Salsicha; f) Lingüiça de porco; g) Asa de frango; h) Coxa de frango.76

Figura 5.12 - Aparelho de ultra-som, ATL HDI 3500 utilizado nos testes deste sistema... 77

Figura 5.13 - Imagem capturada da lingüiça de porco capturada no equipamento de ultrasom dentro dos diferentes Potes: a) Pote A; b) Pote B; c) Pote C.................................. 78

Figura 5.14 - Imagem de um feto de 18 semanas de uma fatia de uma seqüência de volume

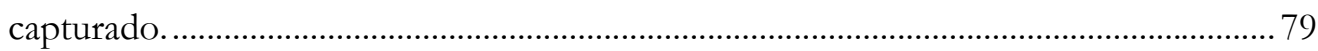

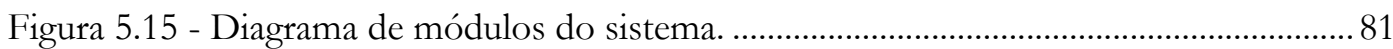

Figura 5.16 - Fluxograma do esquema de funcionamento do algoritmo para reconstrução

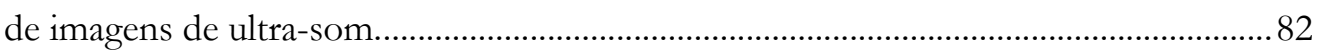

Figura 5.17 - Acoplamento do sensor no transdutor para a realização dos testes deste trabalho: a) Modo correto; b) Modo errado...................................................................... 85

Figura 5.18 - Imagens mostrando a trajetória percorrida para capturar um volume tridimensional. Os quadrados brancos representam a detecção do movimento do transdutor e representam a imagem capturada: a) Volume capturado com o sensor afastado do transdutor $3 \mathrm{~cm}$; b) Volume capturado com o sensor próximo do transdutor, caracterizando um desvio de trajetória na movimentação do transdutor

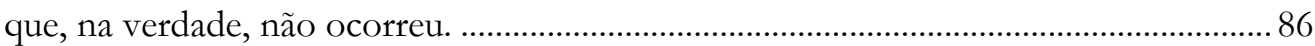

Figura 5.19 - Estrutura interna do arquivo RAW utilizada neste trabalho. .............................. 87

Figura 5.20 - a) Imagem original capturada utilizando o Modo-B; b) Aplicação da técnica de redução do efeito speckle na imagem original utilizando o método do filtro Gaussiano implementando neste trabalho.

Figura 5.21 - Modelo de posicionamento das imagens dentro do cubo da matriz de pixels. 89

Figura 5.22 - Imagem mostrando a seleção da RI e do ponto de orientação do início da imagem. 90

Figura 5.23 - Imagem contendo a seleção feita pelo usuário na grade da imagem utilizando

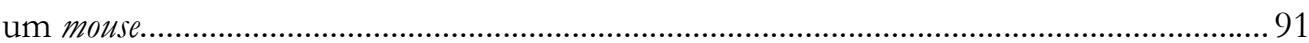

Figura 5.24 - Interface para montagem do volume.......................................................... 95

Figura 5.25 - Caminho percorrido pelo transdutor para a captura de imagens. Os quadrados brancos representam cada imagem capturada. ................................................. 96

Figura 5.26 - Esquema de visualização direta de dados por texturas em OpenGL

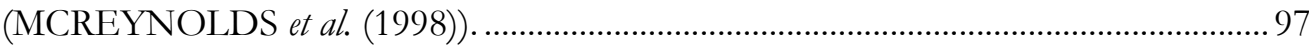


Figura 5.27 - Sistema funcionando na plataforma Windows com o sistema operacional Windows XP. .98

Figura 5.28 - Sistema funcionando na plataforma Linux na distribuição Suse versão 10.2.99 Figura 5.29 - Zona de ação de captura de imagens utilizando o transdutor em uma gestante. 101

Figura 6.1 - Seção transversal das estruturas geométricas originais criadas para a geração do volume 3d: a) Cubo; b) Esfera; c) Cone; Inserção do ruído speckle nas imagens originais: d) Cubo; e) Esfera; f) Cone. 105

Figura 6.2 - Seção transversal do Phantom mesclado com várias imagens geométricas: a) Sem adição do efeito speckle; b) Com adição do efeito speckele. 106

Figura 6.3 - Imagem da reconstrução de volume nos phantom's computacionais gerados neste trabalho: Imagens dos objetos originais: a) Cubo; b) Esfera; c) Cone; Imagens dos objetos processados com o efeito speckle: d) Cubo; e) Esfera; f) Cone. 107

Figura 6.4 - Imagem da reconstrução do modelo de phantom computacional composto por várias figuras geométricas: a) Sem adição do efeito speckle; b) Com adição do efeito

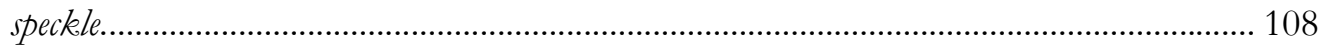

Figura 6.5 - Imagem de exemplo mostrando como foram feitas as aquisições das seqüências de imagens dos phantoms, neste caso a lingüiça de porco. 109

Figura 6.6 - Imagem mostrando a realização da captura da seqüência de imagens do phantom boneca de brinquedo.

Figura 6.7 - Imagem reconstruída da boneca de brinquedo: a) Fatia 2D do volume capturado; b) Reconstrução 3D.

Figura 6.8 - Imagem reconstruída da luva cirúrgica: a) Fatia 2D do volume capturado; b) Reconstrução 3D. 112

Figura 6.9 - Imagem reconstruída do preservativo: a)Fatia 2D do volume capturado; b) Reconstrução 3D. 113

Figura 6.10 - Imagem reconstruída da lingüiça de porco: a) Fatia 2D do volume capturado;

b) Reconstrução 3D. 114

Figura 6.11 - Imagem reconstruída da mini-salsicha: a) Fatia 2D do volume capturado; b)

Reconstrução 3D. 115

Figura 6.12 - Imagem reconstruída da salsicha de porco: a) Fatia 2D do volume capturado;

b) Reconstrução 3D. ………………………………………………………………... 116

Figura 6.13 - Imagem da RI do volume do feto in vivo 117 
Figura 6.14 - Imagens de fetos reais geradas neste sistema: a) Reconstrução 3D; b)

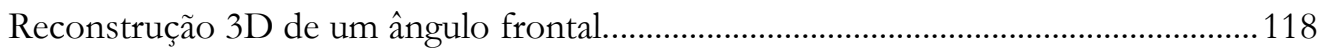

Figura 7.1 - Imagem do sistema USOTri funcionando como uma applet dentro do browser FireFox versão 1.5.0.11 120

Figura 7.2 - Gráfico comparativo, mostrando o consumo de memória RAM entre uma

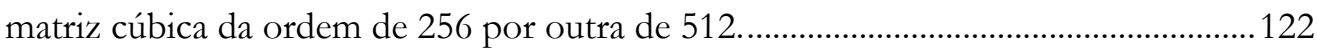

Figura 7.3 - Imagem ilustrando o esquema de acoplamento do sensor do trabalho de

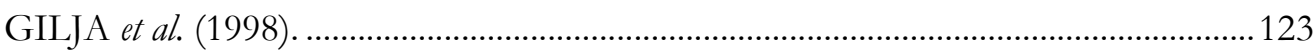

Figura 7.4 - Cadeira para exames obstétricos feita de metal. .................................................. 124 


\section{CAPÍTULO 1}

\section{Introdução}

\subsection{Considerações Iniciais}

Na maioria das clínicas ginecológicas, existe à disposição o aparelho convencional de ultra-som que gera imagens em duas dimensões dos fetos em gestantes. Com o advento do ultra-som com imagens em três dimensões, os médicos adquiriram mais uma ferramenta na área de diagnóstico, facilitando a identificação de má-formação fetal, além de obter melhor visualização de patologias.

O fator negativo deste tipo de tecnologia é que equipamentos com esta tecnologia são muito mais caros que os aparelhos de ultra-som convencionais. Em média, um aparelho de ultra-som comercial, custa aproximadamente $\mathrm{R} \$ 40.000,00$. Já o aparelho com recursos de geração de imagens tridimensionais possui o preço médio de $\mathrm{R} \$ 250.000,00$.

O objetivo deste trabalho é desenvolver um esquema de adaptação dos aparelhos convencionais de ultra-som de forma que com o acoplamento de um sensor de 
coordenadas tridimensionais, e com o sistema computacional que deverá ser implementado, possibilitem a visualização tridimensional (3D) do feto.

A vantagem deste sistema em relação aos já existentes é que é um sistema livre de plataforma computacional, ou seja, pode ser utilizado em qualquer plataforma computacional. Outra vantagem deste sistema diferente dos sistemas desenvolvidos em trabalhos anteriores, é a utilização do suporte a aceleração dos gráficos 3D utilizando as bibliotecas gráficas OpenGL.

Esse sistema utiliza um aparelho em especial para o auxilio na localização do transdutor do ultra-som no espaço. O driver de controle desse aparelho é fornecido apenas em Linguagem computacional C. Neste trabalho diferente de todos os outros trabalhos onde se utiliza um sistema freehand de ultra-som, foi criado um novo driver para a comunicação com esse aparelho em Linguagem computacional Java no sistema aqui desenvolvido.

Para facilitar a portabilidade (capacidade do programa ser executado em várias plataformas e sistemas computacionais diferentes sem a necessidade de modificação no código fonte) deste sistema, a programação será voltada para Internet, de modo que o usuário poderá utilizá-lo através de um browser (programa computacional com a capacidade de visualização de páginas no padrão HTML) com suporte a HTML (Hyper Text Markup Language) e linguagem Java, para torná-lo compatível com a maior parte dos sistemas operacionais, independentemente da plataforma computacional utilizada.

\subsection{Justificativas}

Os exames pré-natais de ultra-som são atualmente de grande importância para detectar anormalidades em crianças recém-nascidas. 
O processo de reconstrução $3 \mathrm{D}$ em imagens de ultra-som possibilita um grande aprimoramento em relação ao auxílio do diagnóstico em exames pré-natais. Este tipo de recurso tem como característica a visualização aprimorada da estrutura fetal em estudo, pois os exames de ultra-som 3D demonstram possuir superioridade em relação aos exames em 2D na identificação de várias anormalidades, como má-formação labial, crânio facial, e no rastreamento de anormalidades no tubo neural.

O modo 3D facilita a identificação do nível e gravidade de qualquer anormalidade morfológica. Este tipo de recurso adicional no diagnóstico de má-formação possibilita aos médicos especialistas planejar a estratégia a ser tomada para cada caso patológico.

Em aparelhos de ultra-som 3D disponíveis atualmente no mercado, existe a grande desvantagem em relação ao alto custo de aquisição desses aparelhos e também da utilização do sistema de controle disponibilizados pelos fabricantes destes aparelhos para poderem manipular as imagens off-line do aparelho de ultra-som. Esse tipo de sistema fornecido pelo fabricante permite que o sistema de manipulação das imagens em 3D possa ser instalados em outros computadores. O fato negativo é que é limitado a quantidade de licenças para a utilização desse sistema, ou ainda, alguns fabricantes disponibilizam um hardware especifico para ser introduzido na porta USB do computador, e somente com a utilização desse hardware especial é que o sistema do ultra-som 3D comercial pode funcionar fora do aparelho de ultra-som.

Nesta pesquisa, pretende-se contribuir para a qualidade de diagnóstico dos exames obstétricos, mais precisamente nos de má-formação fetal, desenvolvendo para os especialistas da obstetrícia uma ferramenta de visualização 3D de fácil utilização e que possa ser utilizada em qualquer aparelho de ultra-sonografia e em qualquer computador.

$\mathrm{Na}$ literatura científica, até o presente momento não foi descrito nenhum sistema semelhante a este que contenha as idéias de um sistema multi-plataforma com suporte a 
aceleração gráfica 3D por hardware e com comunicação direta do sistema com o hardware de sensoriamento $3 \mathrm{D}$

\subsection{Disposição do trabalho}

Este trabalho está dividido em 7 capítulos, incluindo a presente introdução e os temas estão distribuídos na seguinte forma:

Capítulo 2: Ultra-som; Neste capítulo é abordado o princípio básico do funcionamento e da formação da imagem em aparelhos de ultra-som. Também é mostrado um comparativo entre as características de diagnósticos utilizando imagens de ultra-som bidimensionais e tridimensionais e os problemas e as vantagens da utilização de cada um desses métodos.

Capítulo 3: Reconstrução de Volume; São discutidas algumas técnicas de algoritmos para a geração de imagens tridimensionais a partir de uma série de imagens transversais baseadas no levantamento da revisão bibliográfica. Neste capítulo também se discute o propósito da utilização da linguagem Java e da utilização da tecnologia OpenGL para a visualização das imagens tridimensionais.

Capítulo 4: Formas de Aquisição de Imagens 3D em Aparelhos de Ultra-som; Neste capítulo é debatido alguns dos esquemas mais utilizados na bibliografia para a aquisição e geração de imagens tridimensionais em equipamentos de ultra-som, quais os seus pontos favoráveis e desfavoráveis, e qual o método que foi tomado como base para o desenvolvimento deste trabalho. 
Capítulo 5: Materiais e Métodos; É descrito aqui como foi realizada a construção de phantoms computacionais para a obtenção dos resultados da visualização tridimensional. Também é indicado como e quais tecnologias foram empregadas para o desenvolvimento do protótipo do programa que será desenvolvido.

Capítulo 6: Resultados; É apresentado neste tópico os resultados da elaboração do software proposto neste trabalho com os resultados da reconstrução tridimensional das imagens de phantoms computacionais, phantoms reais e imagens de pacientes geradas e implementadas neste projeto.

Capítulo 7: Discussão e Conclusões; Aqui é mostrado os fatos finais e toda conclusão e experiência adquirida na elaboração deste projeto e o traçado de novas visões que podem ser elaboradas a partir deste trabalho. 


\section{CAPÍTULO 2}

\section{Ultra-som}

\subsection{Introdução}

Neste capítulo é abordada a definição de ultra-som, bem como os processos físicos para sua obtenção. Também é apresentado o esquema de funcionamento de um aparelho ultra-sonográfico, como é realizado um exame de rotina de ultra-som obstétrico e quais tipos de diagnósticos são determinados neste tipo de exame. Na última parte deste capítulo apresentam-se alguns exames realizados com o ultra-som 3D.

\subsection{Definição de Ultra-som}

CARR et al. (1998) afirmam que o som é a propagação de ondas de pressão por algum meio físico. Normalmente o meio é o ar, embora os líquidos geralmente conduzam 
melhor as ondas. As ondas de pressão são geradas de algum tipo de perturbação mecânica. Som é uma transferência de força. A energia mecânica é convertida em uma forma de onda que irradia energia ao longo da perturbação. Vibrações mecânicas se tornam pressão ondular, enquanto transferem energia ao meio e para objetos que estão no alcance dos contatos das ondas. O ser humano não é capaz de ouvir o ultra-som porque sua audição é limitada (não vai além de $18 \mathrm{KHz}$, enquanto o ultra-som tem freqüências da ordem de $\mathrm{MHz})$.

O aparelho de ultra-som funciona convertendo pulsos elétricos em vibrações sonoras de alta freqüência que são transmitidas e direcionadas para um corpo, e através da captação dos ecos de retorno dessa vibração sonora são novamente convertidas em pulso elétrico, os sinais do eco são diferentes dos sinais emitidos, devido as diferentes estruturas presentes no corpo que resultam em diferentes tipos de sinais dependendo das estruturas que as ondas sonoras atravessam e refletem durante o trajeto. Na Tabela 2.1 é apresentado a velocidade de propagação do som em diferentes estruturas. Os dispositivos ou sondas que criam o som e recebem os ecos usam transdutores feitos de materiais piezelétricos. Estes materiais têm a propriedade de vibrar quando estimulados através da eletricidade e geram eletricidade quando são vibrados através de som.

Tabela 2.1 - Relação entre a velocidade do som em alguns materiais.

\begin{tabular}{|l|r|}
\hline \multicolumn{1}{|c|}{ Material } & \multicolumn{1}{|c|}{ Velocidade (m/s) } \\
\hline Ar & 330 \\
\hline Água & 1497 \\
\hline Metal & $3000-6000$ \\
\hline Gordura & 1440 \\
\hline Sangue & 1570 \\
\hline Tecido mole & 1540 \\
\hline
\end{tabular}


Os pulsos elétricos criados nos transdutores pelos ecos são convertidos em representações digitais que podem ser convertidas, então, de uma linha de números para uma imagem em um monitor de vídeo.

\subsection{Componentes Básicos de um Aparelho de Ultra-som Convencional}

Um aparelho convencional ultra-sonográfico pode ser dividido em 5(cinco) partes principais que são: Transdutor, CPU, Controlador de Pulsos, Dispositivos de Entrada e os Dispositivos de Saída (Figura 2.1).

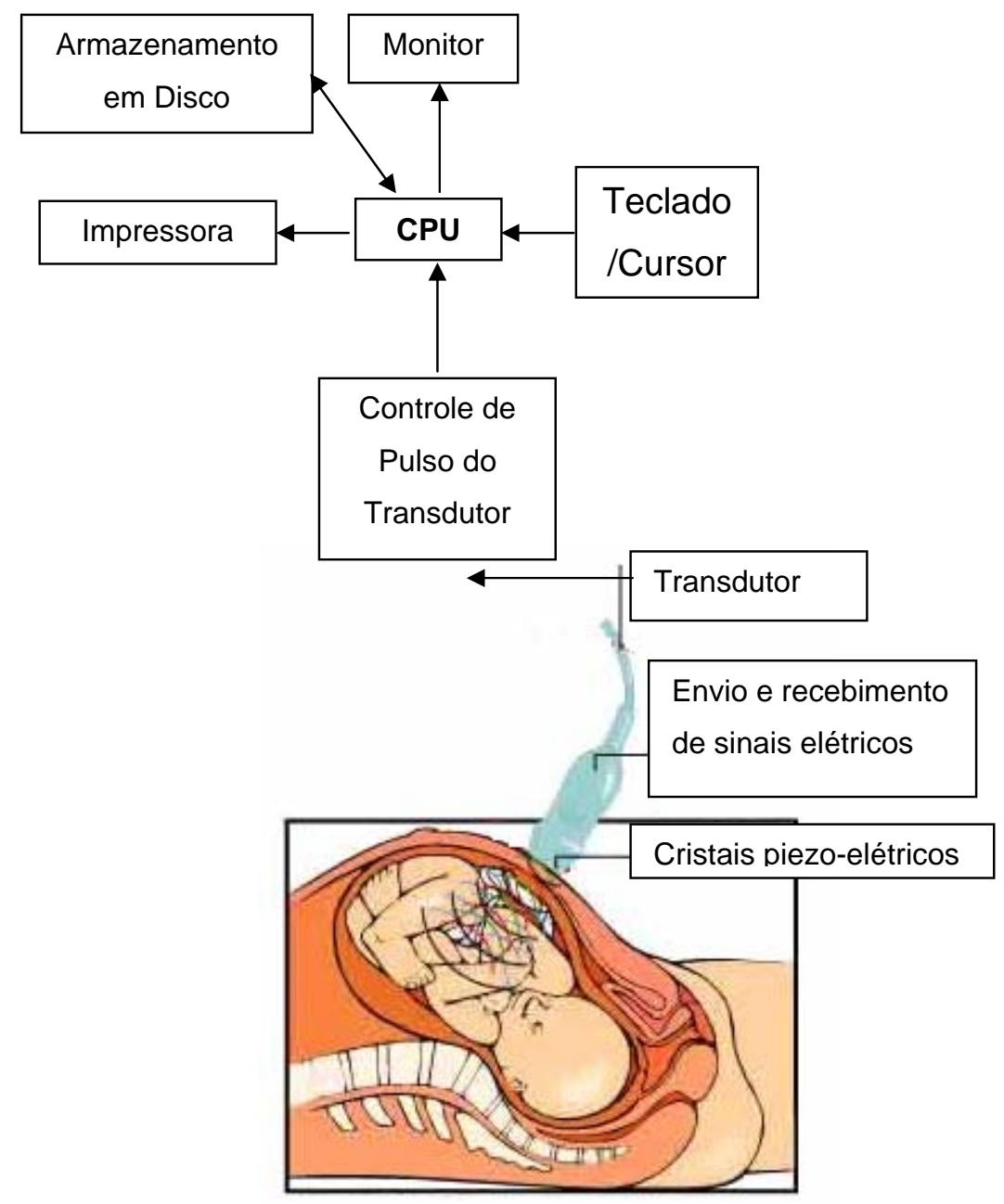

Figura 2.1 - Principais partes de um equipamento de Ultra-som convencional. 
A sonda transdutora é o componente principal da máquina de ultra-som. Ela emite as ondas sonoras e recebe os ecos. Por assim dizer, ela é a boca e os ouvidos da máquina de ultra-som. A sonda transdutora gera e recebe ondas sonoras usando um princípio chamado efeito piezo-elétrico (ou pressão elétrica), que foi descoberto por Pierre e Jacques Curie, em 1880. Na sonda, há um ou mais cristais de quartzo, chamados cristais piezo-elétricos. Quando uma corrente elétrica é aplicada a esses cristais, eles mudam de formato rapidamente.

Mudanças rápidas de formato ou vibrações dos cristais produzem ondas sonoras que se deslocam para fora. Por outro lado, quando ondas sonoras ou de pressão atingem os cristais, eles emitem correntes elétricas. Assim, os mesmos cristais podem ser usados para enviar e receber as ondas sonoras. A sonda também possui uma substância absorvente de som, para eliminar reflexos posteriores da própria sonda, e uma lente acústica, para ajudar a focalizar as ondas sonoras emitidas.

Os transdutores são feitos em vários formatos e tamanhos, como é apresentado na Figura 2.2. O formato da sonda determina seu campo de visão, ao passo que a freqüência das ondas sonoras emitidas determina a que profundidade as ondas sonoras vão penetrar e a resolução da imagem. Os transdutores podem conter um ou mais cristais piezo-elétricos. Em sondas de múltiplos elementos, cada cristal possui seu próprio circuito.

Além da possibilidade de mover as sondas ao longo da superfície do corpo, algumas são projetadas para serem inseridas através das diversas aberturas do corpo, de modo que possam chegar mais perto do órgão que é examinado (útero, próstata, estômago). Chegar mais próximo do órgão pode permitir vistas mais detalhadas.

A Unidade de Processamento Central (CPU) é o controle central da máquina de ultra-som. Ela consiste de um computador que contém o microprocessador, a memória, os amplificadores de fontes de alimentação para o microprocessador e a sonda transdutora. 

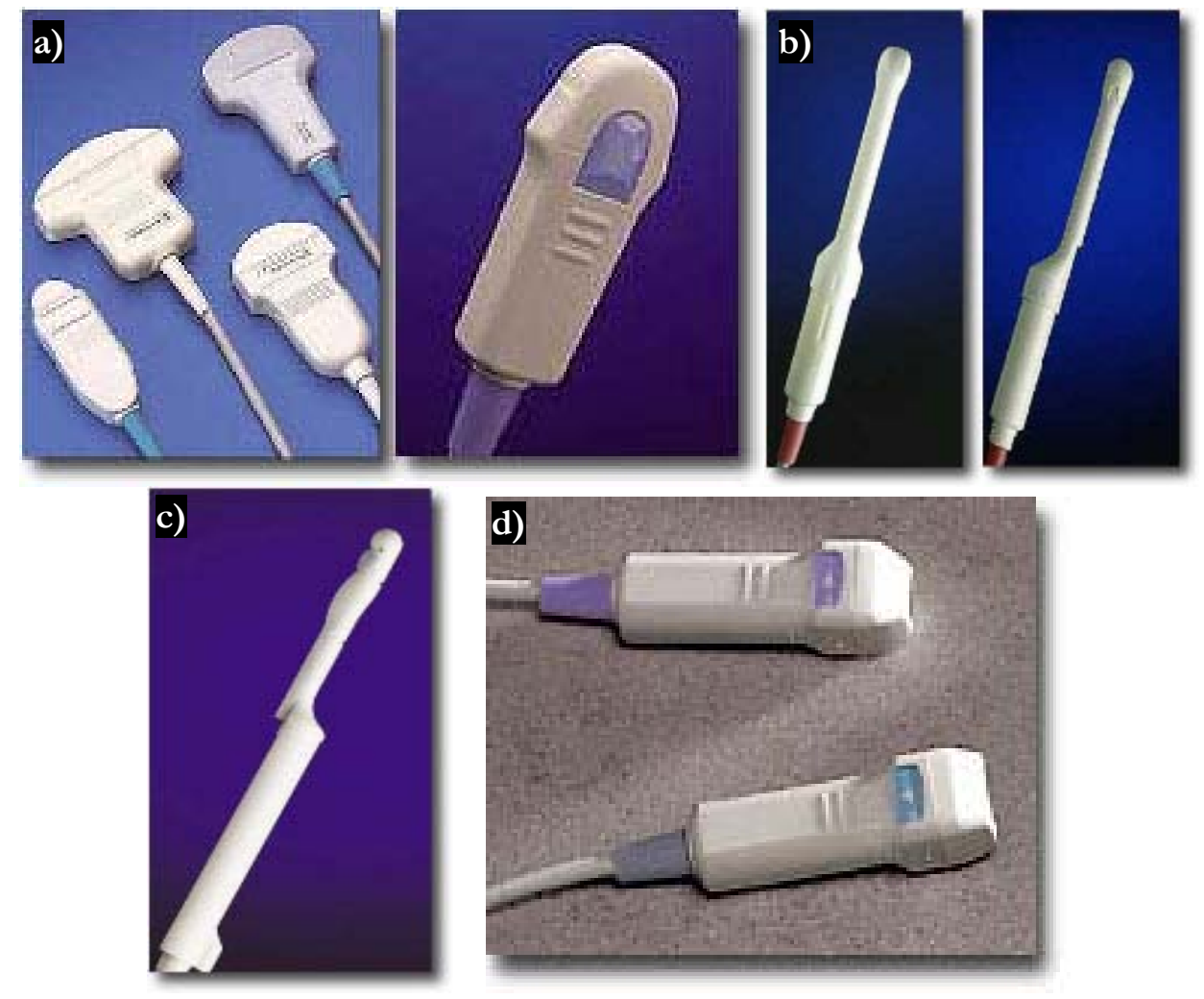

Figura 2.2 - Diferentes tipos de transdutores utilizados em exames por equipamentos de Ultra-som. a) Convexos; b) Endocavitários ou Transvaginais; c) Transrectal; d) Setoriais. (Fonte: Shimadzu do Brasil).

O transdutor recebe correntes elétricas emitidas pela CPU para a emissão de ondas sonoras e também recebe os pulsos elétricos das sondas que foram criados a partir do retorno dos ecos. A CPU faz todos os cálculos envolvidos no processamento dos dados. Assim que os dados brutos são processados, a CPU forma a imagem no monitor. Também é possível armazenar os dados ou imagens processadas em um disco rígido.

O Controle de pulsos do transdutor permite que o operador, ajuste e altere a freqüência e a duração dos pulsos de ultra-som, assim como o modo de varredura da máquina. Os comandos do operador são traduzidos em correntes elétricas que se alteram e são aplicadas aos cristais piezo-elétricos na sonda transdutora. 
Os dispositivos de saída podem ser monitores, armazenamento em disco ou impressoras. O monitor exibe os dados processados pela CPU, e podem ser preto e branco ou coloridos, dependendo do modelo da máquina.

Os dados ou imagens processadas podem ser armazenados em disco. Eles podem ser discos rígidos, discos flexíveis, compact discs (CDs) ou discos de vídeo digital (DVDs). Tipicamente, as varreduras de ultra-som de um paciente são armazenadas em discos rígidos e arquivadas com os registros médicos do paciente.

Algumas máquinas de ultra-som possuem impressoras térmicas que podem ser usadas para capturar uma cópia em papel da imagem ativa no monitor.

Os dispositivos de entrada podem ser os teclados ou cursores que ficam embutidos nos aparelhos ultra-sonográficos. Esses dispositivos permitem que o operador acrescente observações e faça medidas a partir dos dados.

\subsection{Esquema de um Transdutor}

O transdutor é a principal peça de funcionamento de um aparelho de ultra-som, é nele que são convertidos e gerados os pulsos de ultra-som e elétricos.

O principal componente de um transdutor é o cristal de material piezelétrico com eletrodos em lados opostos que criam a polaridade variável (HEDRICK et al. (1995)). Os eletrodos são formados colocando um fino filme de ouro ou prata na superfície do cristal. Para aumentar a energia de transferência do sinal do transdutor para o corpo do paciente, uma capa emparelhada é localizada próxima a um dos eletrodos.

A vibração do cristal é diminuída pela introdução do material de apoio que se junta com o eletrodo de superfície do paciente. A montagem inteira do cristal, incluindo os eletrodos, a camada combinada e o material de apoio, é alojada em uma cobertura isolante elétrica. Essa cobertura proporciona suporte estrutural. Um isolador acústico, feito de 
borracha ou cortiça, previne a transmissão da energia do ultra-som para a cobertura. A imagem de um transdutor e do seu esquema interno pode ser visualizada na Figura 2.3.

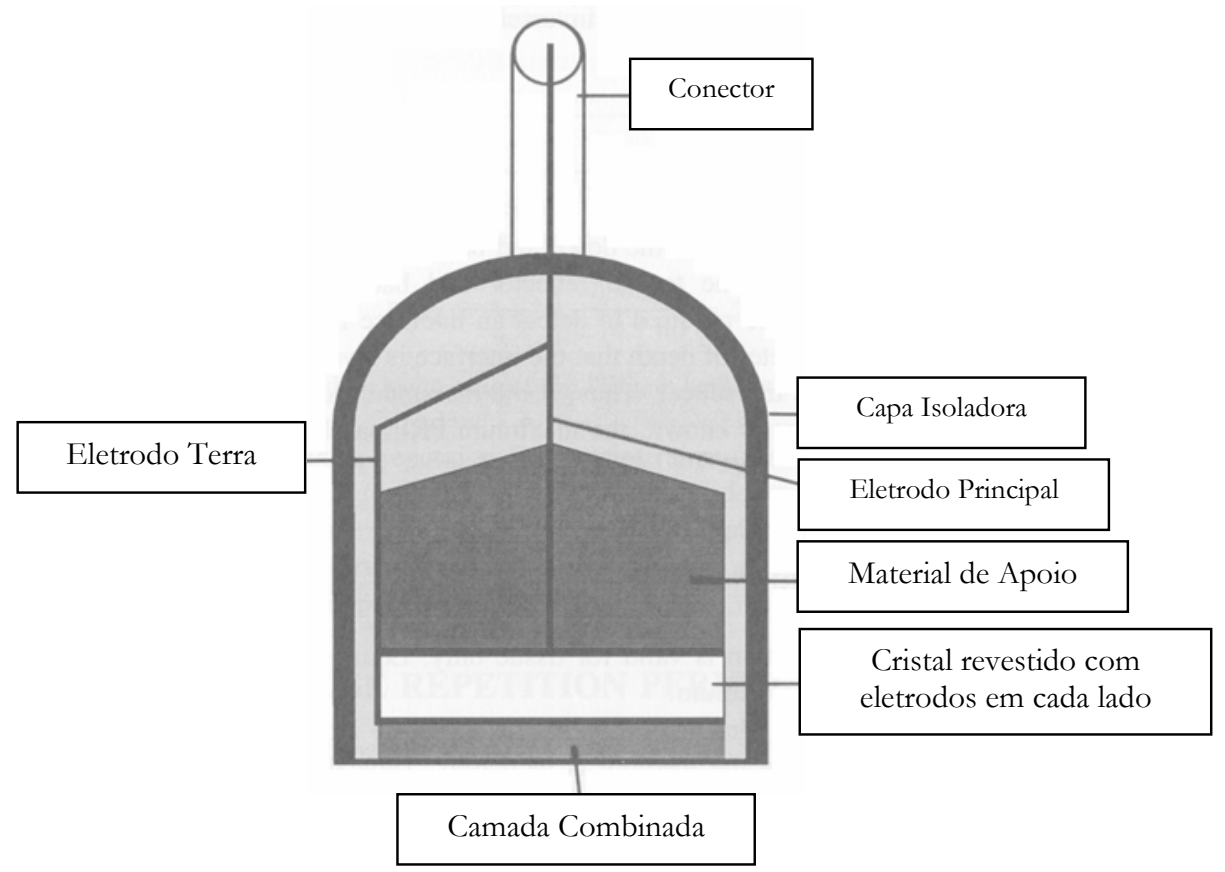

Figura 2.3 - Esquema interno de um transdutor. Fonte: HEDRICK et al. (1995).

\subsection{Funcionamento do Aparelho de Ultra-som}

O esquema básico do funcionamento de um aparelho de ultra-som pode ser observado na Figura 2.4, onde, segundo HEDRICK et al. (1995), o pulso dos aparelhos de ultra-som é gerado por meio de um material piezelétrico que é eletronicamente estimulado para produzir uma onda ultra-sônica por meio da conversão do efeito piezelétrico. Esta onda de ultra-som entra no corpo do paciente, e uma pequena porção é refletida nas várias interfaces, de acordo com a resistência dos tecidos que esta onda intercepta. Os ecos das ondas ultra-sônicas retornam para o transdutor e, por causa do efeito piezelétrico, induzem um sinal elétrico. 


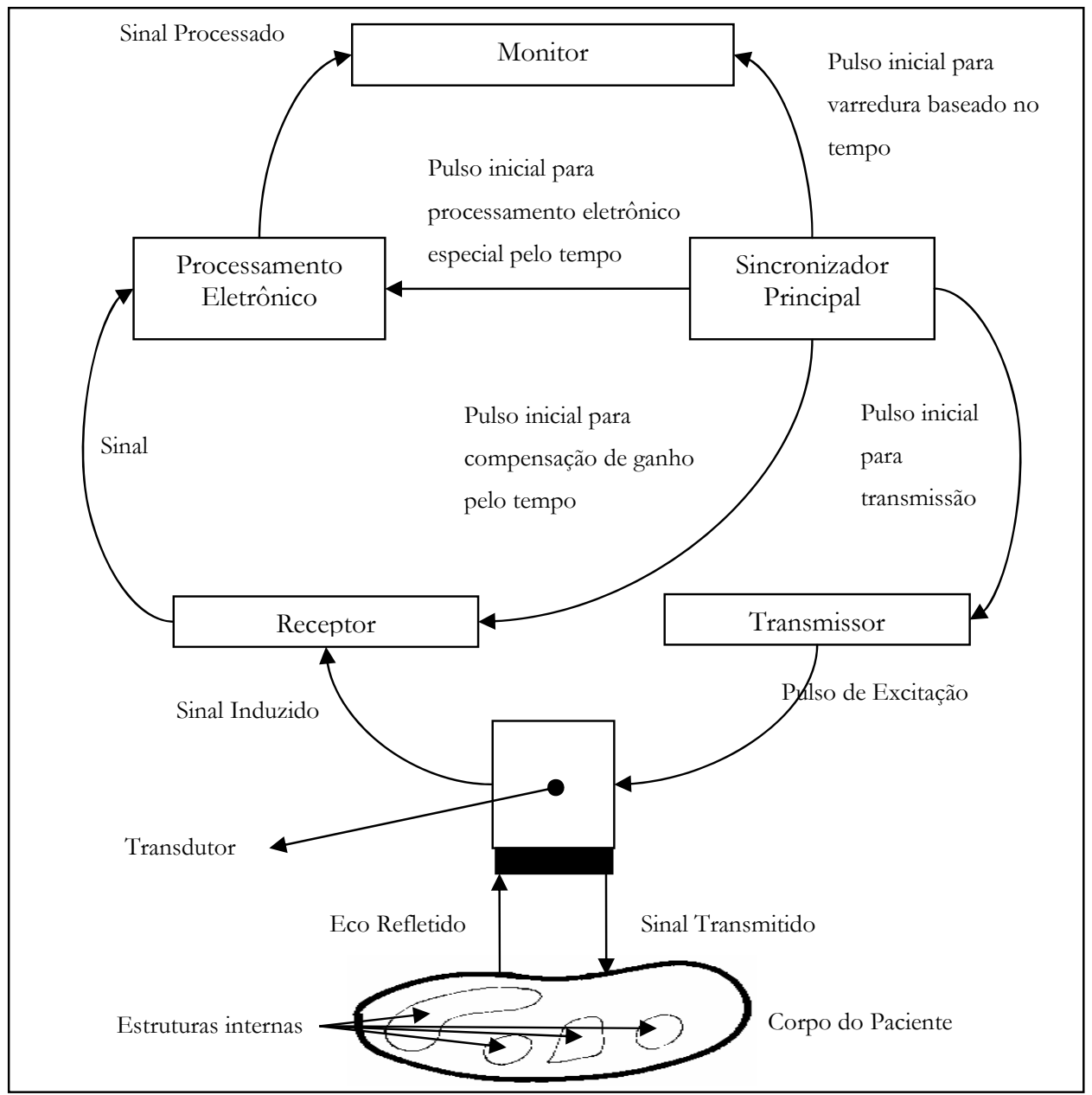

Figura 2.4 - Esquema de funcionamento de um aparelho de ultra-som. Fonte: HEDRICK et al.

(1995).

Os sinais dos ecos agora eletrônicos sofrem uma amplificação e este sinal é representado como um pico de tensão no monitor. A altura do pico é proporcional à amplitude do sinal original detectado.

O formato de amostragem para o monitor consiste na amplitude, na direção vertical versus a distância ou a direção horizontal. Uma tensão aumentada linearmente é aplicada na deflexão horizontal pelo sincronizador principal. O feixe de elétrons se move a uma taxa de 
$1 \mathrm{~cm}$ a cada $13 \mu$ s. O gatilho para esse sinal eletrônico deve ocorrer exatamente no mesmo tempo para a correta profundidade (tempo) de cada interface para ser mostrado na tela.

As varreduras pelo monitor são repetidas de 200 a 2000 vezes por segundo e, assim, o padrão das deflexões aparece estacionário para o olho humano.

Segundo HEDRICK et al. (1995) e CARR et al. (1998), existem basicamente cinco modos de visualização de imagens por equipamentos de ultra-som: Modo-A, Modo-B, Modo-C, Modo-M e Doppler.

\subsection{Diagnóstico de Imagens pelo Ultra-som}

A ultra-sonografia é uma técnica de imagem que obteve grande desenvolvimento durante os últimos anos. É um dos métodos, dentre os de diagnóstico por imagem, mais utilizados no rastreamento de doenças, especialmente por ser um procedimento não invasivo, ter boa sensibilidade e baixo custo, permitindo o exame de diferentes órgãos como coração, abdômen, bexiga, mama, globo ocular, tireóide, cérebro, útero, sistema músculo-esquelético e fetos (Figura 2.5), sem sujeitar a efeitos secundários indesejáveis como os da radiação ionizante.

Segundo BEGA et al. (2001), a primeira aplicação do ultra-som na Medicina ocorreu em 1942. Naquela época, o que se via na tela eram traços produzidos por ondas sonoras emitidas pelo aparelho. Com a evolução do exame, foi possível obter fotos bidimensionais (2D). 


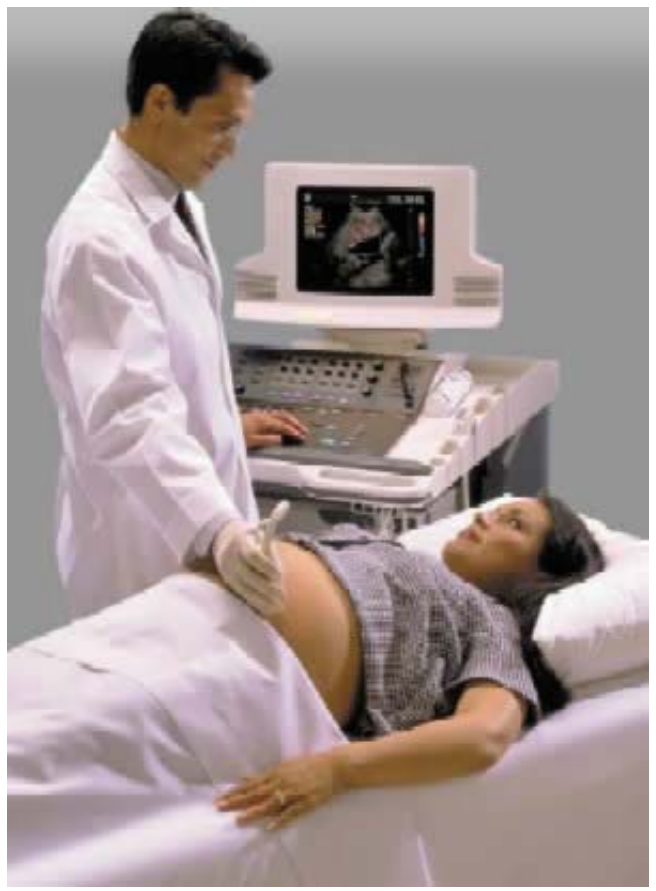

Figura 2.5 - Exame de ultra-som obstétrico sendo realizado em uma paciente (Fonte: Philips

Research).

O aumento da capacidade de processamento dos computadores fez com que as imagens pudessem ser mostradas de forma mais rápida. Recentemente, surgiu o ultra-som tridimensional (3D), com resultados coloridos e em tempo real.

\subsection{Principais Usos do Ultra-som}

O ultra-som tem sido usado em uma variedade de áreas clínicas, incluindo a obstetrícia, a ginecologia, a cardiologia e a detecção do câncer.

A principal vantagem do ultra-som é que determinadas estruturas podem ser observadas sem usar radiação. O ultra-som transmite o resultado muito mais rapidamente do que o exames de aparelhos de raios-X e outras técnicas radiográficas.

Abaixo é apresentado uma lista de alguns usos dos equipamentos médicos de ultrasom: 
- Medição do tamanho do feto para determinar a data prevista para o parto;

- Determinação da posição do feto para comprovar o posicionamento normal da cabeça para baixo ou com apresentação pélvica;

- Verificação da posição da placenta para comprovar se o desenvolvimento está de modo impróprio sobre a abertura do útero (cérvix);

- Contar o número de fetos no útero;

- Comprovar o sexo do bebê;

- Aferir a taxa de crescimento do feto por meio de várias medições ao longo do tempo;

- Diagnosticar a gravidez ectópica, situação de risco de morte na qual o bebê está implantado na trompa de Falópio em vez de estar no útero;

- Determinar se há uma quantidade apropriada de líquido amniótico protegendo o bebê;

- Monitorar o feto durante procedimentos especializados: o ultra-som tem sido útil para ver e evitar atingir o bebê durante a amniocentese (coleta de amostra do fluido amniótico com uma agulha para testes genéticos). No passado, os médicos costumavam efetuar esse procedimento às cegas. Entretanto, com o acompanhamento por meio do ultra-som, os riscos do procedimento diminuíram;

- Observar tumores do ovário e seios.

\subsection{Riscos da Utilização do Ultra-som}

Existem preocupações a respeito da segurança do ultra-som durante a execução de um exame. O fato do ultra-som ser uma onda mecânica de alta freqüência, gera a questão 
de como essa onda afeta os tecidos internos da paciente ou do feto ou embrião em estado gestacionário?

O que pode ser afirmado é que, fisioterapeutas utilizam aparelhos específicos de ultra-som que, através de ondas de ultra-som com uma freqüência maior do que a utilizada em aparelhos médicos ultra-sonográficos para geração de imagens, conseguem induzir uma aceleração no metabolismo celular através das ondas de ultra-som direcionadas em regiões adjacentes a lesões para, dessa forma, fazer com que o tecido celular em regiões lesionadas possa ser regenerado com maior rapidez.

Existem alguns relatos de partos de bebês prematuros de mães que haviam feito exames freqüentes de ultra-som durante a gravidez. Os dois maiores riscos com o ultrasom podem ser classificados como:

Acréscimo de calor: os tecidos ou a água absorvem as ondas do ultra-som, que aumentam sua temperatura;

Constituição de bolhas (cavitação): formá-se quando gases dissolvidos saem de uma solução em razão do calor local causado pelo ultra-som.

Todavia, não existem relatos de efeitos destrutivos adversos confirmados e documentados em estudos quanto ao ultra-som médico para geração de imagens, seja em seres humanos ou animais.

\subsection{Ultra-som 3D}

O ultra-som 3D é uma modalidade que permite a captação de imagens do corpo humano através de seções adquiridas através do processo chamado modo-B. A diferença entre o ultra-som 2D e o 3D é que este exame é realizado com um transdutor especial para captar as imagens que, com o auxílio de um programa contido no aparelho de ultra-som, transforma as informações em imagens tridimensionais. 
Além de apontar o sexo do bebê dentro do útero materno o ultra-som 3D acusa máformação, fazendo um retrato mais fiel de estruturas fetais como face, mãos, pés e coluna vertebral. Em adultos, o ultra-som 3D ajuda a avaliar tumores e a verificar o volume dos órgãos (BEGA et al. (2001)).

$\mathrm{Na}$ ultra-sonografia convencional, as imagens obtidas de fetos são planos longitudinais ou transversais, com detalhes das estruturas internas, com as quais o examinador consegue formar uma imagem mental do corpo inteiro do feto. Esta capacidade do examinador depende da sua experiência prática e de uma boa percepção espacial. O exame é realizado em tempo real, sendo possível avaliar a movimentação fetal. Na ultra-sonografia 3D, o aparelho armazena um certo volume de informações, isto é, vários planos de imagens do feto e, posteriormente, essas informações são processadas e analisadas, como ocorre nos exames de tomografia computadorizada e ressonância magnética.

Existem recursos que possibilitam a visualização da superfície do feto, tornando possível a produção de uma imagem bastante semelhante a uma foto do mesmo. Por isso o método tem-se revelado útil no estudo da anatomia fetal, permitindo uma melhor avaliação das características e relações espaciais entre as partes fetais. As imagens obtidas são de mais fácil entendimento para pessoas sem treinamento na área, como médicos de outras especialidades e pacientes.

As vantagens do ultra-som 3D sobre o ultra-som 2D em obstetrícia, segundo BEGA et al. (2001) são:

- A possibilidade de armazenar dados digitalizados, para revisão posterior.

- Manipulação interativa dos dados, de modo a obter ângulos de visão não possíveis em tempo real.

- Possibilidade de avaliação simultânea das imagens multi-planares e da superfície. 
- Apresentação das imagens de uma maneira padronizada, melhorando o entendimento da anatomia fetal.

- Demonstração da anatomia fetal com imagens mais realistas, de mais fácil compreensão para não-especialistas.

- Possível aumento do vínculo emocional materno-fetal.

- Melhor avaliação da extensão e localização das más-formações fetais.

- Possibilidade de uma mensuração mais precisa dos volumes, especialmente útil para estruturas irregulares. Os autores ressaltam que esta técnica não substitui o ultra-som 2D, sendo uma complementação, uma ferramenta para resolver problemas na realização do exame.

De acordo com MERZ et al. (1995), MEINEL et al. (1998) e BABA et al. (1999), as limitações do ultra-som 3D são semelhantes às do ultra-som 2D, como artefatos devidos à movimentação fetal, dificuldade de obter imagens em casos de redução do líquido amniótico, baixa resolução nos planos paralelos próximos ao plano de aquisição. Esta é uma técnica que ainda está em desenvolvimento e, apesar dos avanços recentes, ainda precisa de melhoramentos, como redução do tempo necessário para a aquisição e processamento das imagens, transdutores menores e mais leves, maior resolução das imagens e mensuração automática dos volumes. As limitações do ultra-som 3D são:

- É um método ainda muito dependente do operador, havendo necessidade de uma boa habilidade pelas técnicas de ultra-som convencionais e ainda facilidade de visualização de imagens em 3 (três) planos ortogonais.

- O tipo de aparelhagem 3D também influencia positiva ou negativamente na qualidade do resultado final. 
- A posição fetal deve ser adequada, pois a interposição de outras estruturas como, por exemplo, membros e cordão sobre a estrutura a ser examinada poderão gerar artefatos e impedir uma adequada visualização.

- A imagem bidimensional da estrutura a ser observada deve ser excelente para que a sua reconstrução em três dimensões também seja de boa qualidade.

O biotipo materno influencia qualquer tipo de técnica de imagem ultra-sonográfica. Assim, o sobrepeso materno ou apenas o acúmulo abdominal de tecido adiposo poderá colaborar para uma baixa qualidade técnica do ultra-som, seja ele 2D ou 3D.

As gestações múltiplas apresentam limitações principalmente pela interposição de uma parte fetal de um gemelar sobre a do outro a ser observada e também pela movimentação de um gemelar, podendo prejudicar a aquisição de imagem de si mesmo ou do outro gemelar.

Para a visualização da face fetal, a idade gestacional também pode limitar o exame, sendo ideal sua realização entre 28 a 32 semanas de gestação. Idades gestacionais superiores a 32 semanas poderão oferecer um exame de difícil avaliação pela diminuição fisiológica de líquido amniótico e aumento fetal, havendo, na maioria das vezes, interposição de estruturas que poderão até mesmo inviabilizar o exame.

Na Figura 2.6 são ilustradas as diferenças de resolução da imagem real para o ultrasom 2D e para o ultra-som 3D.

Nas aplicações realizadas pelo ultra-som é possível realizar no primeiro trimestre de gravidez a medida da translucência nucal, quando o feto está numa posição que não permite a adequada mensuração (BLUTH et al. (1998)).

Nos segundo e terceiro trimestres é possível fazer a medição do volume dos órgãos para avaliação do desenvolvimento e crescimento fetais, anomalias e estudo dos efeitos de infecções e doenças como a isoimunização. É possível obter, também, a estimativa mais acurada do peso fetal, usando o volume dos membros como parâmetros, possibilidade de 
avaliar o volume pulmonar, estudar a superfície fetal, avaliar o coração, o colo uterino, comprimento e avaliação da cerclagem.

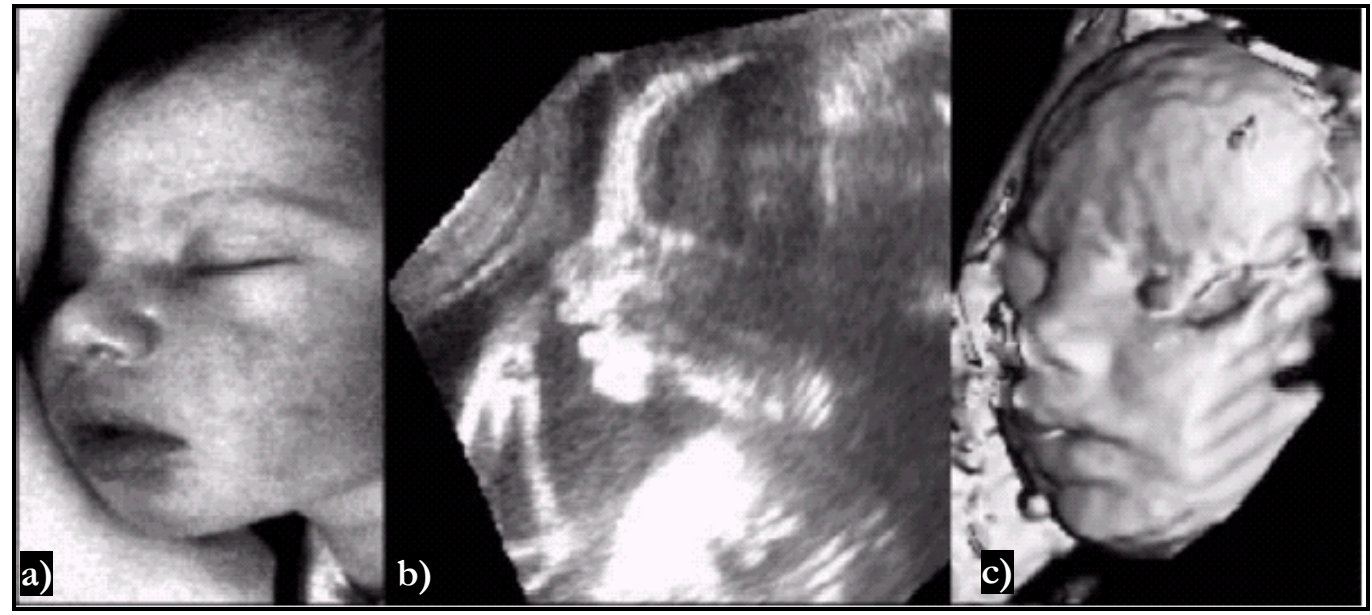

Figura 2.6 - Diferença visual nos modos de ultra-som 2D para o ultra-som 3D: a) Imagem de um bebe após o parto; b) Imagem do bebe com o ultra-som 2D; c) Imagem do bebe em um ultra-som 3D. Fonte: SAKAS et al. (1995).

A Figura 2.7 ilustra um feto com aproximadamente 20 semanas de idade, enfocando as diferenças entre imagens 2D e 3D.
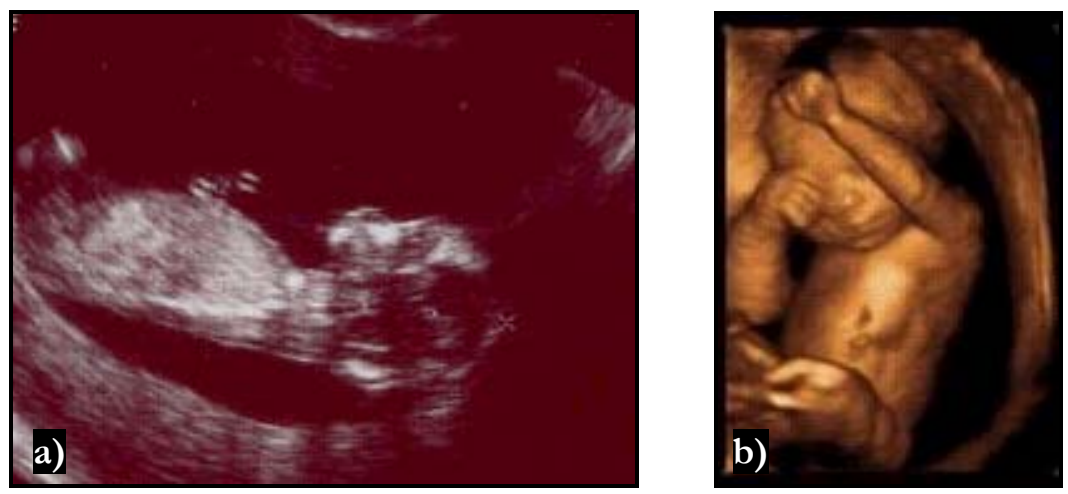

Figura 2.7 - Imagem de ultra-som ilustrando o crescimento do feto com aproximadamente 20 semanas de idade dentro do útero da mãe: a) Imagem de uma criança em um ultra-som 2D; b) Imagem de uma criança em um ultra-som 3D. Fonte: www.pregnancyweekly.com. 
BLUTH et al. (1998) ressaltam o uso do ultra-som no diagnóstico de doenças, afirmando que o advento de novas técnicas, e a utilização do método através de sondas endocavitárias permitiram um avanço no diagnóstico de patologias ginecológicas com o uso de sonda endovaginal; de patologias prostáticas do exame endo-retal, e no estudo do tubo digestivo através de ultra-sonografia endoscópica.

De acordo com CAMPBELL (2002), o mais moderno aparelho de ultra-som atualmente é o equipamento de ultra-som 4D que é capaz de projetar imagens em uma velocidade de 16 quadros por segundo, o que dá um aspecto de imagem quadro-a-quadro (slow-motion) e aproxima-se muito da imagem em tempo real, possibilitando a visualização dos movimentos fetais no interior do útero.

A utilização desta técnica trouxe vantagens, dentre as quais é importante destacar:

- Permite uma avaliação melhor, com melhor entendimento das imagens em comparação à visão 2D, o que é fundamental em casos de más-formações fetais. Neste sentido auxilia melhor a compreensão do ultra-sonografista;

- Possibilita o armazenamento do volume das imagens 3D, que poderão ser reconstruídas e trabalhadas por outros ultra-sonografistas e especialistas, viabilizando a realização do exame por outro profissional sem a necessidade de que o paciente se submeta a um segundo exame.

Segundo DYSON et al. (2000), a ultra-sonografia tridimensional apresenta vantagens sobre o método tradicional, pois permite uma reconstituição mais fiel e mais nítida da imagem. Novos ângulos de visão favorecem a visualização dos órgãos internos do corpo como também do feto, no caso do exame obstétrico, favorecendo até intervenções cirúrgicas.

O ultra-som é feito inicialmente pelo modo 2D, para avaliar o crescimento e morfologia do feto e só depois são feitas as reconstruções em 3D. O exame não substitui 
nenhum dos exames de rotina que devem ser realizados durante o pré-natal, como: a ultrasonografia morfológica do primeiro trimestre (translucência nucal) e a ultra-sonografia morfológica do segundo trimestre (morfológico). No entanto, GHI et al. (2000) acreditam que a experiência que as imagens $3 \mathrm{D}$ proporcionam aos pais vai acabar introduzindo a ultra-sonografia 3D na rotina obstétrica.

Para que se possa aliar o desejo dos pais à boa prática clínica, deve-se indicar esta modalidade de exame em momento obstétrico adequado, por exemplo: antes da $26^{a}$ semana, as estruturas que mais sobressaem são as estruturas ósseas, dando ao esqueleto fetal um aspecto muito evidente, podendo impressionar os leigos que esperam visualizar, muitas vezes, a fisionomia e o sexo do bebê. A Figura 2.8(a) ilustra a imagem de um exame de um feto com menos de 26 semanas, e a Figura 2.8(b) a imagem do exame de um feto após a $26^{\mathrm{a}}$ semana de gestação.
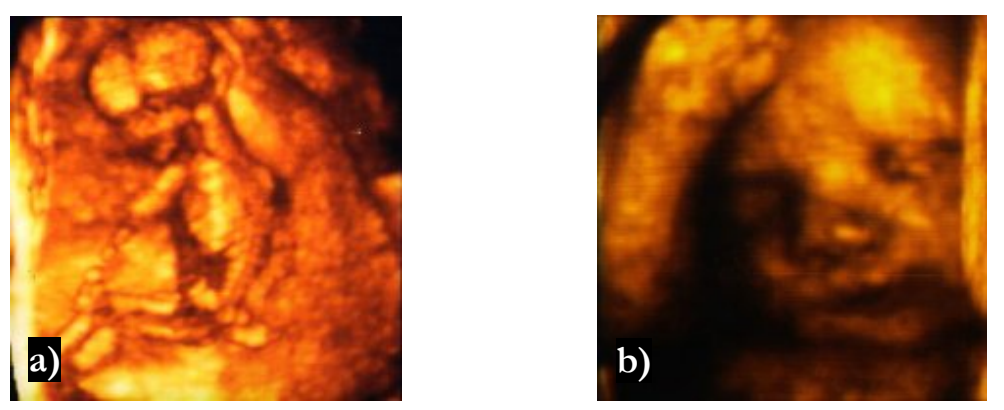

Figura 2.8 - Visualização do ultra-som 3D: a) Antes da 26a semana de gestação; b) Após a $26^{a}$ semana de gestação. Fonte: GHI T. et al. (2000).

Esse exame aplicado à obstetrícia destaca-se na avaliação da malignidade de uma lesão, da necessidade ou não de uma biópsia, na sua utilização para guiar a agulha em procedimento de uma punção e até em procedimentos cirúrgicos, inclusive em fetos, além dos exames de rotina para verificação do desenvolvimento fetal. 
Segundo CHMAIT et al. (2001), algumas más-formações fetais de difícil diagnóstico no segundo trimestre, como as cardiopatias, as obstruções intestinais e a hidrocefalia, são melhores identificadas e avaliadas de acordo com o grau da deformidade, se comparadas ao exame 2D. A Figura 2.9 mostra a diferença na visualização entre o ultra-som convencional, exibido na Figura 2.9(a) e o ultra-som 3D, ilustrado na Figura 2.9(b), enfatizando que a análise e o reconhecimento de uma anormalidade se tornam mais evidentes no método 3D.
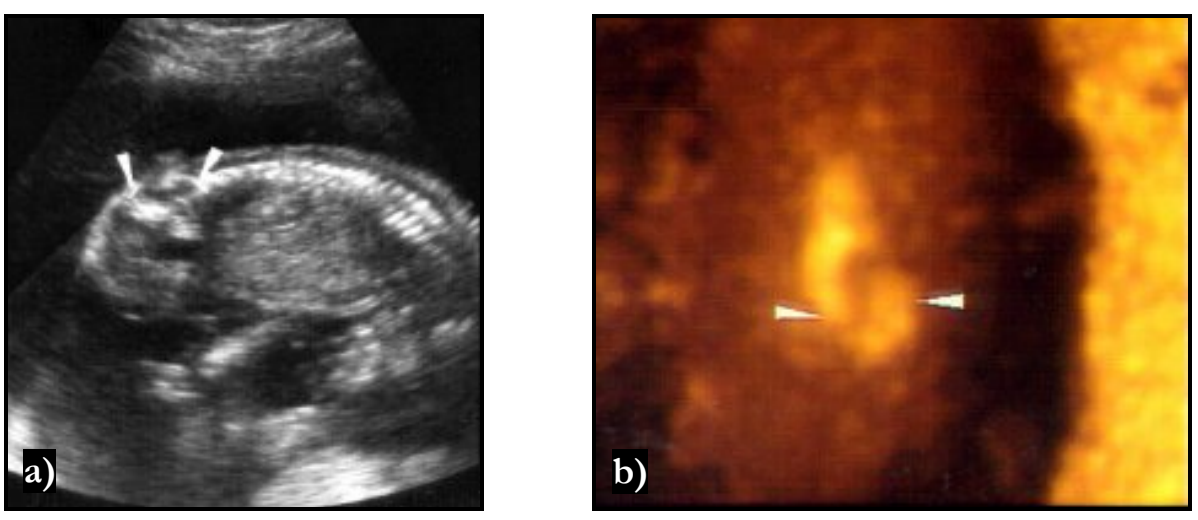

Figura 2.9 - Aspecto de meningomielocele: a) Ultra-som convencional 2D; b) Ultra-som 3D. Fonte:

CHMAIT et al. (2001).

Atualmente algumas pacientes procuram clínicas especializadas que possuam o equipamento de ultra-som 3D para visualizar a feição do feto ainda na gestação. Contudo, apesar de ajudar a confirmar o diagnóstico do ultra-som normal e permitir melhor visualização de defeitos como o lábio leporino, o ultra-som 3D não sé um equipamento imprescindível para o médico.

Para os médicos o diagnóstico e as aferições de medidas do feto são feitas utilizando o Modo-B de visualização das imagens. 


\section{CAPÍTULO 3}

\section{Reconstrução de Volume em Imagens Digitais}

\subsection{Introdução}

A base deste trabalho é a reconstrução do volume tridimensional a partir de imagens bidimensionais. Este capítulo mostra o modelo básico apresentado na bibliografia para a reconstrução de volumes.

A reconstrução de volume é um método de produzir dados volumétricos em uma imagem bidimensional. Os dados volumétricos são o resultado da amostragem de um objeto no formato tridimensional (LICHTENBELT et al. (1998)).

Na computação gráfica uma cena pode ser simulada através da construção de formas básicas de blocos chamados de primitivas.

As primitivas incluem pontos, linhas, e polígonos. Estas primitivas podem ser combinadas em diversos tamanhos, cores e orientações para representar objetos em uma 
cena. Efeitos de texturas e iluminação podem ser adicionados aos objetos para aumentar o realismo da cena.

A ação da construção das primitivas dos objetos para a tela do computador é chamada de reconstrução (rendering) (WOO et al. (1999)). Um exemplo da reconstrução de uma cena pode ser observado na Figura 3.1.

A simulação de cenários realísticos do mundo real podem ser obtidos com uma determinada facilidade com o auxílio da computação gráfica, embora, diferentemente da realidade quando se observam as estruturas internas de um objeto, não fazem referência à realidade, pois estes objetos não possuem estruturas internas. Isto acontece, pois, na maior parte das vezes apenas se deseja observar o exterior dos objetos, e por motivos de economia de performance computacional, a informação do conteúdo dos objetos na cena é descartada. Existe um alto custo computacional de processamento de dados envolvido para que seja possível representar a primitiva de um objeto como é no mundo real, como por exemplo, as estruturas internas do corpo humano.

Para suprir esse tipo de necessidade existem dentro da computação gráfica as técnicas de reconstrução por volume, que têm como principal objetivo à visualização interna das estruturas de um objeto.

A reconstrução de volume opera os dados tridimensionais, processa e os transforma em uma imagem bidimensional. A Figura 3.2 ilustra uma representação bidimensional de um conjunto de dados de uma cabeça de um cadáver formada utilizando uma técnica de reconstrução de volume direta proposto por LEVOY (1987, 1988a, 1988b). 


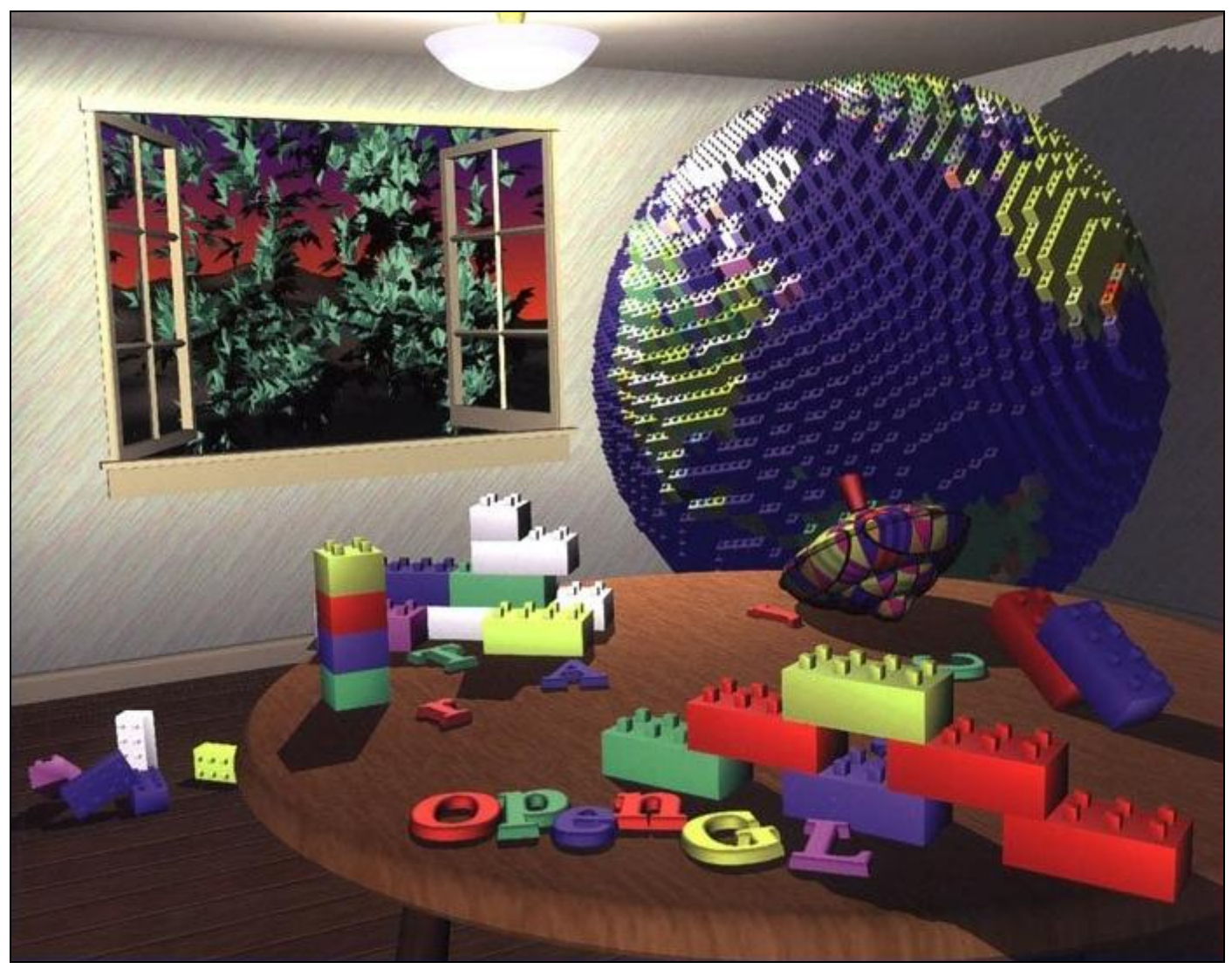

Figura 3.1 - Exemplo da reconstrução de alguns objetos em uma cena. Fonte: WOO et al. (1999).

A característica principal na reconstrução de volumes está em criar dados, para que posteriormente utilizando uma técnica de visualização tridimensional eles possam ser interpretados como uma imagem bidimensional. 


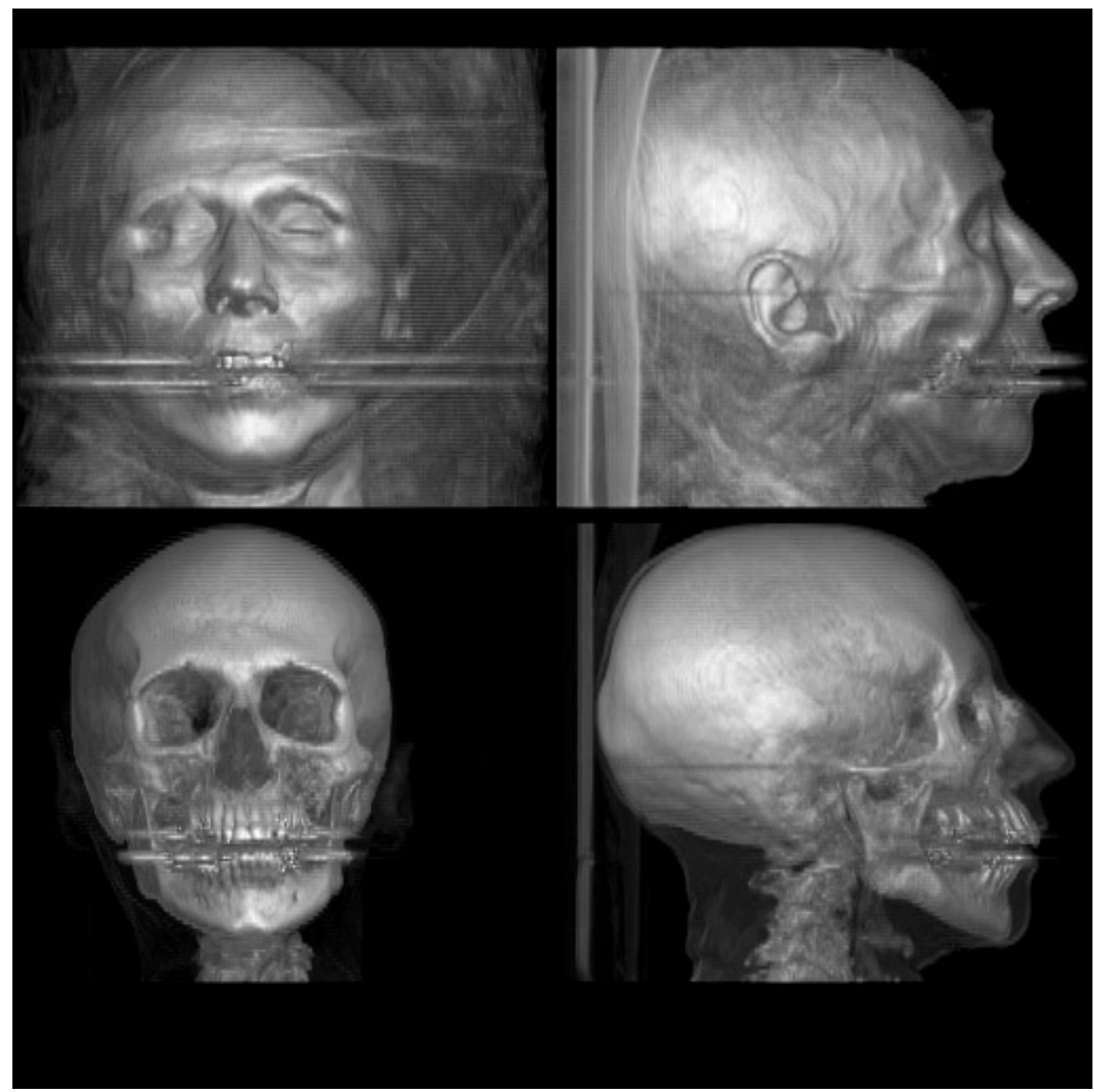

Figura 3.2 - Reconstrução de volume a partir de seções planares adquiridas por tomografia computadorizada de uma cabeça humana de um cadáver. Fonte: LEVOY (1988b).

\subsection{Métodos para Visualização de Volumes}

Em ELVINS (1992) e LEVOY (1987, 1988a, 1988b) é dito que, a visualização volumétrica de modelos de dados montados a partir de imagens $2 \mathrm{D}$ divide-se em duas categorias distintas: métodos por Rendering Volumétrico Direto e por Rendering de Superfície. 
A visualização por Rendering Volumétrico Direto engloba algoritmos como Ray-casting, métodos de integração e o $V$-buffer. Os dois últimos são chamados de métodos de projeção. Esses métodos são caracterizados pelo mapeamento de elementos diretamente na tela sem utilizar primitivas geométricas como uma representação intermediária. A especialidade apropriada desses métodos é criar imagens de um conjunto de dados contendo características amórficas como fluidos, névoas e gases. A desvantagem de se utilizar os métodos volumétricos é que o conjunto de dados inteiro deve ser processado toda vez que a imagem sofre a reconstrução. Uma passagem de baixa resolução ou uma amostragem aleatória dos dados algumas vezes é utilizada para criar imagens de baixa qualidade apenas como parâmetro de orientação do usuário.

A visualização por Rendering de Superfícies é realizada ajustando as primitivas da superfície como polígonos ou malhas de pontos para uma seqüência de valores de tons de pixels, selecionados automaticamente ou pelo usuário dentro do conjunto de dados que possuem a seqüência de imagens.

Existem vários algoritmos que podem ser utilizados para a reconstrução de volumes por superfícies como, por exemplo, o algoritmo por Marching Cubes (LORENSEN et al. 1987).

Para a reconstrução neste método o usuário inicia escolhendo um valor de limiar e então as primitivas geométricas são automaticamente ajustadas aos contornos de alto contraste do volume que são iguais ao limiar. As células que possuem seus valores acima do limiar escolhido ou que possuem o valor abaixo do limiar são descartadas e não têm efeito na imagem final.

Os algoritmos por Reconstrução de Superfície são geralmente mais rápidos do que os por Volume, pois o algoritmo por Superfície atravessa somente uma vez o conjunto de dados para extrair as características. Após extrair as superfícies, a aceleração por hardware gráfico da placa de vídeo pode ser utilizada para rapidamente renderizar a superfície cada 
vez que o usuário mudar a visão ou os parâmetros de iluminação. Alterar o valor do limiar consome tempo pelo fato de requerer que todas as células sejam acessadas para extrair um novo conjunto de primitivas de superfície.

O problema da utilização desta técnica, é que a partir do momento que é necessário a introdução de um limiar para se realizar a reconstrução, cria-se o problema da decisão binária, ou seja, é decidido através do limiar se o voxel que está sendo atravessado pertence ou não a superfície do volume. Como resultado desse método podem ser gerados vários resultados falso-positivos (superfícies que não existem) e falso-negativos (buracos nas superfícies que não existem) que podem ser acarretados por causa do erro ou de uma escolha pobre da definição das características do limiar (LEVOY (1988b)).

\subsection{Aquisição do volume}

Uma imagem digital consiste em uma matriz de elementos de dados representando a cor ou a intensidade do tom. Estes elementos de dados são referenciados como pixel(Picture Element) (Figura 3.3(a)). No mesmo sentido, um volume pode ser representado como uma matriz de valores. Estes valores, chamados de voxel(Volume Element) podem ser representados em uma matriz tridimensional (Figura 3.3(b)).

É possível encontrar na literatura duas definições diferentes para voxels. A primeira considera que um voxel é um pequeno cubo. A segunda definição considera um voxel um elemento individual de um espaço tridimensional. Um voxel pode ser considerado como outra primitiva na computação gráfica, utilizada para visualizar um cenário. 


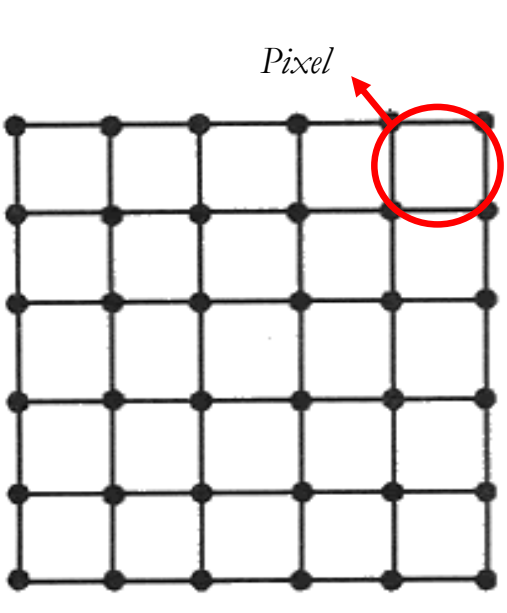

a)

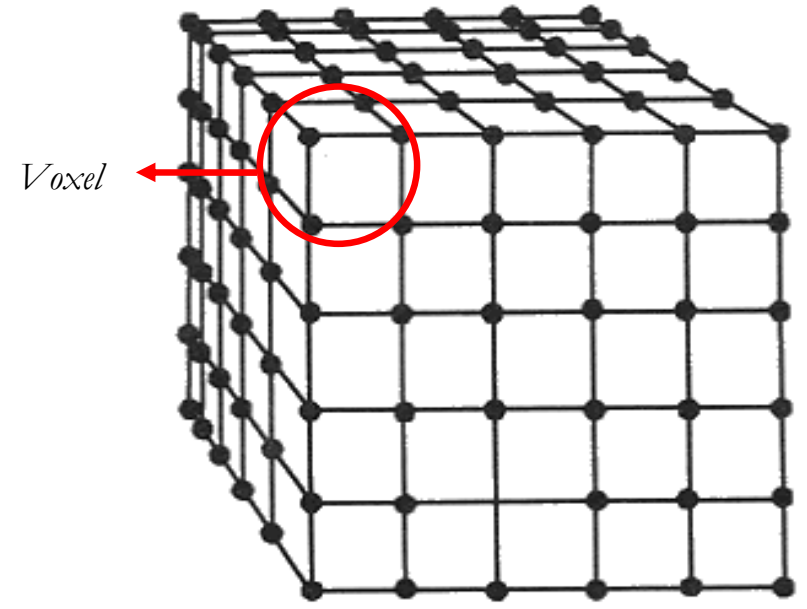

b)

Figura 3.3 - Ilustração da representação de uma matriz de: a) Pixels; b) Voxels.

\subsection{Reconstrução de Volume por Ray-casting e Ray-tracing}

O algoritmo de Ray-casting foi originalmente proposto por LEVOY (1988a,1988b) e DREBIN et al. (1988), como uma técnica que permitia a visualização de pequenos detalhes internos ao volume, através do controle de transparência dos voxels, removendo trivialmente as partes escondidas atrás de partes definidas como opacas, e visualizando o volume a partir de qualquer direção.

ELVINS et al. (1992) afirmam que este tipo de algoritmo volumétrico direto é bastante utilizado para a produção de imagens de alta qualidade. É um algoritmo baseado no espaço da imagem (image-order) que calcula, para cada pixel, a cor e a opacidade correspondente. Esse cálculo é realizado a partir do disparo de um raio, partindo em direção ao volume de dados. As cores e opacidades, para cada pixel, são determinados pela soma das cores e opacidades encontradas ao longo da trajetória do raio correspondente ao pixel. Tal trajetória termina quando a opacidade calculada atinge o valor máximo ou quando o raio ultrapassa o limite do volume. 
O raio segue uma trajetória reta sem desvios, pois reflexões do mesmo não são consideradas. Esta última característica diferencia esse método do algoritmo por Ray-tracing. Na Figura 3.4 é mostrado o caminho percorrido por um raio para formar um único pixel no monitor.

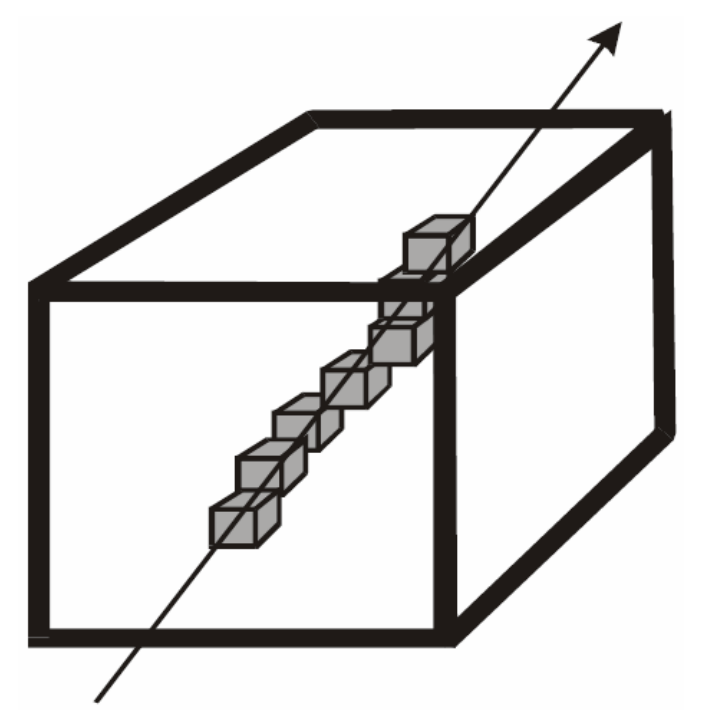

Figura 3.4 - Raio percorrendo um volume de dados para formar um único pixel no monitor.

O algoritmo funciona efetuando um lançamento de raios a partir do observador em direção ao volume. A cor final de cada pixel da imagem é obtida integrando as contribuições de $\operatorname{cor} C(x)$ e opacidade $\alpha(x)$ de cada voxel $x$ interceptado pelo raio.

Na Figura 3.5, a cor do pixel correspondente ao raio antes do cálculo da contribuição do voxel em questão é $c_{\text {in }}$. Computada a contribuição de um voxel $x$, a cor passa a $\operatorname{ser} c_{\text {out }}$ :

$$
c_{\text {out }}=c_{\text {in }}(1-\alpha(x))+C(x) \alpha(x)
$$


Levoy (1988) implementou este algoritmo através de dois pipelines independentes: um para iluminação e um para classificação do material, concluindo com uma fase final de composição dos dois pipelines.

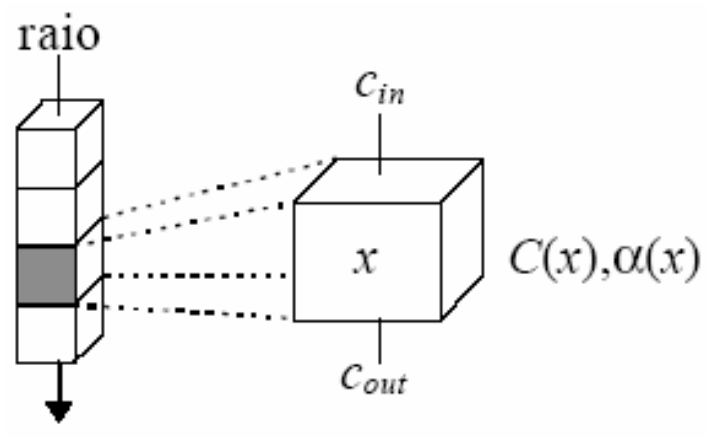

Figura 3.5 - Composição final da cor do voxel. Fonte: FOLEY et al. (1990).

Na etapa de iluminação, as componentes RGB da cor $C(x)$ para cada voxel $x$ são calculadas a partir de uma estimativa do gradiente da função densidade $\mathrm{D}(x)$ e da intensidade de luz, usando o algoritmo de Phong (Foley et al. (1990)). Na etapa de classificação, uma opacidade $\alpha(x)$, baseada na densidade dos materiais, é associada a cada voxel. A composição final é realçada enfatizando-se as bordas das regiões de densidade quase uniforme, e removendo a acentuação de seus interiores, multiplicando-se o valor da opacidade pelo gradiente:

$$
\alpha^{\prime}(x)=\alpha(x)|\nabla \mathrm{D}(x)|
$$

A visualização final da imagem é feita gerando amostras de cada raio que intercede o volume e o valor do pixel é o resultado da integração desta amostragem. 


\subsection{Diagrama da Reconstrução de Volume}

A reconstrução do volume é realizada através de uma seqüência de operações que podem ser representadas em um diagrama (LICHTENBELT et al. (1998)). A partir do final de cada operação, os dados são enviados para a próxima etapa do diagrama (Figura 3.6).

As operações consistem da segmentação, computação do gradiente, reamostragem, classificação, sombreamento e composição. A ordem e a inclusão destes procedimentos podem variar dependendo do tipo de implementação da reconstrução do volume. Geralmente a classificação é um processo que pode vir antes ou depois da reamostragem.

Algumas características não podem ser visualizadas no conjunto de dados adquirido como: densidade, impedância acústica, e outros fatores peculiares de cada tipo de imagem. Para que esses dados possam ser visualizados numa interpretação visual, algumas vezes é necessário atribuir cores, iluminação e opacidade a esses fatores que não são visuais.

A segmentação é uma etapa do estágio de pré-processamento e é realizada antes do processo de reconstrução. Ela marca os voxels em um conjunto de dados. Essa marcação

pode ser qualquer informação que se deseja armazenar com o voxel. É possível marcar em um volume de dados determinados voxels que sejam pertencentes a materiais diferentes, como, por ex., os tecidos e os ossos em um exame de Tomografia Computadorizada, desde que estes dados possuam diferentes níveis de intensidade ou formatos. As imagens segmentadas do volume podem ser armazenadas juntamente com os dados do volume, para que possam ser utilizadas no estágio de classificação. 


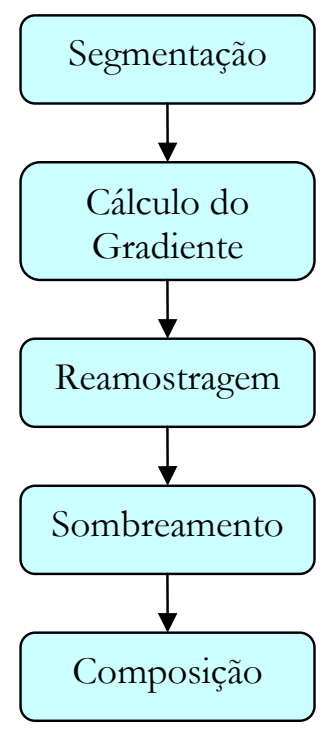

Figura 3.6 - Diagrama da reconstrução de volume. Fonte: LICHTENBELT et al. (1998).

As seleções realizadas no procedimento de segmentação podem ser utilizadas no estágio de classificação no diagrama de reconstrução de volume para atribuir valores de opacidade e cores, separando os voxels em um conjunto de classes com diferentes características. Em um exame de Tomografia Computadorizada, pode-se ajustar os voxels marcados como sendo parte de ossos para ser visualizados com tons de cinza e os voxels marcados como sendo tecidos para ser visualizados com tons de verde, por exemplo. Também é possível atribuir um nível de opacidade mais baixo fazendo com que os tecidos fiquem transparentes para a visualização melhor dos ossos.

Essa combinação da segmentação e da classificação é um recurso importante no diagrama de reconstrução de volume. A segmentação é um processo complexo para que possa ser realizado automaticamente por um algoritmo computacional. Por este motivo, no estágio da segmentação deve ser oferecido suporte para uma intervenção humana.

O gradiente das cores atribuídas às imagens é utilizado para detectar bordas e fronteiras entre materiais diferentes. Uma imagem é formada por diferentes níveis de gradientes. Essa informação é utilizada no estágio de classificação e de sombreamento. 
Quando raios de luz imaginários passam através dos blocos de voxels, amostras são capturadas durante o trajeto do raio para acumulação. Esses pontos de amostras são raramente alinhados com a exata localização dos voxels.

O sombreamento é utilizado para destacar partes em um conjunto de dados utilizando um modelo de iluminação. Os modelos de iluminação podem variar em complexidade dependendo dos parâmetros em uso como velocidade da CPU (Central Processor Unit ou Unidade de Processamento Central), número de fontes de luz e necessidades de cores.

Um pixel na tela pode representar centenas de valores que foram acumulados durante a passagem do raio pelo volume. Por esse motivo, é necessário computar todos esses valores em apenas um. Esse processo de acumulação é realizado através de uma função de composição. A fórmula a ser utilizada neste processo depende da direção da travessia do raio.

\subsection{Classificação}

Segundo LEVOY (1988b), DREBIN et al. (1988) o procedimento de classificação permite selecionar estruturas em um conjunto de dados de um volume, sem a necessidade da interferência manual para a demarcação de uma estrutura. A classificação também permite observar dentro de um objeto e explorar as estruturas ao invés de apenas observar a superfície do objeto.

Este tipo de recurso presente na reconstrução de volume é de grande utilidade e permite boa praticidade nas tarefas de segmentação de estruturas. Comparado com a técnica de reconstrução por superfícies na qual envolve um pré-processamento para determinar se uma superfície está ou não presente no conjunto de dados antes de realizar a reconstrução. 
A decisão de se uma superfície pertence ou não ao conjunto de dados é susceptível a erros. Se a decisão sobre a existência de uma determinada superfície for feita na etapa do pré-processamento, mas na verdade essa superfície não existe, a reconstrução irá mostrar uma falsa representação do conjunto de dados.

Por outro lado, a classificação na reconstrução de volume é muito mais sofisticada que um processo de decisão binária. Se existir uma estrutura em um conjunto de dados, ela pode se tornar visível com a classificação. Este procedimento é realizado atribuindo uma nova propriedade chamada opacidade, a cada voxel no conjunto de dados. A opacidade é uma medida de quanto um voxel é translúcido. Na realidade, é um valor entre 0 e 1 que descreve a quantidade de luz que atinge o voxel e é absorvida.

\subsection{Histogramas}

O histograma na reconstrução de volumes ilustra quantas vezes um voxel de um certo valor está presente em um conjunto de dados (Figura 3.7(a)). O histograma é um gráfico com os valores do voxel no eixo horizontal pelo seu número de ocorrências, ou freqüência, em um determinado eixo (Figura 3.7(b)).

Um histograma fornece a informação da extensão de todos os valores do voxel do conjunto de imagens do volume. Este método é muito útil, pois quando as informações das intensidades dos voxels ao longo da extensão do volume são conhecidas, é possível selecionar com mais facilidade qual função de transferência será utilizada para o procedimento de classificação. 

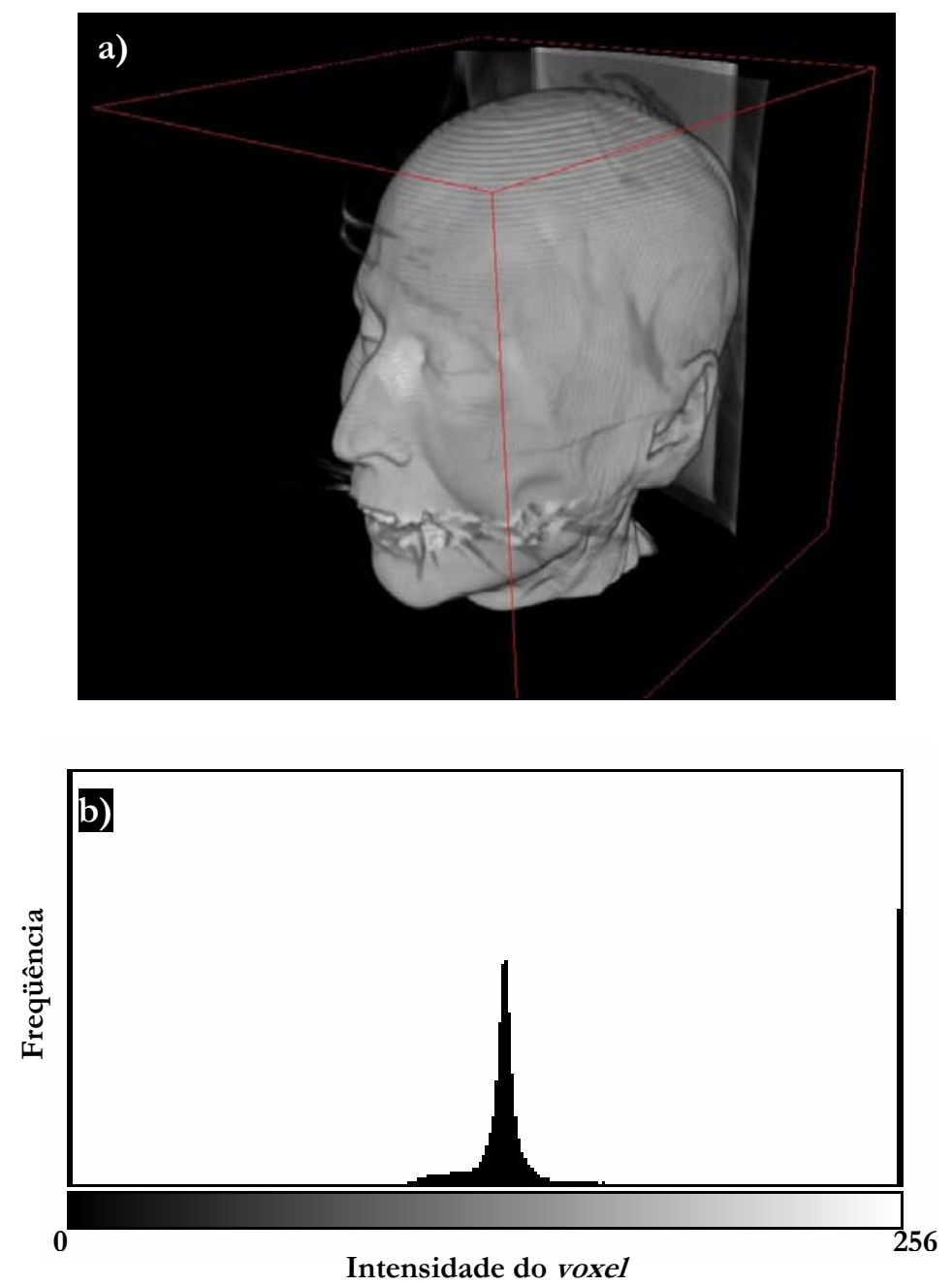

Figura 3.7 - Exemplo de um volume reconstruído e seu histograma: a) Volume reconstruído; b)

Histograma obtido do conjunto de dados do volume.

\subsection{Funções de Transferência}

A classificação é o processo de designar um valor de opacidade para um voxel. Esta indicação é alguma função de propriedades de um voxel, como sua intensidade, ou sua magnitude local de gradiente. Esta função é chamada de função de transferência de opacidade (HE et al. (1996) e MARKS et al. (1997)). Esta função pode conter qualquer número de propriedade de voxels, como entrada de dados, mas normalmente é apenas uma 
função de intensidade de voxels ou, em outros casos, uma função de intensidade e magnitude local de gradiente. A sua formula correspondente é:

$$
\alpha_{1}=O\left(I_{i},\left|\nabla_{i}\right|, \ldots, \ldots, \ldots\right)
$$

onde $O(. .$.$) é a função de transferência de opacidade, e |\nabla|$ é o gradiente local de magnitude.

\subsection{Coloração e Sombreamento}

A atribuição de cores é um processo de classificação. Neste processo de transformar as intensidades dos voxels em cores, com o objetivo de aprimorar a compreensão do conjunto de dados, são utilizadas três funções de transferência, para cada função RGB (Red, Green and Blue ou Vermelho, Verde e Azul):

$$
\begin{aligned}
R_{i} & =T_{r}\left(I_{i}, \ldots\right) \\
G_{i} & =T_{g}\left(I_{i}, \ldots\right) \\
B_{i} & =T_{b}\left(I_{i}, \ldots\right)
\end{aligned}
$$

Onde $T_{r}, T_{g}$ e $T_{b}$ são as funções de transferências para as cores RGB. Estas três funções podem ser diferentes para cada cor. Se forem as mesmas, será gerada uma imagem em tons de cinza. Normalmente existe apenas uma função de intensidade de voxel, e suas cores não precisam necessariamente corresponder às de um objeto real. É possível ainda atribuir ao objeto segmentado cores diferentes da realidade para aumentar o contraste e a compreensão da reconstrução do volume em estudo. 
Na Figura 3.8 é apresentado um corte transversal na altura da pélvis de um ser humano, utilizando uma variação de cores para as funções de transferência, sendo possível atribuir pseudo cores. Este tipo de recurso de função de transferência torna possível que determinado conjunto de intensidade de voxels selecionados possuam uma cor associada, fazendo com que seja aprimorado a visualização de determinadas estruturas, de acordo com a seleção de voxels realizada.

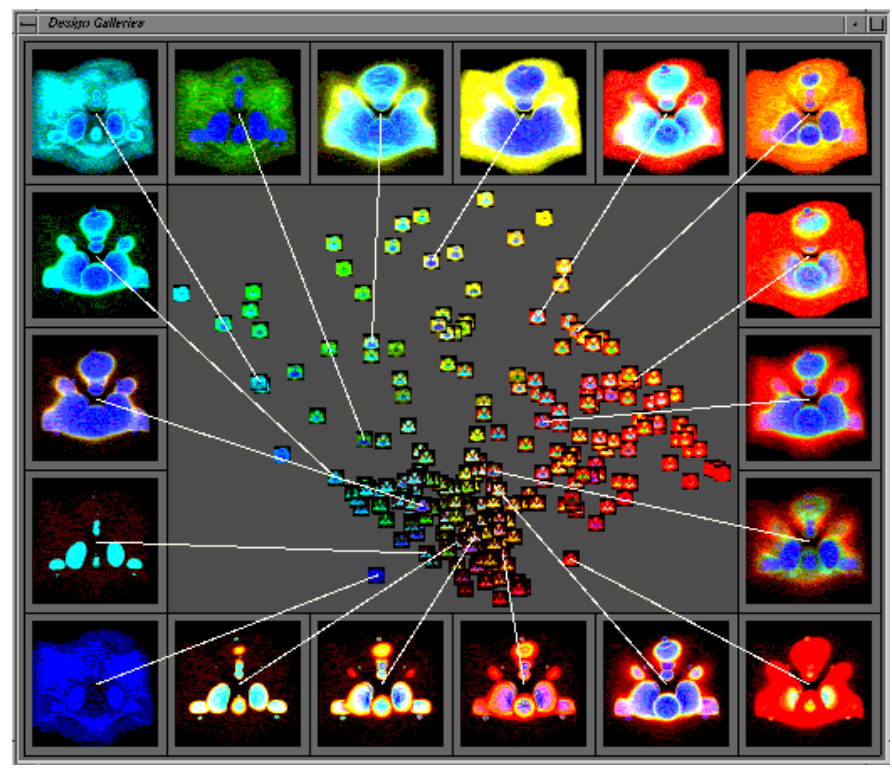

Figura 3.8 - Galeria contendo diferentes níveis de funções de transferência de cores e opacidades.

Fonte: MARKS et al. (1997).

A Figura 3.9 apresenta um segmento de um conjunto de imagens de uma pélvis reconstruída utilizando o método de Ray-casting. Para cada imagem foi gerada uma variação na função de transferência da intensidade de um agrupamento de voxels com valores de intensidade próximos, fazendo desta maneira com que determinadas estruturas presentes neste volume reconstruído fiquem com a opacidade variada, e que desta forma seja possível observar internamente o volume, determinando qual estrutura deseja-se que se torne mais transparente ou mais opaca. 


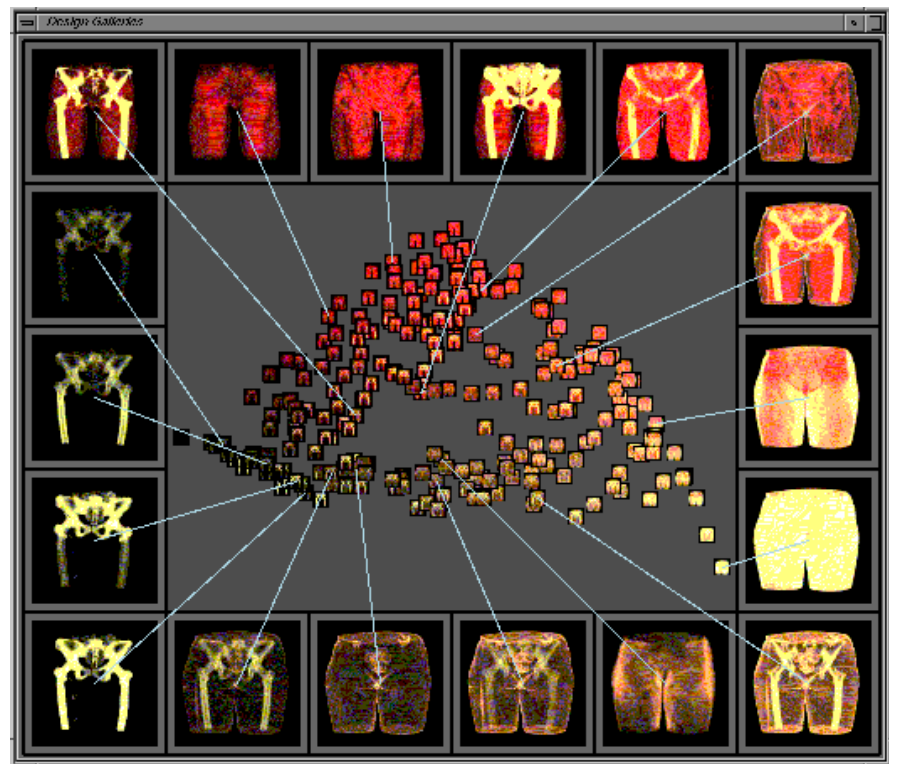

Figura 3.9 - Galeria contendo diferentes níveis de função de transferência de opacidades. Fonte:

MARKS et al. (1997).

\subsection{Segmentação}

A classificação e a coloração são estágios do diagrama do volume. Uma vez que as funções de transferência foram atribuídas, a classificação e a coloração podem ser executadas automaticamente.

Embora o procedimento de segmentação seja importante na reconstrução de volume, possui, por outro lado, muitos limites. Não é possível utilizar cada função de transferência para cada característica em um conjunto de dados. Existem vários procedimentos sofisticados e algoritmos para a extração de características e reconhecimento de padrões.

Geralmente estes algoritmos são semi-automáticos e requerem algum nível de interação com o usuário. Em alguns casos, em um conjunto de dados não é possível utilizar 
um algoritmo de segmentação automática para selecionar determinada característica. Neste caso o procedimento necessário é marcar a região manualmente que não foi selecionada.

Em alguns casos também é possível desenvolver um algoritmo que atue em conjunto com o escolhido para satisfazer alguma peculiaridade no conjunto de dados em uso.

\subsection{Interpolação}

O principal conceito do Ray-casting é seguir os raios através do bloco de voxels. Ao longo de cada raio é necessário fazer a amostragem e compor os valores para determinar o valor final para representar o raio.

Em determinadas circunstâncias é necessário fazer a amostragem entre voxels para se obter um voxel intermediário. Primeiramente é encontrado um ponto inicial onde o raio transpasse o bloco de voxels. Este raio é seccionado em pequenos passos de incrementos e é realizada a reamostragem. Uma vez que os pontos iniciais são calculados, os próximos pontos são encontrados adicionando o $\Delta x$ ou o $\Delta y$ ou o $\Delta z$ dependendo da direção do raio traçado. Na Figura 3.10 é apresentada essa transversal com os passos de incremento.

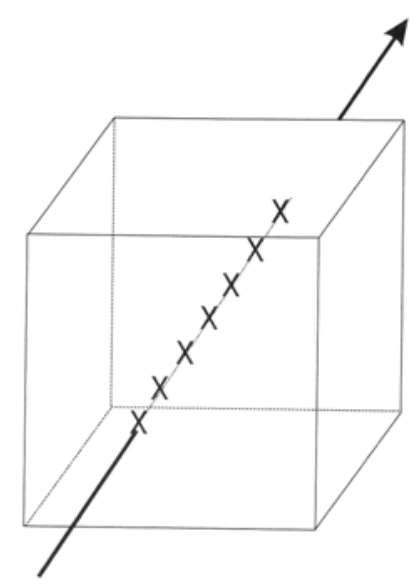

Figura 3.10 - Divisão do raio dentro de um volume por passos de incrementos. 
A Figura 3.11 mostra a necessidade de se realizar a amostragem entre dois valores conhecidos. A geração das amostragens entre voxels envolve a ponderação da soma dos voxels ao redor do ponto da amostragem. O novo valor criado utilizando os voxels existentes é chamado de interpolação.

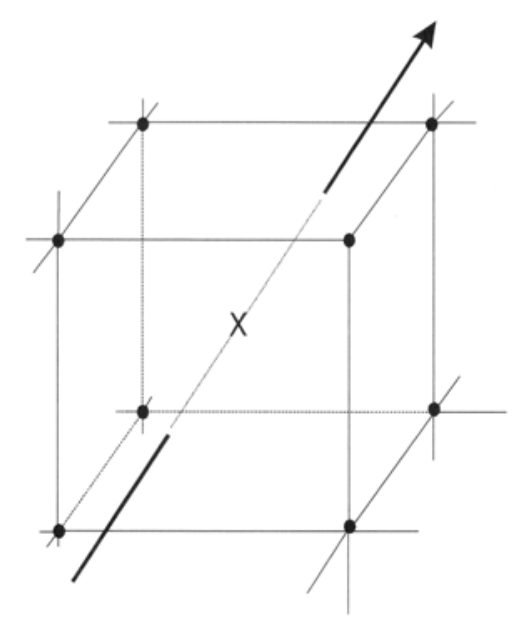

Figura 3.11 - Passos ao longo de um raio.

\subsubsection{Núcleos de Interpolação}

Existem vários métodos diferentes para gerar a interpolação. Cada método é controlado por um operador chamado de núcleo de interpolação. A forma do núcleo de interpolação oferece um coeficiente para a ponderação da soma da interpolação.

A Figura 3.12 mostra a diferença entre alguns núcleos utilizados para a interpolação. A qualidade da imagem resultante é dependente da escolha de qual núcleo será utilizado como operador na imagem.

Quando é necessário interpolar-se um valor, o núcleo é posicionado entre os valores conhecidos. O núcleo é centralizado exatamente no ponto de interpolação de interesse. Em 
qualquer ponto onde o núcleo interceda a posição de um valor conhecido, os dois valores são multiplicados.

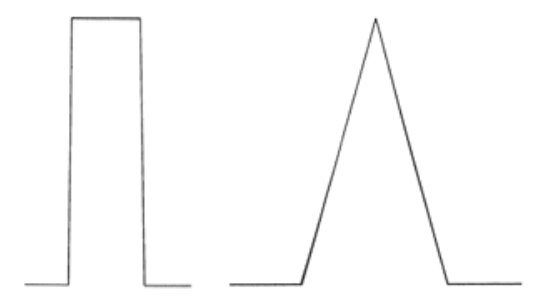

a) b)

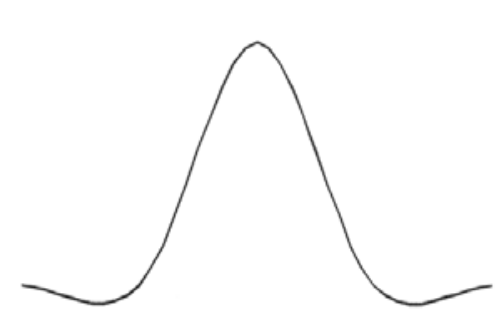

c)

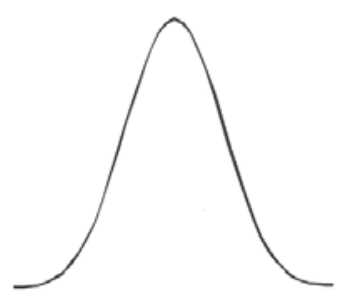

d)

Figura 3.12 - Diferentes núcleos de interpolação: a) Vizinho mais Próximo; b) Linear; c) Convolução Cúbica; d) B-spline.

Na Figura 3.13 é apresentada a aplicação do núcleo de interpolação em dois valores com a utilização do núcleo da Figura 3.12(c).

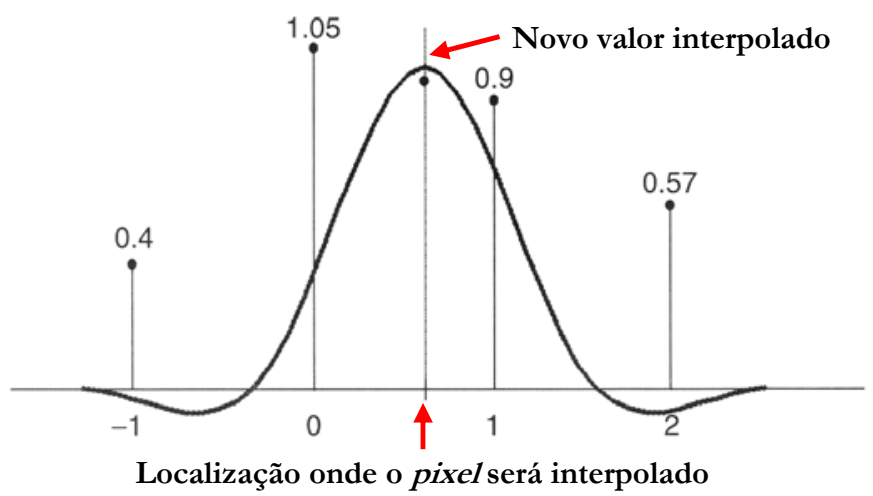

Figura 3.13 - Ilustração do procedimento de interpolação.

\subsubsection{Viæinho mais Próximo}

A interpolação pelo núcleo de interpolação do vizinho mais próximo é realizada utilizando o valor no vizinho mais próximo do voxel no ponto de interpolação. Através da 
forma do núcleo de interpolação da Figura 3.14, é possível observar que apenas um valor é utilizado no processo.

Este método é diferente dos outros núcleos de interpolação, pois é um processo de seleção ao invés de um cálculo da ponderação da soma como os que outros métodos de interpolação utilizam.

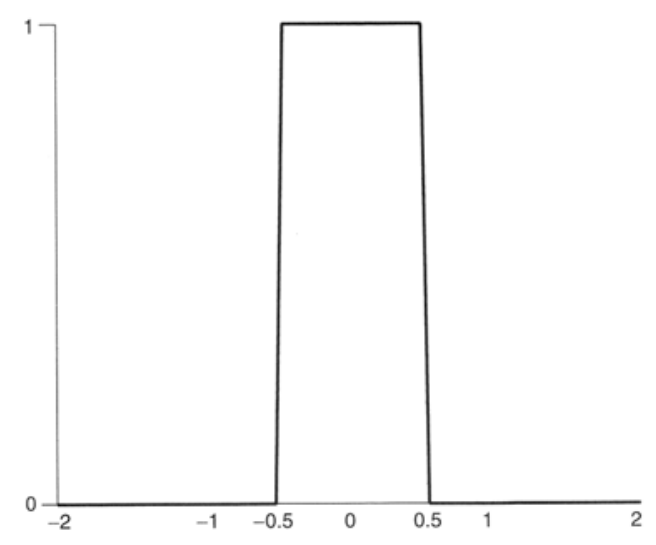

Figura 3.14 - Núcleo de interpolação do Vizinho mais Próximo.

\subsection{OpenGL (Open Graphics Library)}

Segundo WRIGHT (1996) as bibliotecas OpenGL são uma padronização de funções de primitivas gráficas. O precursor do OpenGL foi o GL, desenvolvido pela empresa SGI (Silicon Graphics Industries). A IRIS GL foi a API (Application Program Interface) 3D de programação para a estação gráfica IRIS, sendo que eram API's de programação de alto nível.

Estes computadores tinham um hardware especializado e aperfeiçoado para a exibição de gráficos sofisticados. Este hardware conseguia realizar rapidamente transformações de matrizes (uma condição prévia para a exibição de gráficos 3D), suporte de hardware para o buffer de profundidade, e outras características. A empresa SGI tentou transportar a IRIS 
GL para outras plataformas de hardware, mas foram observados vários problemas de compatibilidade.

A criação do OpenGL foi o resultado dos esforços da empresa SGI para tornar as bibliotecas da IRIS GL mais portáveis (capacidade de utilização em outras plataformas). A nova linguagem oferecida tinha o poder da IRIS GL, mas possuía o código aberto e permitiria uma adaptação mais fácil entre outras plataformas de hardware e sistemas operacionais.

Um padrão aberto não está realmente aberto se só um fornecedor o controla. Assim, todos os aprimoramentos do OpenGL são decididos pela OpenGL ARB (Architecture Review Board), nos quais os sócios são a SGI, Corporação de Equipamento Digital, IBM, Intel e Microsoft.

No OpenGL, o programador deve descrever como o objeto 3D será visualizado, juntamente com as instruções necessárias para atingir uma certa aparência ou efeito.

Estas instruções envolvem chamadas para uma API altamente portátil, que inclui mais de 120 comandos e funções pré-definidas. Estes comandos e funções são utilizados para acessar primitivas gráficas como pontos, linhas, e polígonos em três dimensões. Além disso, o OpenGL suporta iluminação, sombras, mapeamento de texturas, animações e outros efeitos especiais.

\subsection{A Linguagem Computacional Java}

HORSTMANN et al. (2001) afirmam que Java é uma linguagem de programação orientada a objetos desenvolvida em 1991 pela empresa Sun Microsystems.

Essa linguagem foi modelada tomando como base a linguagem $\mathrm{C}++$ como parte de um projeto de pesquisa para desenvolver um software para dispositivos eletrônicos como televisões, videocassetes e os outros tipos de máquinas que podem ser adquiridos em lojas 
de departamentos. A meta para a linguagem Java era possuir um código compacto, rápido, eficiente, e portátil, para que uma grande variedade de dispositivos de hardware pudessem utilizar dos recursos desta linguagem de programação. Essas mesmas metas tornaram essa linguagem ideal para distribuir programas executáveis pela Internet e também como um propósito de ser uma linguagem de programação para desenvolvimento, que é facilmente utilizada e portável para plataformas diferentes e sistemas operacionais diferentes, do código fonte ao binário.

Os programas em Java são facilmente encontrados na Internet. Quando os browsers ${ }^{1}$ como o Mozilla, ou o Internet Explorer da Microsoft executam os programas Java como applets ${ }^{2}$, outros browsers podem carregar os applets desde que possuam suporte para carregar esses programas.

Os programas em Java que funcionam em forma de applets são dinâmicos e interativos, podendo ser utilizados para funcionar na forma de um programa, mas com a diferença que podem ser executados dentro ou fora da janela do browser. A utilização das applets em páginas HTML servem para aprimorar os recursos, pois podem ser utilizados para criar animações, figuras, formulários para interação com o usuário ou outros efeitos interativos.

Para criar um programa em Java, como em qualquer outra linguagem de programação, onde o código fonte é compilado, o programador deve transcrever o seu algoritmo para o código fonte da linguagem, utilizando qualquer editor de texto ou editores desenvolvidos especialmente com suporte a recursos especiais para a linguagem Java, para facilitar a programação como os editores: Eclipse, NetBeans, JDeveloper, JBuilder, JEdit, entre outros (DEITEL et al. (2005)).

\footnotetext{
${ }^{1}$ Categoria de softwares que permitem visualizar um documento criado em um certo padrão, no caso
} HTML (Hiper Text Markup Language). 
O código fonte é constituído de comandos e funções específicas da linguagem de programação que, inseridos em uma seqüência lógica, possibilitam ser interpretados e executados para realizar determinadas tarefas.

Um programa em Java é compilado para o chamado byte-code, que é uma forma binária próxima às instruções de linguagem de máquina, mas não da máquina real. $\mathrm{O}$ motivo para o qual o programa não é compilado diretamente para as instruções binárias da máquina que é utilizada na compilação faz com que o programa seja portável para outras arquiteturas de computadores.

O byte-code é um código de uma máquina virtual idealizada pelos criadores da linguagem. O motivo pelo qual um programa em Java é muito mais rápido que linguagens interpretadas, como Pearl, PHP e Python, é que, no momento da execução do programa em Java, um programa chamado de Java Virtual Machine, que é instalado no computador onde o programa está sendo executado, compila o byte-code para as instruções do código de máquina.

A linguagem de programação Java tem vantagens significativas sobre outras linguagens e outros ambientes que fazem a sua utilização satisfatória para qualquer tarefa de programação. Esta seção descreve algumas dessas vantagens.

A linguagem Java é independente de plataforma, ou seja, possui a característica de poder ser transferida facilmente de um sistema de computador para outro. Essa é uma das vantagens mais significantes que essa linguagem possui sobre outras linguagens de programação, particularmente se o software precisa funcionar em muitas plataformas diferentes e se o software está sendo desenvolvido para a Internet. Caso possa existir a possibilidade do programa necessitar funcionar em vários sistemas diferentes, é fundamental o programa ser independente de plataforma.

2 Programa computacional desenvolvido em linguagem Java que é executado dentro da janela do browser. 
Na Figura 3.15 é mostrado um exemplo de um código fonte de um programa em Java. Se este código fonte for transformado no byte-code e executado, as instruções presentes neste programa fazem com que seja mostrado no monitor de um computador a mensagem "Exemplo de Programa em Java". A saída deste programa, ou seja, o resultado da execução desse programa será o mesmo em qualquer arquitetura computacional e em qualquer sistema operacional.

Embora esse exemplo apenas faça aparecer uma mensagem na tela de um computador de qualquer sistema operacional e arquitetura, a linguagem Java permite que seja criado um programa mais complexo, como por exemplo, o programa que será desenvolvido neste trabalho para realizar a reconstrução e visualização de volumes 3D de imagens ultra-sonográficas, da mesma forma como o exemplo da Figura 3.15 e possuirá a mesma característica da facilidade de portabilidade.

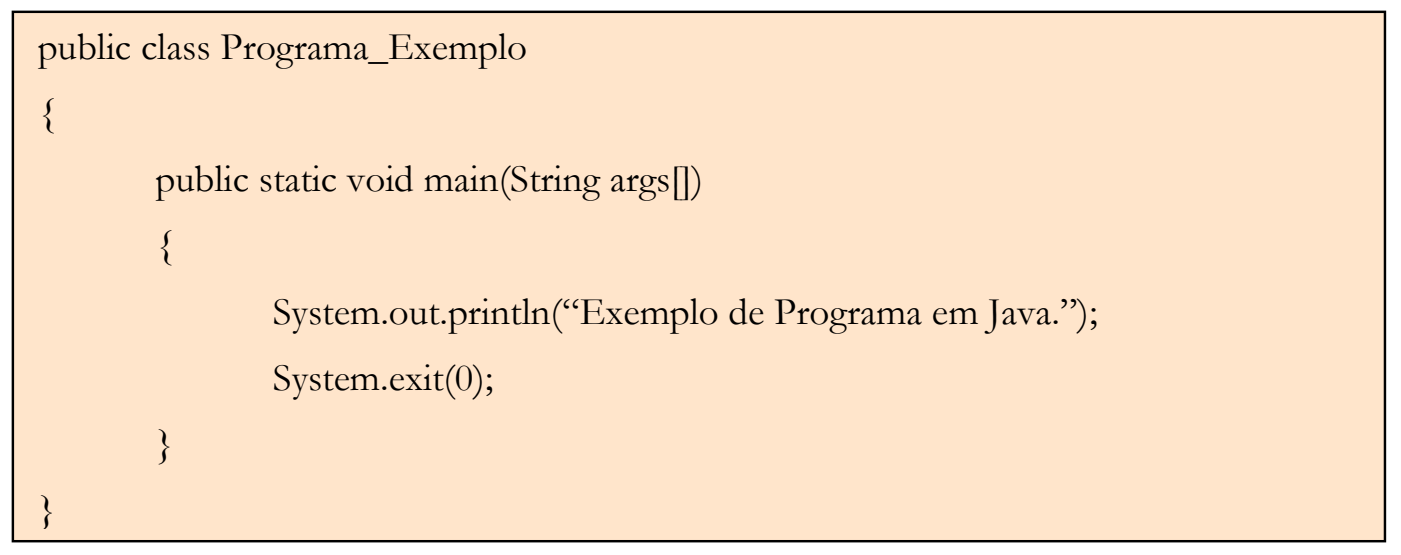

Figura 3.15 - Exemplo de um código fonte de um programa em linguagem Java.

Em relação ao código fonte, os tipos de dados primitivos da linguagem Java têm tamanhos consistentes para todas as plataformas de desenvolvimento. As bibliotecas de classe da fundação possibilitam o código ser movido de uma plataforma para outra sem a necessidade de compilar o código para a outra plataforma. 


\section{CAPÍTULO 4}

\section{Formas de Aquisição de Imagens 3D em Aparelhos de Ultra-som}

\subsection{Introdução}

Neste capítulo é apresentado que a maior vantagem do equipamento de ultra-som é a sua capacidade de se obter imagens em vários planos e de se capturar a varredura contínua.

CANDIANI (1998) cita que, diferentemente dos aparelhos de Tomografia Computadorizada e de Ressonância Magnética, o aparelho de ultra-som convencional não identifica as fatias iniciais capturadas das seções e precisa ser informado do posicionamento do sensor de captura das imagens.

Atualmente existem várias maneiras de se obter imagens 3D em aparelhos de ultrasom. Esses métodos são por:

- Processamento Externo 
- Sensores mecânicos provendo varredura volumétrica.

- Transdutores convencionais conectados a sensores espaciais.

- Transdutores em matriz.

Todos esses modos de obtenção de imagens em 3D em aparelhos de ultra-som são explicado ao decorrer deste capítulo.

\subsection{Processamento Externo}

Segundo SACKMAN et al. (1994), o método de visualização 3D através do processamento externo consiste em utilizar um computador conectado a um aparelho de ultra-som. O computador armazena uma série de imagens recebidas da unidade de ultrasom capturadas em uma determinada seqüência de movimento (Figura 4.1). Essas imagens são processadas após o final da captura do volume e são ordenadas em uma seqüência contínua.

As imagens capturadas podem ser orientadas manualmente no computador pelo manipulador e podem ser visualizadas em 3D utilizando algoritmos como Ray-casting ou Ray-tracing. Após este procedimento podem ser rotacionadas em diferentes eixos, permitindo o pós-processamento de medidas de cores e contraste.

O grande fator negativo deste tipo de reconstrução é que o operador do aparelho de ultra-som necessita conduzir o transdutor em uma direção retilínea, e com velocidade uniforme sobre o corpo do paciente, e em momento algum o transdutor pode ser inclinado. Esta é uma operação muito difícil de se realizar pela anatomia do corpo humano. Este procedimento é necessário, porém, uma vez que, como o transdutor não fornece qualquer tipo de informação sobre posicionamento e inclinação de onde se está obtendo as 
imagens no corpo do paciente, a falta dos critérios acima ocasiona distorções no volume 3D reconstruído.

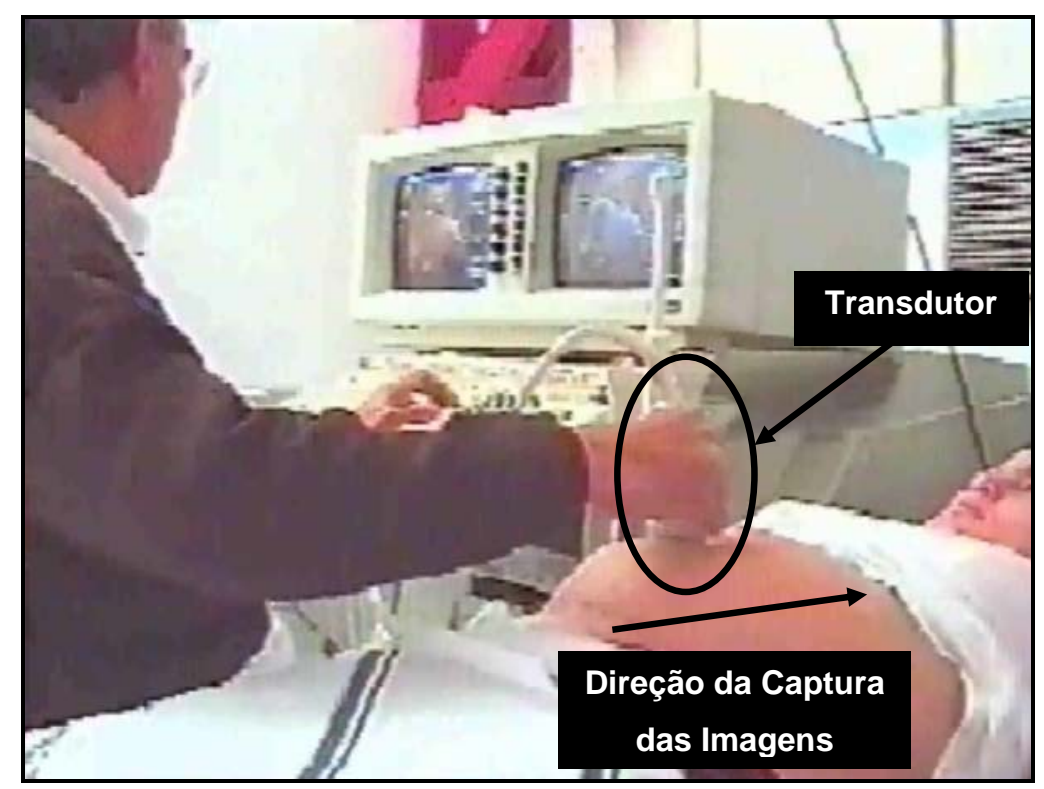

Figura 4.1 - Direção e sentido do transdutor para a captura das imagens em uma gestante geralmente utilizado em sistemas de processamento externo.

\subsection{Sensores Mecânicos Provendo Varredura Volumétrica}

Este método de reconstrução é baseado no modo de aquisição por Processamento Externo, com a diferença que o transdutor é fixado em um sensor mecânico (Figura 4.2). GEISER et al. (1982a,1982b), RAICHLEN et al. (1986) e SAWADA et al. (1983) alegam que este tipo de sensor permite o rastreamento seqüencial da imagem com precisão, através do movimento do transdutor. 


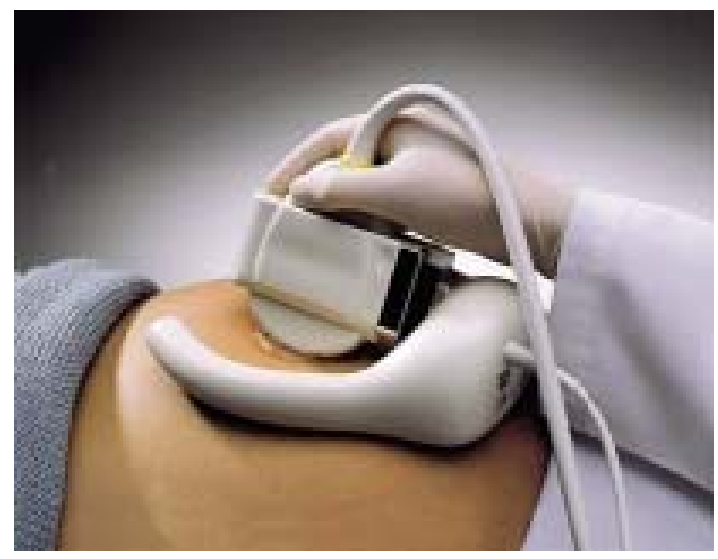

Figura 4.2 - Imagem de um sensor mecânico acoplado a um transdutor sobre o corpo do paciente.

O sensor envia as coordenadas 3D de acordo com o movimento do transdutor para o computador, que armazena as coordenadas 3D referentes à angulação do transdutor juntamente com as imagens que são capturadas através de uma placa de vídeo-captura. Há necessidade do rastreamento manual com o transdutor e tem a desvantagem de depender de variantes anatômicas do corpo do paciente.

Além da falta de mobilidade causada pelo aparato mecânico que necessita ser acoplado ao transdutor para a aquisição da informação do seu posicionamento, limita os movimentos do usuário e as áreas que podem ser adquiridas para a reconstrução do volume nesta modalidade (HUGHES et al. (1996)).

Atualmente, por causa da falta de mobilidade imposta pelo acoplamento de equipamentos mecânicos e o surgimento de novas tecnologias que fornecem o direcionamento do transdutor, sem causar a perda da mobilidade imposta pelos equipamentos mecânicos, esse tipo de sensor não está sendo mais utilizado em aparelhos comerciais.

Na Figura 4.3 é mostrado a nova geração de transdutores de ultra-som mecânicos 3D. Esse tipo de sensor proporciona mais mobilidade e facilidade de aquisição de imagens 
em 3D. Os equipamentos mais modernos conseguem também gerar imagens 3D com movimentos utilizando esse tipo de equipamento

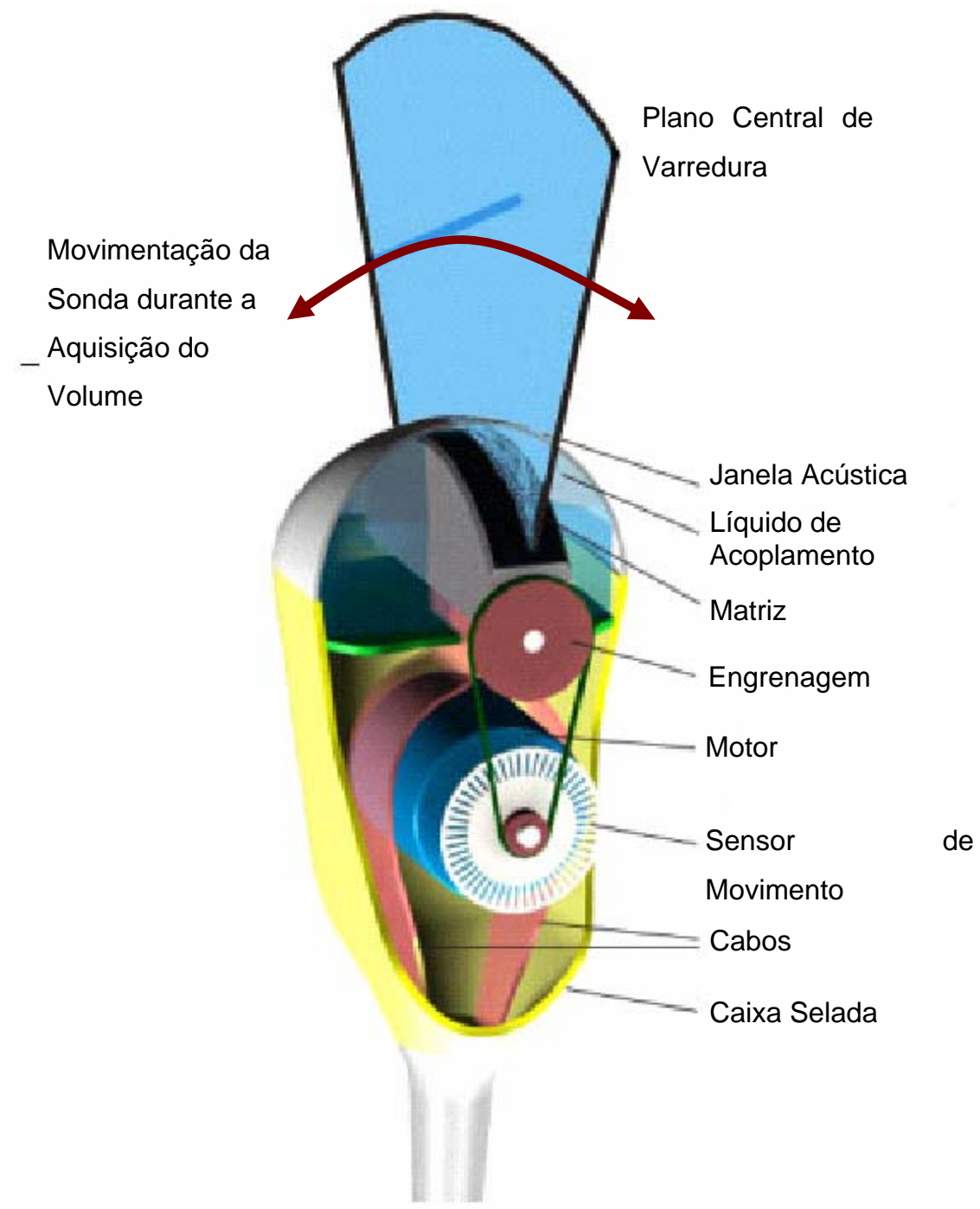

Figura 4.3 - Esquema interno de um transdutor 3D mecânico moderno.

\subsection{Transdutores Convencionais Conectados a Sensores Espaciais}

Este tipo de modalidade de aquisição de dados para a visualização 3D também deriva da aquisição por Processamento Externo e é similar a aquisição por Sensores Mecânicos, 
com a diferença que sensores espaciais são conectados aos transdutores convencionais e estes podem ser do tipo acústico ou magnético. São utilizados para registrar a posição do transdutor e sua inclinação no espaço para o computador em forma de coordenadas cartesianas x, y e z e grau de inclinação.

Esta técnica permite ao operador movimentar o transdutor em qualquer caminho sem restrições de movimento. A técnica mais comum é baseada na variação acústica e faz uso de um transmissor sonoro montado no transdutor com pequenos microfones que recebem ondas sonoras emitidas pelo transmissor. Através do conhecimento da velocidade da propagação do som no ar, a localização dos microfones e o tempo de transmissão das ondas sonoras, a localização do sensor e sua orientação no espaço podem ser determinadas.

Segundo STEINER et al. (1994) e RANKIN et al. (1993) este tipo de modalidade de construção do volume tridimensional é denominado de freehand. O operador apenas move o transdutor manualmente enquanto o sensor armazena as coordenadas do movimento.

Sensores que utilizam um campo magnético variável também podem ser acoplados no transdutor. Os receptores magnéticos podem ser móveis ou fixos, múltiplos ou únicos e geralmente ficam na mesa de exame do paciente. Como o sensor acústico, os dados das coordenadas de orientação do sensor são armazenados no computador juntamente com as respectivas imagens capturadas através de uma placa de vídeo.

Atualmente a empresa Polhemus fornece vários tipos de sensores de rastreamento de posição magnético que são comuns na utilização em sistemas de reconstrução de imagens de ultra-som 3D por Freehand, como o Fastrak (Figura 4.4(a)) e o modelo Patriot (Figura 4.4(b)) que se destaca principalmente por seu baixo custo em relação aos outros sensores disponíveis. 


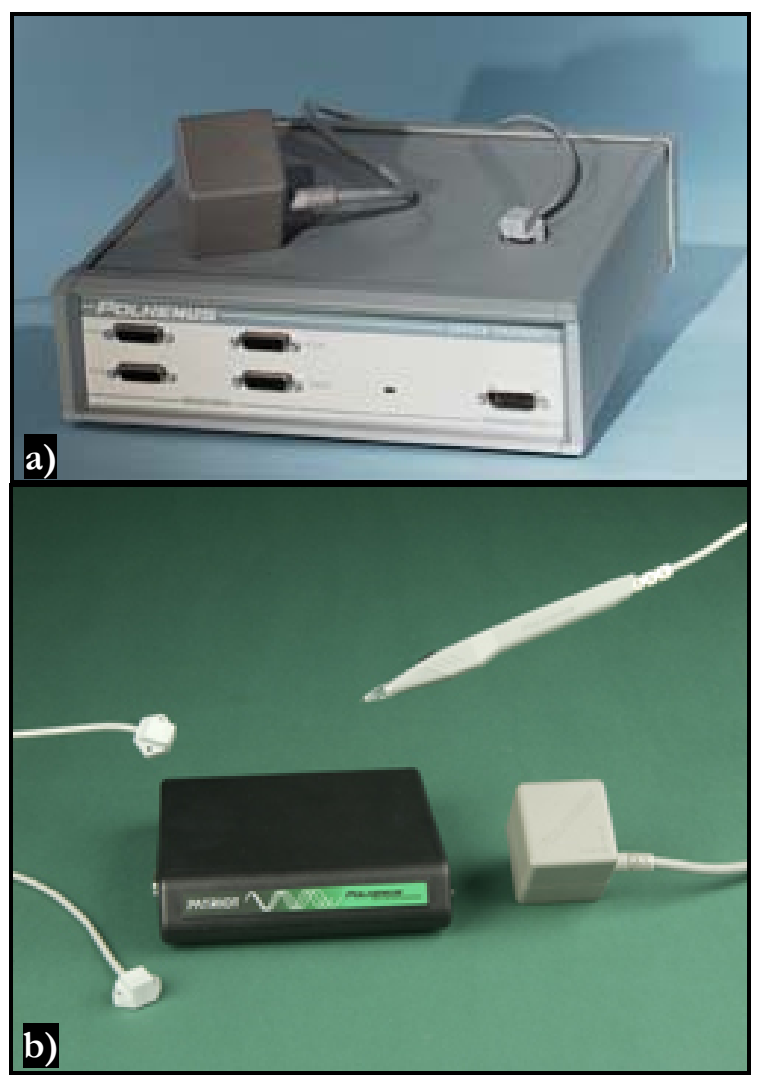

Figura 4.4 - Sensores de rastreamento de posição magnéticos comercializados pela empresa Polhemus: a) Modelo Fastrak; b) Modelo Patriot.

\subsection{Transdutores em Matriz}

Este sistema funciona através de um transdutor eletrônico que possui cristais piezelétricos encadeados posicionados em ambos os planos longitudinais e transversos do transdutor que permitem adquirir a imagem do volume diretamente (BREDTHAUER et al. (2004), VON RAMM et al. (1991,2003), SMITH et al. (1991,1992) e SHEIKH et al. (1991)).

A Figura 4.5 mostra a diferença entre os 2 tipos de transdutores presentes em equipamentos de ultra-som. 


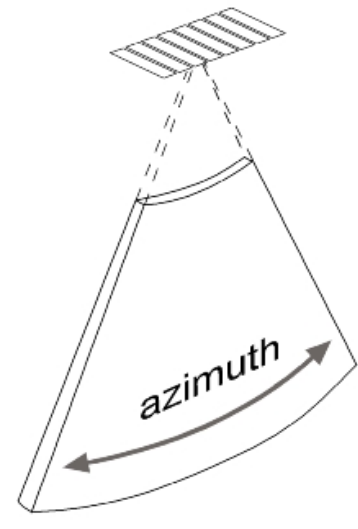

a)

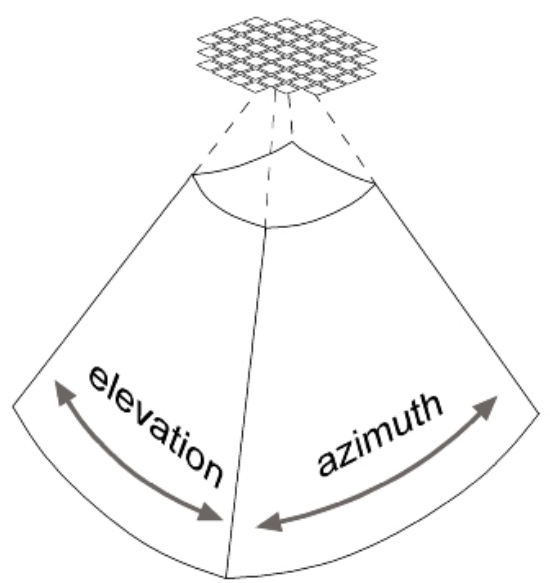

b)

Figura 4.5 - Diferença entre a posição e o encadeamento de cristais piezelétricos em transdutores e o formato da onda ultra-sônica em transdutores: a) Convencionais; b) Matriz. Fonte: STETTEN et al. (1999).

O transdutor da Figura 4.5b não necessita de um computador ligado externamente ao aparelho de ultra-som para processar a imagem adquirida.

Atualmente os novos aparelhos comerciais de ultra-som 3D utilizam essa tecnologia como meio de captura e exibição das imagens em 3D.

Esses aparelhos possuem a desvantagem, pois seu funcionamento fica restrito ao software e ao hardware disponibilizados dentro do equipamento, não sendo possível a atualizações da CPU.

Outro fator negativo deste tipo de tecnologia é seu custo relativamente alto, e a necessidade da substituição do aparelho de ultra-som 2D por outro que utiliza a tecnologia de transdutores em matriz, não sendo possível apenas substituir o transdutor convencional pelo transdutor em matriz. 


\section{CAPÍTULO 5}

\section{Materiais e Métodos}

\subsection{Introdução}

Efetivamente neste trabalho até o momento foi mostrado o levantamento bibliográfico sobre o funcionamento de um aparelho de ultra-som, o processo de obtenção de imagens através dele, como e quais características são observadas em um exame obstétrico por ultra-som, como funciona o esquema de reconstrução de imagens 3D e a interpolação de imagens, o desenvolvimento de sistemas em linguagem de programação Java, a manipulação das bibliotecas gráficas OpenGL e os vários métodos de se obter uma imagem 3D em aparelhos de ultra-som.

Neste capítulo é apresentado o desenvolvimento do sistema proposto neste trabalho para a reconstrução 3D de imagens adquiridas em aparelhos convencionais de ultra-som, 
que pode funcionar em qualquer arquitetura e sistema computacional, além de também poder funcionar através da Internet dentro de um browser que suporte Applets.

\subsection{Rastreador Magnético Polhemus Patriot}

Para o desenvolvimento desse sistema, foi adquirido "Polhemus Patriot". Esse tipo de equipamento funciona fornecendo as coordenadas 3D, como X, Y, Z, Azimute, Elevação e Rolagem, relativas à distância do posicionamento de um sensor e sua fonte.

Atualmente existem vários tipos de sensor que provêem esse tipo de recurso funcionando com diversas tecnologias como:

- Ótica;

- Ultra-som;

- Mecânica;

- Magnética.

Dentre as referências de trabalhos científicos (DETMER et al. (1994);KELLEY et al. (1994); GILJA et al. (1998)) que utilizam as tecnologias mencionadas acima, a que se adequou a este projeto, e a que é reportada como sendo a melhor, foi a tecnologia utilizando a varredura magnética.

Dentre a lista de fabricantes com seus respectivos modelos de equipamentos que geram coordenadas de orientação 3D por meio magnético, foi escolhido o equipamento “Polhemus Patriot” US\$3,000.00.

O equipamento "Polhemus Patriot" é baseado em um sensor magnético de posicionamento e pode fornecer as coordenadas X, Y, Z, Azimute, Elevação e Rolagem de duas formas: através de caracteres ASCII ou caracteres Binários. 
Este equipamento é fabricado pela empresa Polhemus Inc. e neste trabalho foi utilizado para indicar a posição do transdutor do aparelho em um sistema de coordenadas 3D de EULER.

Na Figura 5.1 o item 1 refere-se ao console do equipamento, o item 2 mostra a fonte magnética, o item 3 apresenta o sensor magnético. O item 4 mostra a fonte de energia, o item 5 apresenta o cabo serial e o item 6 mostra o adaptador serial para USB.

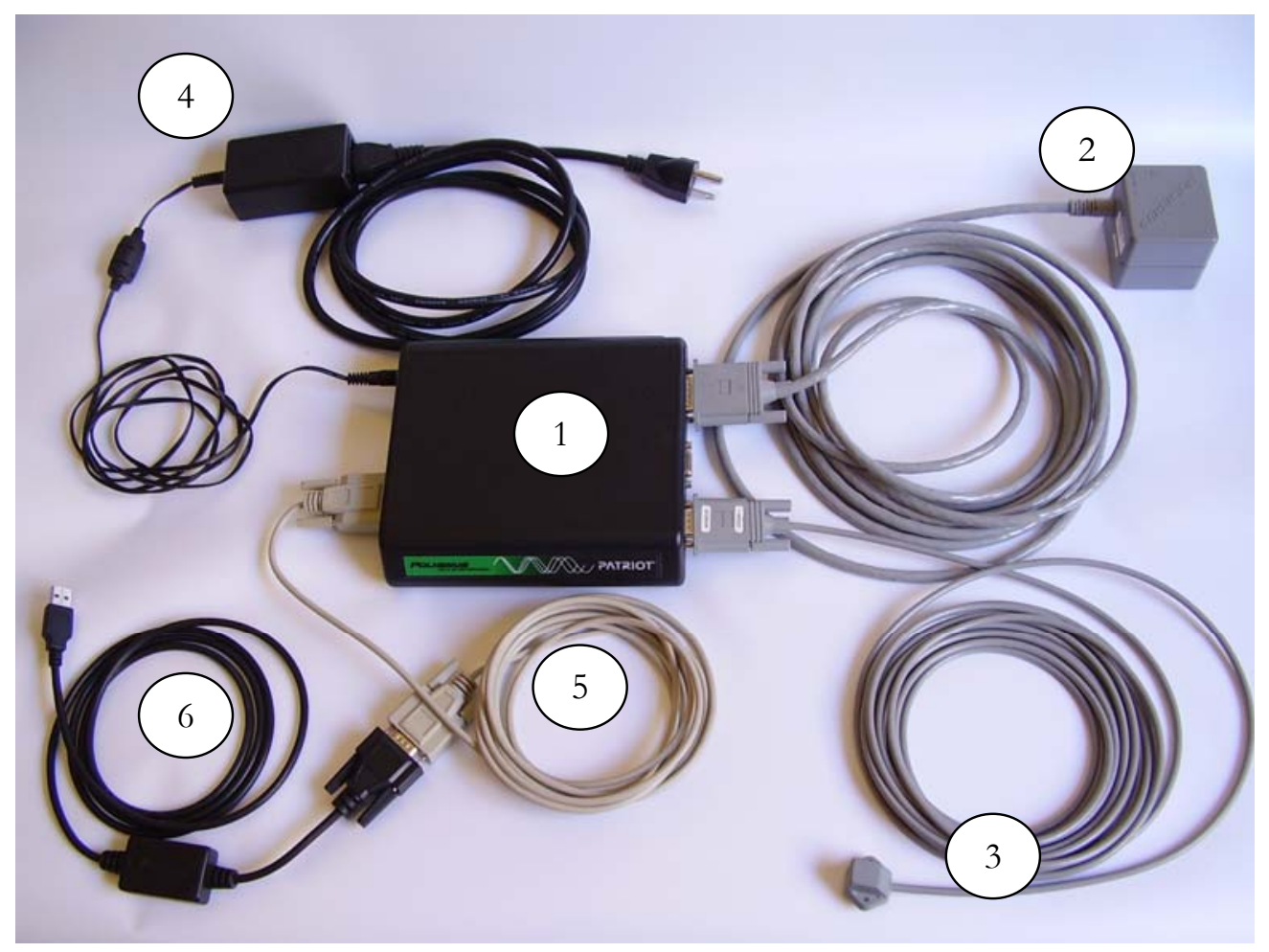

Figura 5.1 - Dispositivos pertencentes ao rastreador magnético Polhemus Patriot.

\subsubsection{Console do Equipamento Polhemus Patriot}

A Figura 5.2 mostra a parte lateral direita do console do sensor Patriot onde existe o interruptor de ligado, desligado, o conector para comunicação de dados via cabo serial de 15 pinos e o conector USB. 
O item 1 da Figura 5.2 mostra a seqüência de chaves para a configuração de aquisição de coordenadas.

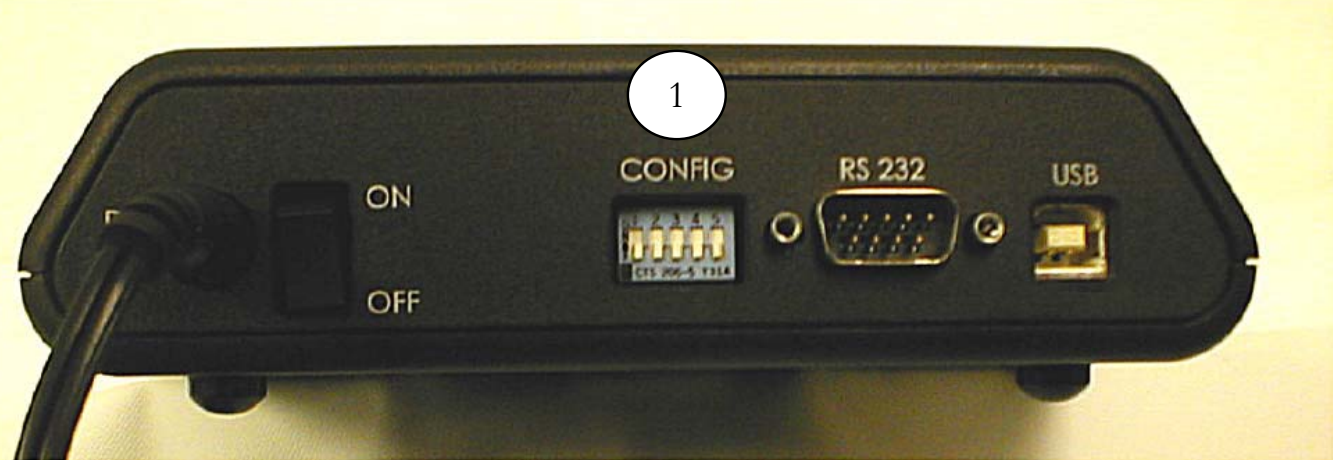

Figura 5.2 - Vista lateral direita do console "Polhemus Patriot".

Na Figura 5.3 é mostrada a visão lateral esquerda do console Patriot. O item 1 mostra a entrada do conector do sensor e o item 2 mostra a entrada do conector da fonte magnética.

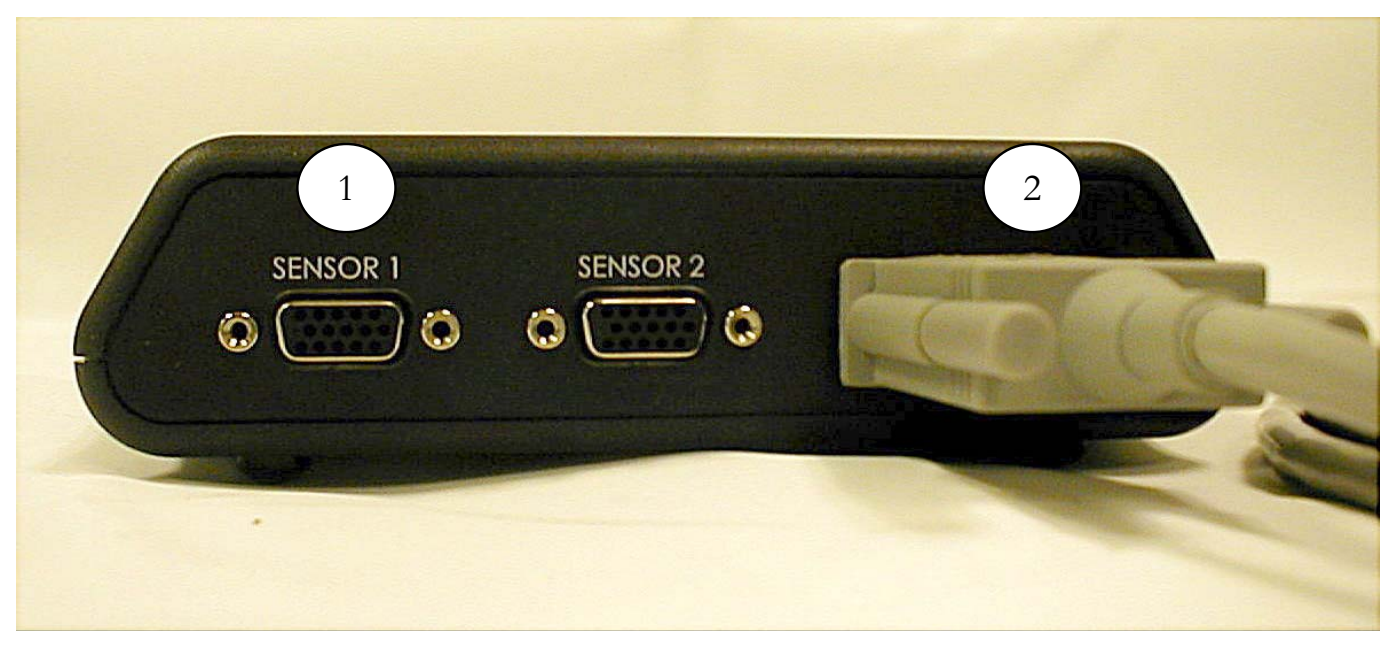

Figura 5.3 - "Vista" lateral esquerda do console "Polhemus Patriot". 


\subsection{2 Ângulos de orientação do Sensor}

Os ângulos azimute, elevação e rolagem definem a orientação atual do sensor em relação à referência da fonte magnética. As coordenadas de saída do sensor Polhemus Patriot em relação ao ângulo de Euler são mostradas graficamente na Figura 5.4.

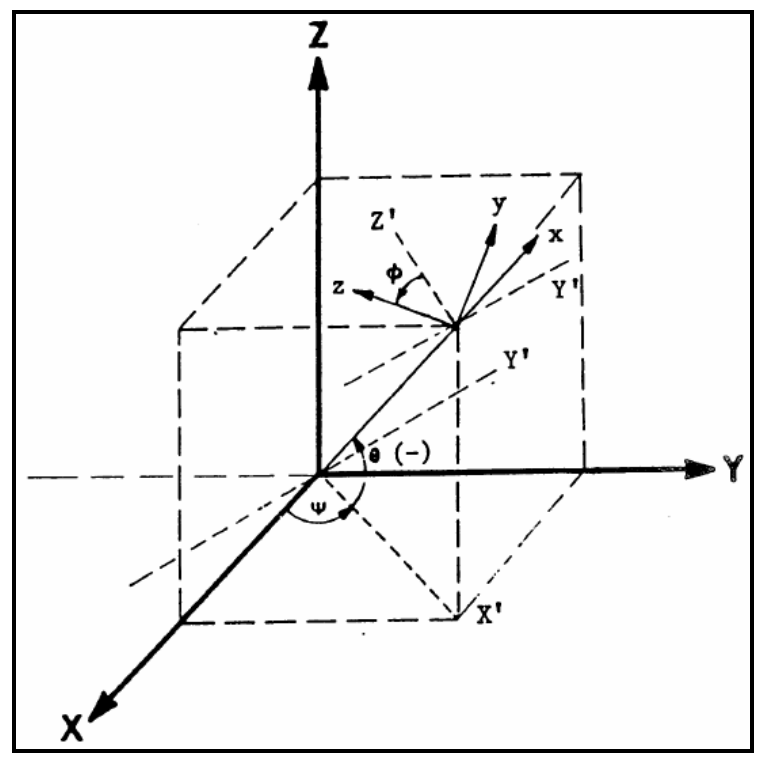

\begin{tabular}{|c|c|}
\hline \multicolumn{2}{|c|}{ Legenda } \\
\hline $\mathrm{X}, \mathrm{Y}, \mathrm{Z}$ & Alinhamento (Referência) \\
\hline $\mathrm{x}, \mathrm{y}, \mathrm{z}$ & Coordenadas do Sensor \\
\hline$\Psi$ & Azimute \\
\hline$\theta$ & Elevação \\
\hline$\phi$ & Rolagem \\
\hline
\end{tabular}

Figura 5.4 Ângulos de Euler utilizados no equipamento "Polhemus Patriot".

O trio x, y e z representa a posição do sensor em seu estado atual. O trio X, Y e Z representa a referência da posição relativa à orientação (da posição) apurada do sensor. Pela definição, o posicionamento $\mathrm{X}, \mathrm{Y}$ e Z também representa a referência de orientação de origem do quadro do sensor. 
São designados de $\Psi, \theta$ e $\phi$ os ângulos de Euler referentes ao azimute, elevação e rolagem. Estes ângulos representam a seqüência primária de giros da rotação do quadro, que definem a orientação do sensor com relação ao seu estado de orientação zero.

A definição da seqüência de rotações do sensor "Polhemus Patriot" é uma rotação em azimute, seguida por uma rotação na elevação e finalizando com uma rotação na rolagem.

O ângulo azimute representado pelo símbolo $\Psi$ é definido na Figura 5.4 como uma rotação do eixo da referência X e Y sobre o eixo da referência Z. A transição do eixo marcado como X' e Y' representa a orientação do eixo X e Y depois da rotação em azimute.

O ângulo de elevação marcado pelo símbolo $\theta$ é definido como uma rotação do eixo de referência Z e a transição do eixo X' sobre a transição do eixo Y'. O eixo de transição marcado como Z' representa a orientação do eixo de referência $Z$ apos a rotação na elevação. O eixo x da posição do sensor representa a orientação da transição X' após a rotação na elevação.

O ângulo de rolagem definido como $\varphi$ é uma rotação da transição do eixo Y' e Z' sobre o eixo x da posição do sensor. O eixo y e z da posição corrente do sensor representa a orientação dos eixos de transição Y' e Z’ após a rotação na rolagem.

Como mostrado na Figura 5.4, as rotações do sensor são, respectivamente, positivas em relação ao azimute, negativas em relação à elevação e positivas em relação a rolagem.

As Tabela 5.1 Tabela 5.2 apresentam algumas características técnicas típicas desse sensor. 
Tabela 5.1 - Características técnicas do Sensor Polhemus Patriot.

\begin{tabular}{|c|c|}
\hline Característica & Descrição \\
\hline Precisão Estática & $\begin{array}{c}0.1^{\prime \prime} \text { RMS para X, Y ou Z de posicionamento; } 0.75^{\circ} \text { RMS para a orientação do } \\
\text { sensor. }\end{array}$ \\
\hline Resolução & $0.0015 "(0.0038 \mathrm{~mm})$ a $12 "(30 \mathrm{~cm})$ de alcance; $0.1^{\circ}$ de orientação. \\
\hline Alcance & $36 "(90 \mathrm{~cm})$; utilizável até $60 "(152 \mathrm{~cm})$. \\
\hline Cobertura angular & Toda posição. \\
\hline Formato dos Dados & $\begin{array}{c}\text { Selecionado pelo operador saída em ASCII ou IEEE } 754 \text { binário; Polegadas ou } \\
\text { Centímetros. }\end{array}$ \\
\hline
\end{tabular}

Tabela 5.2 - Características Físicas do Sensor Polhemus Patriot.

\begin{tabular}{|l|c|c|c|c|}
\hline \multicolumn{1}{|c|}{ Equipamento } & Altura & Comprimento & Profundidade & Peso \\
\hline Console & $4,5 \mathrm{~cm}$ & $17,1 \mathrm{~cm}$ & $15,9 \mathrm{~cm}$ & $400 \mathrm{~g}$ \\
\hline Fonte magnética & $5,6 \mathrm{~cm}$ & $5,8 \mathrm{~cm}$ & $5,6 \mathrm{~cm}$ & $250 \mathrm{~g}$ \\
\hline Sensor & $15,2 \mathrm{~mm}$ & $22,9 \mathrm{~mm}$ & $27,9 \mathrm{~mm}$ & $23 \mathrm{~g}$ \\
\hline Módulo de Força & $3,6 \mathrm{~cm}$ & $8,9 \mathrm{~cm}$ & $6,1 \mathrm{~cm}$ & $160 \mathrm{~g}$ \\
\hline
\end{tabular}

\subsubsection{Conector Serial}

O conector serial RS-232, disponível no console, é o padrão de 9 pinos do tipo "D”. A identificação da entrada e saída de dados entre o console e o computador pode ser observada na Tabela 5.3.

Tabela 5.3 - Pinagem serial da comunicação RS-232.

\begin{tabular}{|c|c|c|c|}
\hline Pino & Patriot & Direção de envio dos dados & Computador \\
\hline $\mathbf{1}$ & Não Utilizado & & Não Utilizado \\
\hline $\mathbf{2}$ & RxD & - & TxD \\
\hline $\mathbf{3}$ & TxD & $\longrightarrow$ & RxD \\
\hline $\mathbf{4}$ & Não Utilizado & & Não Utilizado \\
\hline $\mathbf{5}$ & Aterramento & - & Aterramento \\
\hline $\mathbf{6}$ & Não Utilizado & & Não Utilizado \\
\hline $\mathbf{7}$ & Não Utilizado & & Não Utilizado \\
\hline $\mathbf{8}$ & Não Utilizado & & Não Utilizado \\
\hline $\mathbf{9}$ & Não Utilizado & & Não Utilizado \\
\hline
\end{tabular}


Para a configuração de chaveamento serial para o estabelecimento do protocolo de comunicação entre o console e o sistema desenvolvido neste trabalho, as seguintes configurações foram selecionadas da Tabela 5.4 e da Tabela 5.5.

- Velocidade de transmissão de 115200 bps.

- Sem paridade.

Tabela 5.4 - Chaveamento para seleção de velocidade de transferência.

\begin{tabular}{|c|c|c|c|}
\hline \multicolumn{4}{|c|}{ Chaveamento para taxa de Velocidade bps } \\
\hline Chave & 1 & 2 & 3 \\
Velocidade & & & \\
\hline 115200bps & $\downarrow$ & $\downarrow$ & $\downarrow$ \\
\hline 57600bps & $\downarrow$ & $\downarrow$ & $\uparrow$ \\
\hline 38400bps & $\downarrow$ & $\uparrow$ & $\downarrow$ \\
\hline 19200bps & $\downarrow$ & $\uparrow$ & $\uparrow$ \\
\hline 9600bps & $\uparrow$ & $\downarrow$ & $\downarrow$ \\
\hline 4800bps & $\uparrow$ & $\downarrow$ & $\uparrow$ \\
\hline 2400bps & $\uparrow$ & $\uparrow$ & $\downarrow$ \\
\hline Reservado & $\uparrow$ & $\uparrow$ & $\uparrow$ \\
\hline
\end{tabular}

Tabela 5.5 - Chaveamento para seleção da paridade.

\begin{tabular}{|c|c|c|}
\hline \multicolumn{2}{|c|}{ Chaveamento para Paridade } \\
\hline Chave & 4 & 5 \\
Paridade & & \\
\hline Nenhum & $\downarrow$ & $\downarrow$ \\
\hline Ímpar & $\downarrow$ & $\uparrow$ \\
\hline Par & $\uparrow$ & $\downarrow$ \\
\hline Reservado & $\uparrow$ & $\uparrow$ \\
\hline
\end{tabular}

\subsubsection{Fonte Magnética}

A fonte magnética é um dispositivo que produz um campo eletro-magnético e é a referência para a medida de posição e orientação do sensor. Deve ser montado em uma posição fixa numa superfície não metálica e também deve permanecer próximo ao sensor. A fonte magnética possui como padrão o tamanho de $5,08 \mathrm{~cm}^{3}$. 
Uma imagem da fonte magnética juntamente com seu cabo e conector pode ser visualizada na Figura 5.5 (a). Na Figura 5.5 (b) são mostradas as dimensões relativas da fonte magnética.
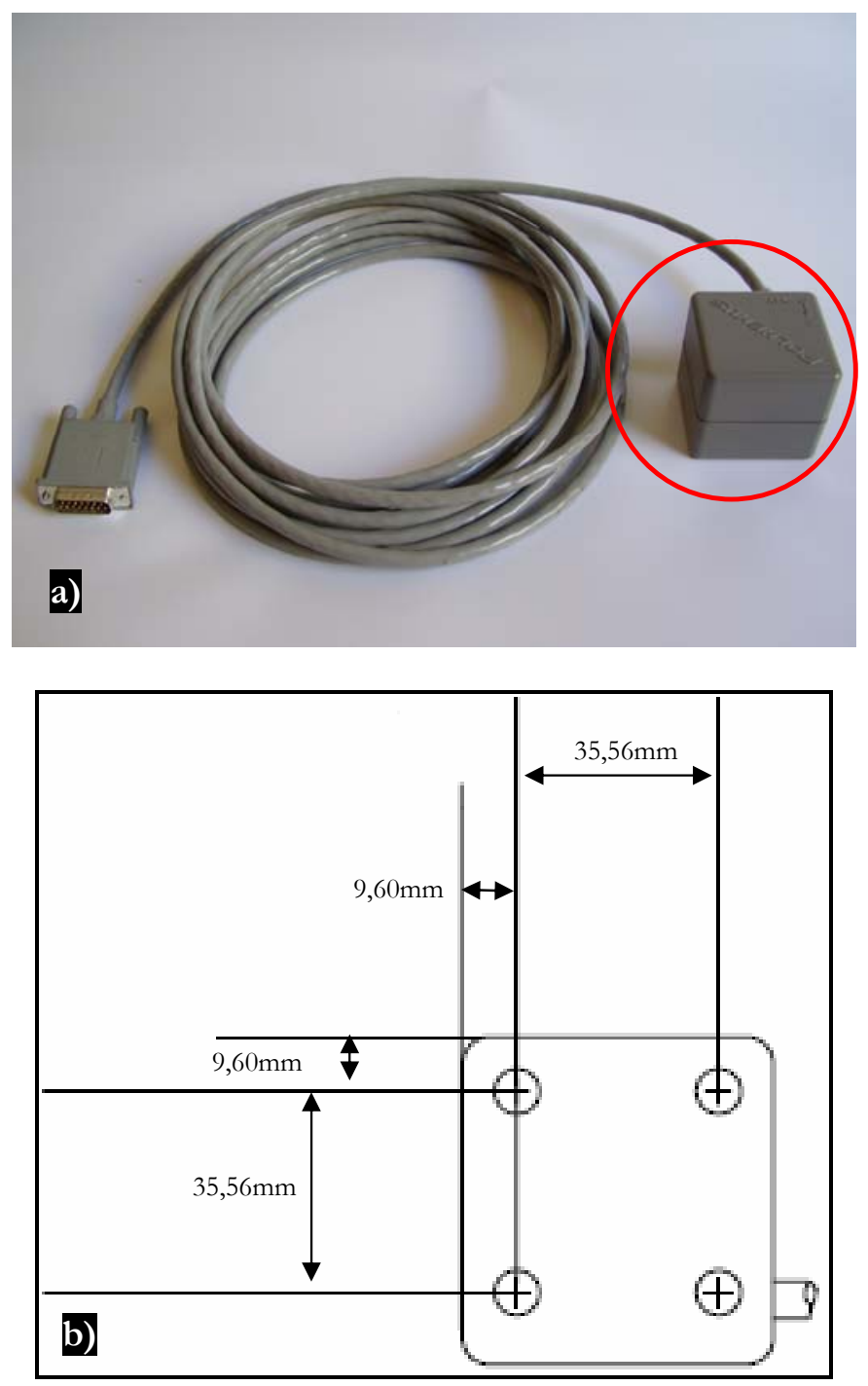

Figura 5.5 - a) Fonte magnética do equipamento Polhemus Patriot. b) Esquema das dimensões da Fonte magnética.

\subsubsection{Sensor}


O sensor magnético mostrado na Figura 5.6 é um pequeno dispositivo cuja posição e orientação são medidas através do respectivo deslocamento entre ele e a fonte magnética.

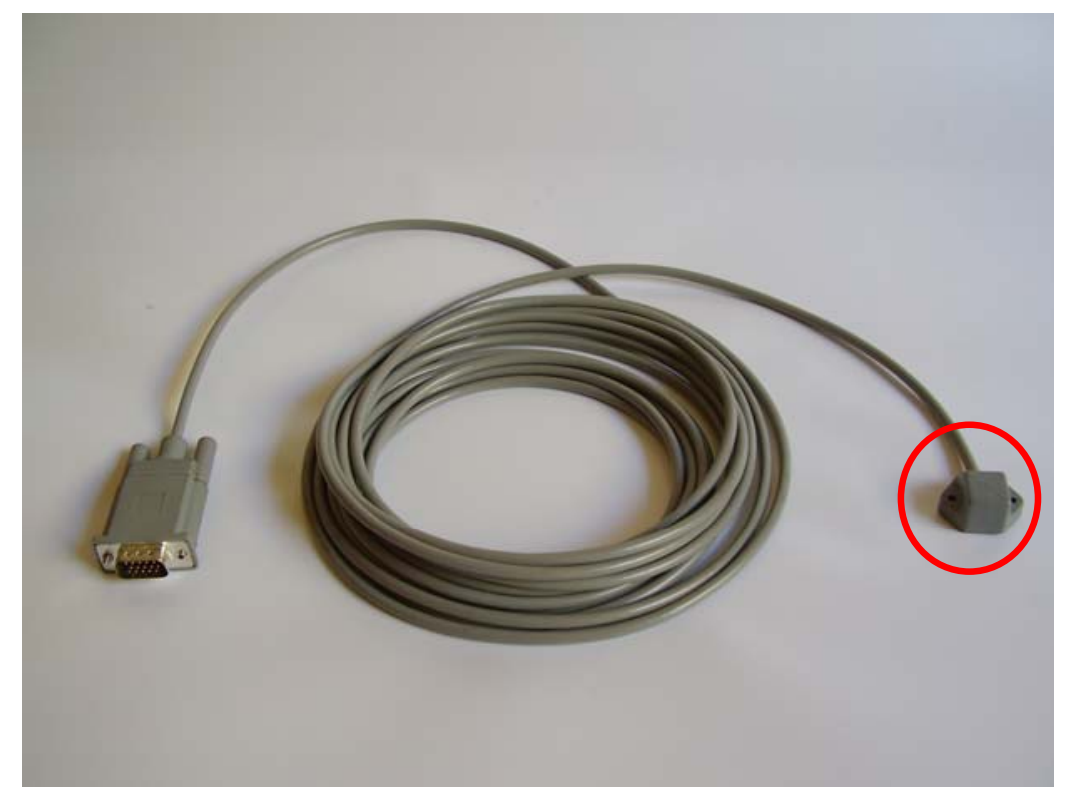

Figura 5.6 - Sensor magnético do equipamento Polhemus Patriot.

O alcance $\mathrm{X}, \mathrm{Y}$ e Z de funcionamento do sensor, maior que $152 \mathrm{~cm}$, tem como saída o valor 0 , ou seja, para o correto funcionamento da aquisição das coordenadas 3D, o sensor deve ficar a uma proximidade inferior á $152 \mathrm{~cm}$ da fonte magnética. Esse valor pode diminuir caso existam interfaces como paredes e aglomerados de madeira entre o sensor e a fonte magnética. Este equipamento possibilita a aquisição de coordenadas X, Y, Z, azimute, elevação e rolagem na ordem de $60 \mathrm{~Hz}$.

Na Figura 5.7 podem ser observadas no esquema apresentado as dimensões do sensor magnético. 


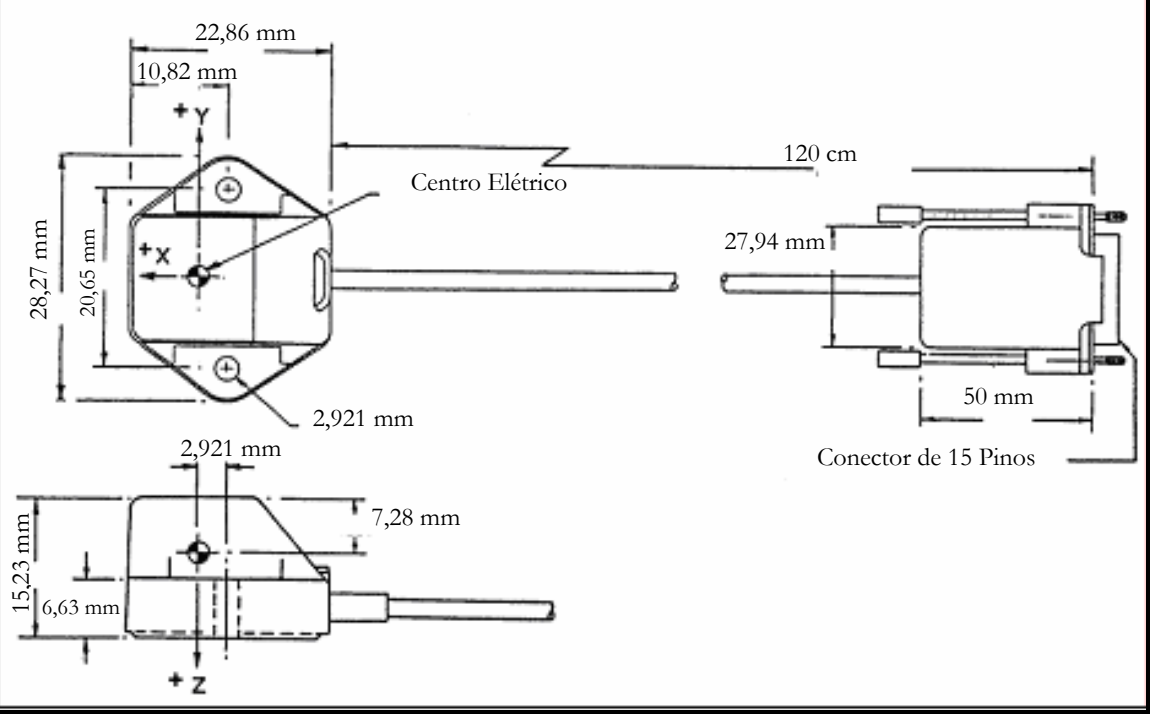

Figura 5.7 - Esquema mostrando as dimensões do sensor.

\subsection{Comunicação dos Dados do Sensor Patriot com o Computador}

A comunicação entre o computador e o sensor descrito na seção anterior pode ser realizada através de um conector serial de 15 pinos ou um conector USB. No presente sistema foi utilizado um adaptador serial/USB da marca LeaderShip. A ponta fêmea desse adaptador foi ligada no console do sensor e a ponta com o conector USB foi ligada no computador para a captura das coordenadas 3D durante os exames.

Foi necessário utilizar tal adaptador, pois o notebook utilizado nos testes não possuía entrada de comunicação serial. Neste caso, a comunicação direta através do conector USB do console não pôde ser utilizada, pois a biblioteca de comunicação via USB da Linguagem Java até o momento está disponibilizada apenas em sua versão beta.

\subsection{Esquema de Desenvolvimento do Sistema Proposto}


O esquema do presente sistema proposto foi desenvolvido tomando como base o modelo de DETMER et al. (1994) e KELLEY et al. (1994) como é mostrado na Figura 5.8. As imagens são adquiridas pelo operador do aparelho ultra-sonográfico no Modo-B, direcionando o transdutor do aparelho que está acoplado com o sensor magnético de coordenadas 3D, de modo que toda a imagem da estrutura de interesse do feto dentro do útero materno seja capturada.

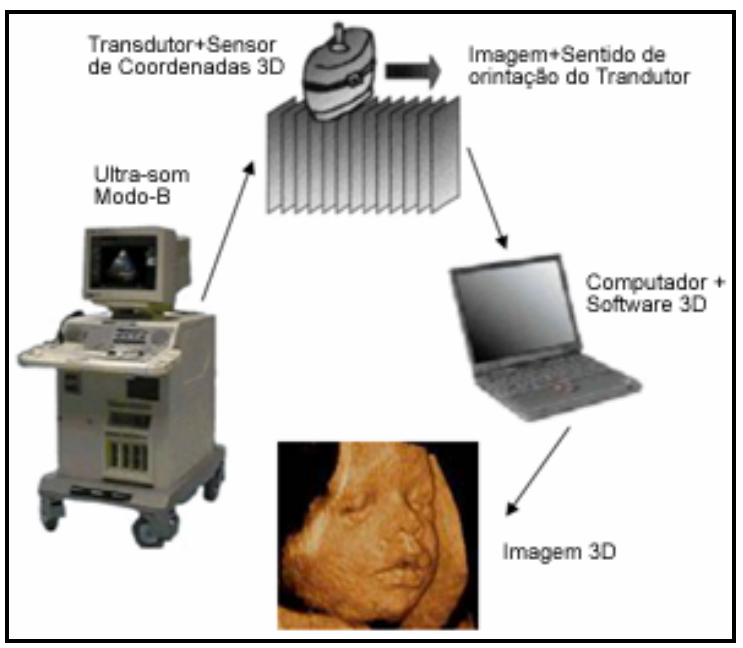

Figura 5.8 - Esquema de visualização 3D proposto por DETMER et al. (1994) e KELLEY et al. (1994).

A realização do processo de reconstrução tridimensional de imagens de aparelhos ultra-sonográficos é um processo dependente do operador. Por este motivo, quando se está adquirindo a imagem, qualquer desvio do transdutor sobre o corpo do paciente pode resultar em erros na reconstrução do volume da estrutura que está sendo analisada.

O problema do posicionamento do transdutor foi resolvido com a aquisição do dispositivo de orientação no espaço tridimensional relatado na seção anterior o dispositivo Patriot que é acoplado ao transdutor e transfere para o computador as coordenadas da direção do transdutor em cada imagem capturada. Assim, é possível reconstruir a imagem 
sem a inconveniência de se perder a aquisição de um volume devido à desorientação do transdutor, tendo que se recomeçar o processo do início. Desta forma, é possível proporcionar mais mobilidade ao operador sem a preocupação se o transdutor está na direção correta e os movimentos estão uniformes.

Na Figura 5.9 é apresentada uma imagem do acoplamento do sensor de coordenadas 3D do tipo por orientação magnética em um transdutor, cujo modelo é normalmente utilizado em sistemas de ultra-som freehand.

Um computador acoplado ao aparelho de ultra-som captura cada imagem do aparelho, através de uma placa de captura de vídeo, juntamente com a sua respectiva orientação no espaço tridimensional enviada pelo sensor de coordenadas 3D.

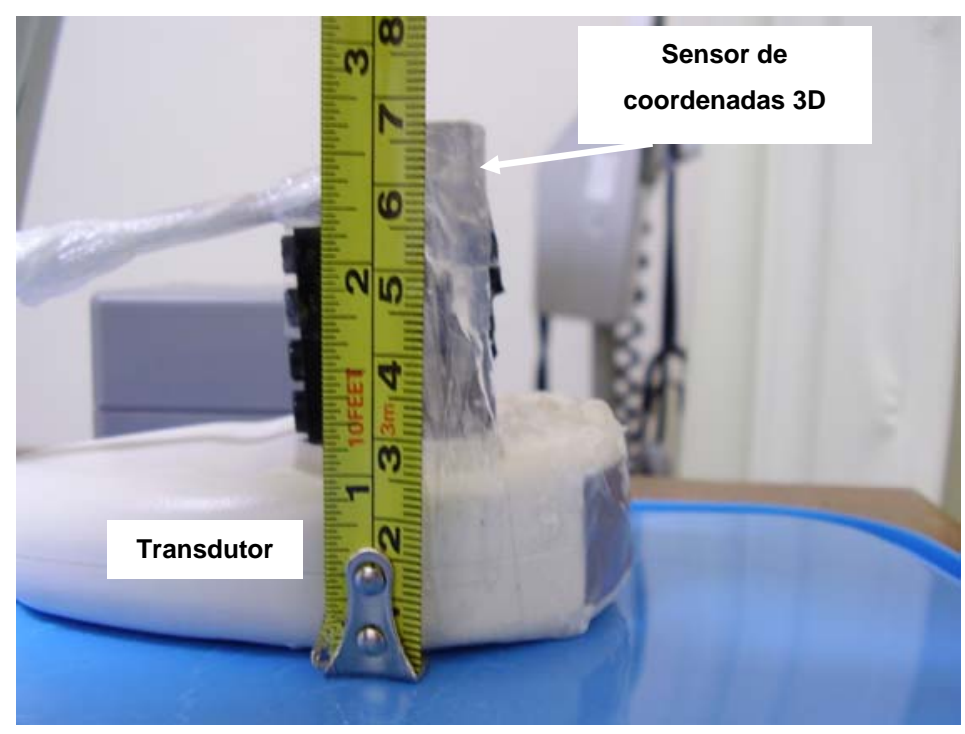

Figura 5.9 - Imagem indicando o posicionamento do sensor de coordenadas 3D em um transdutor de um equipamento de ultra-som.

\subsection{Phantoms de Ultra-Som}


O principal problema em se trabalhar com imagens in vivo no período de desenvolvimento do sistema é a dependência de pacientes voluntárias que aceitem participar da pesquisa.

Para o desenvolvimento deste trabalho primeiramente foram utilizados phantoms. Um phantom comercial de ultra-som, que é utilizado para simulação da morfologia externa do feto, pode ser visualizado na Figura 5.10. A simulação das estruturas fetais é importante, pois, desta forma, não é necessário depender da pronta disponibilidade de pacientes voluntárias para adquirir a seqüência de imagens in vivo do feto.

Como descrito em RICKEY et al. (1995), foram utilizados materiais que possuem índices de atenuação de som próximos dos tecidos humanos. Utilizou-se água para a simulação do líquido amniótico do útero materno nos phantoms reais de ultra-som empregados neste trabalho.
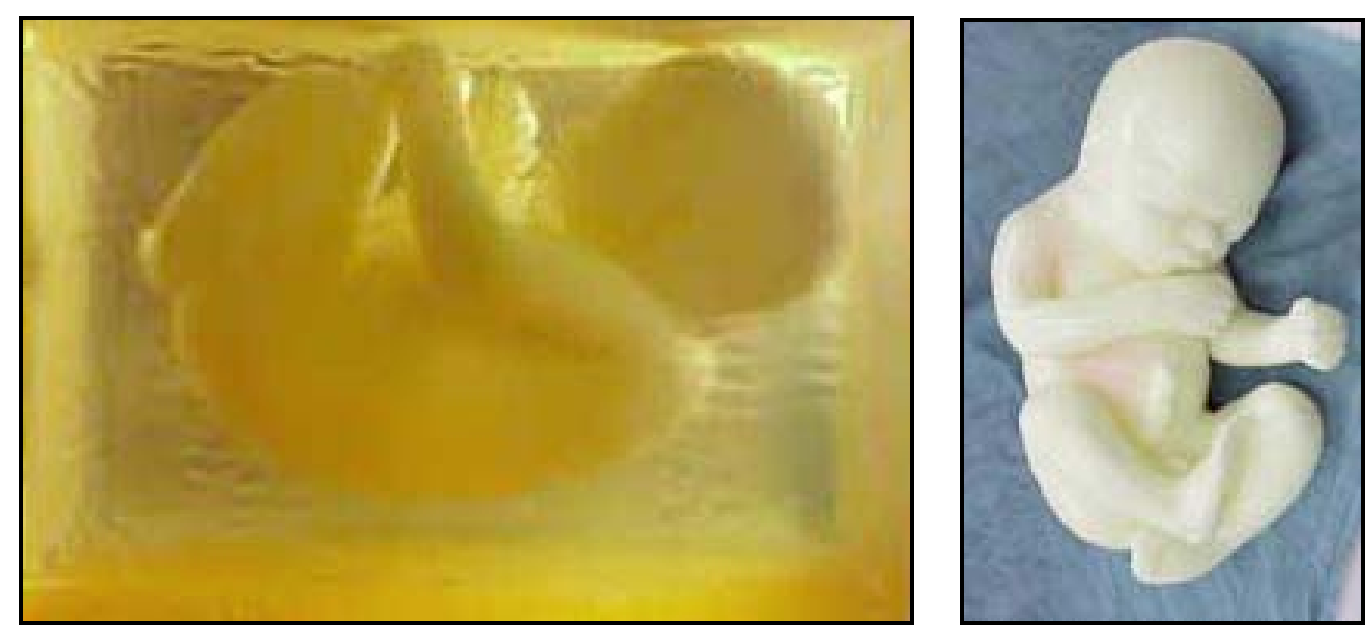

Figura 5.10 - Phantom fetal Modelo CIRS 065-36.

A estrutura morfológica fetal foi simulada, inicialmente utilizando-se uma boneca de brinquedo feita com um polímero de plástico que apresentou um bom índice de atenuação das ondas de ultra-som (Figura 5.11(a)). Apenas para efeito comparativo de testes 
morfológicos de reconstrução 3D, também foram utilizados um preservativo cheio de água (Figura 5.11(b)) e uma luva cirúrgica de borracha cheia de água (Figura 5.11(c)).

Os três phantoms mencionados anteriormente são feitos com material sintético. Para aproximar a simulação da realidade dos tecidos encontrados no corpo humano, foram utilizados também como phantoms uma mini-salsicha de carne de porco (Figura 5.11(d)), uma salsicha de carne de porco (Figura 5.11(e)), uma lingüiça de carne de porco (Figura 5.11(f)), uma asa de frango (Figura 5.11(g)) e uma coxa de frango (Figura 5.11(h)).

É importante que os materiais escolhidos tenham índices de propagação e atenuação da onda de ultra-som parecidos ao do corpo humano, pois, quanto mais semelhantes aos índices das estruturas do útero materno e do feto, os resultados com os testes serão mais próximos da realidade na aquisição das imagens in vivo em um exame clínico.

Para a aquisição de imagens de phantoms em aparelhos de ultra-som, primeiramente é necessário inserir esses objetos de estudo em um pote que irá simular o ambiente natural do feto, que é dentro do útero materno. Três potes foram utilizados para os testes de aquisição. O líquido amniótico é simulado enchendo completamente os potes com água. 

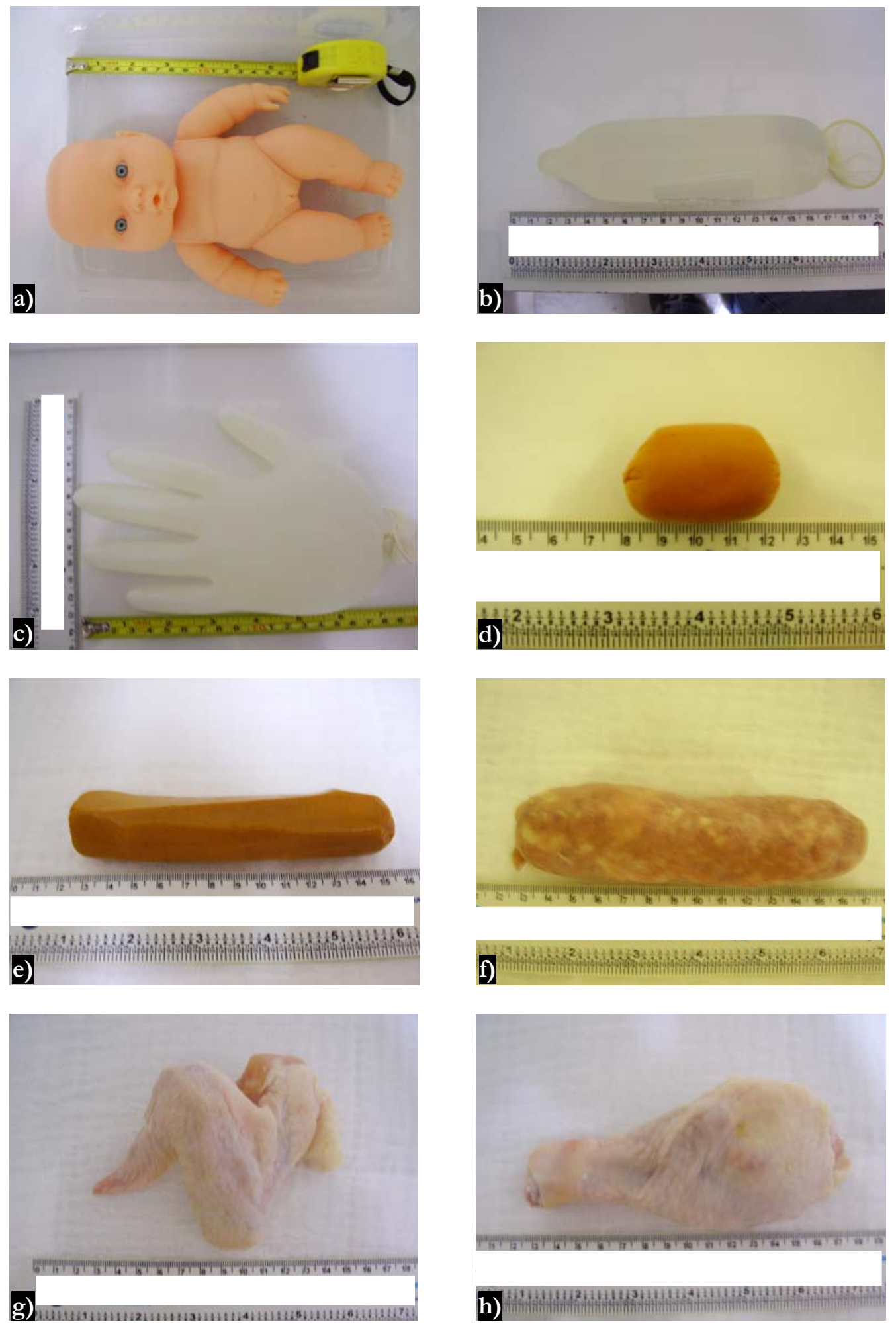

Figura 5.11 - Phantoms utilizados para os testes de reconstrução tridimensional deste sistema: a)

Boneca de Brinquedo; b) Preservativo com água; c) Luva com água; d) Mini-salsicha; e) Salsicha; f)

Lingüiça de porco; g) Asa de frango; h) Coxa de frango. 
A Tabela 5.6 mostra o tamanho em relação ao Comprimento, Largura, Altura e Espessura dos potes utilizados. Todos os potes são de plástico e foram sujeitos aos testes para captura das imagens com o aparelho de ultra-som. A Figura 5.12, mostra uma imagem do aparelho ATL modelo HDI 3500 presente no Hospital das Clínicas de Ribeirão Preto, e utilizado nos testes de captura de imagens de ultra-som neste trabalho. Esse tipo de equipamento não possui recursos de reconstrução 3D de imagens.

Tabela 5.6 - Medidas dos potes utilizados nos testes com phantoms.

\begin{tabular}{|c|l|c|c|c|c|}
\hline \multicolumn{1}{|l|}{ Pote } & Marca/Modelo & Comprimento & Largura & Altura & Espessura \\
\hline A & Sonoco $/ 04$ & $17,5 \mathrm{~cm}$ & $13,0 \mathrm{~cm}$ & $11 \mathrm{~cm}$ & $1,0 \mathrm{~mm}$ \\
B & Plasvale $/ 292$ & $24,0 \mathrm{~cm}$ & $15,3 \mathrm{~cm}$ & $18 \mathrm{~cm}$ & $1,5 \mathrm{~mm}$ \\
C & Plasútil $/ 778$ & $27,0 \mathrm{~cm}$ & $19,8 \mathrm{~cm}$ & $15 \mathrm{~cm}$ & $2,0 \mathrm{~mm}$ \\
\hline
\end{tabular}

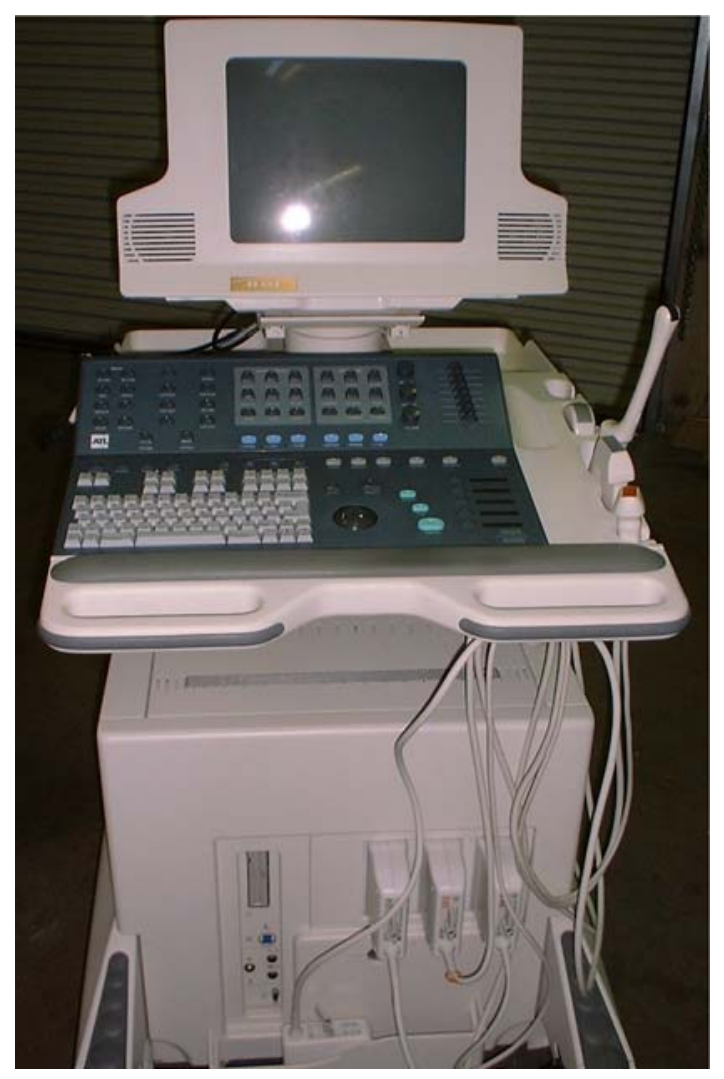

Figura 5.12 - Aparelho de ultra-som, ATL HDI 3500 utilizado nos testes deste sistema. 
O pote escolhido para a realização dos testes de captura das imagens de phantoms foi o Pote C, pelo fato de não apresentar reverberação do sinal da imagem. Esse tipo de interferência acontece por causa da variação de velocidade de propagação do som que pode ocorrer devido o fato do fundo dos Potes A e B serem chatos enquanto o Pote C possui as extremidades das paredes até o fundo mais alisadas. Outro fato que torna o Pote do tipo C mais eficaz em relação aos outros dois é que sua espessura da parede e do fundo são mais grossas.

A Figura 5.13 mostra a diferença entre a qualidade das imagens capturadas dentro dos 3 Potes. Todas as imagens são do phantom de lingüiça de porco mostradas na Figura 5.11(f). É possível de se observar a qualidade superior do Pote $C$ onde a imagem é mais nítida e não apresenta a reverberação que ocorre na Figura 5.13(a) e na Figura 5.13(b).
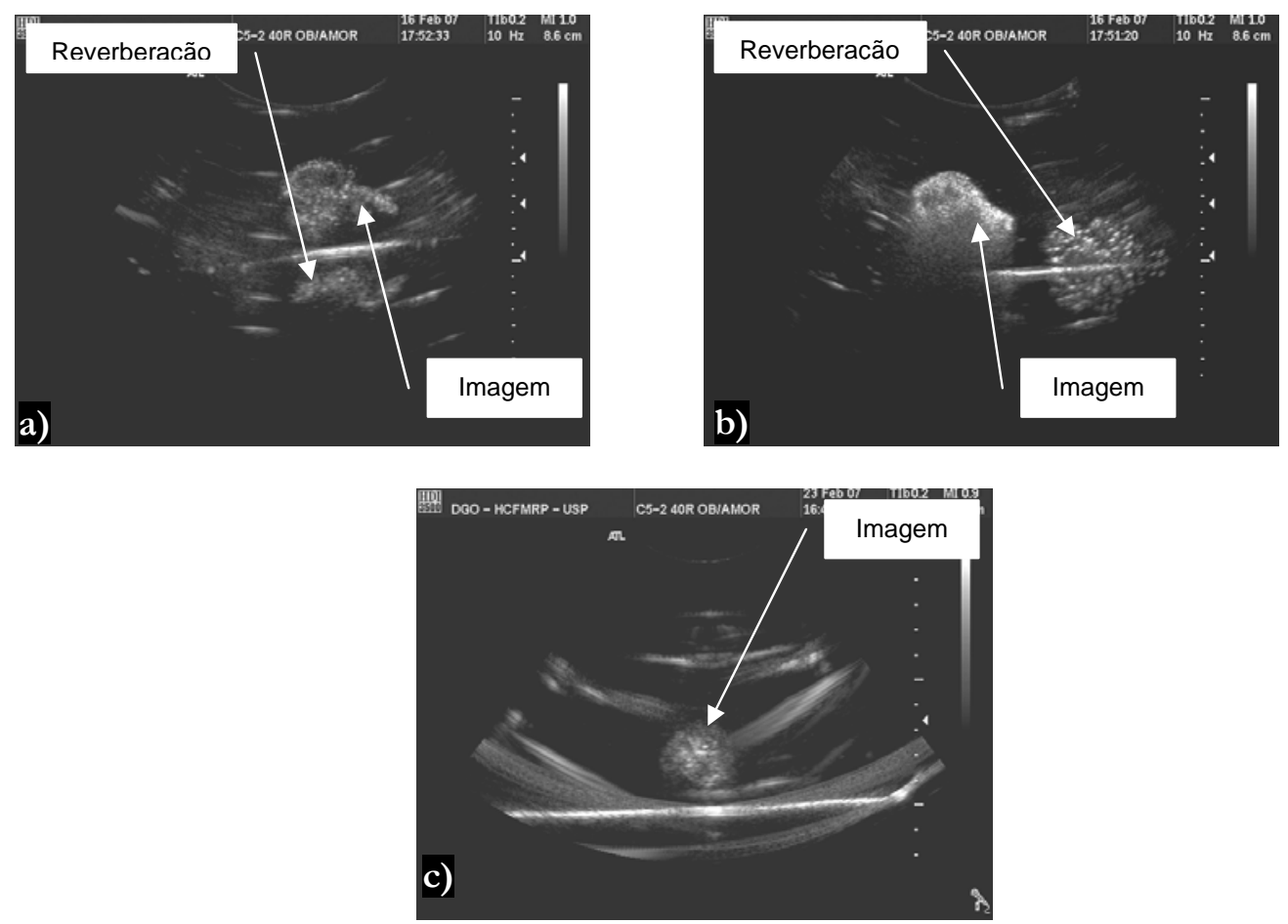

Figura 5.13 - Imagem capturada da lingüiça de porco capturada no equipamento de ultra-som dentro dos diferentes Potes: a) Pote A; b) Pote B; c) Pote C. 


\subsection{Captura de Imagens Ultra-sônicas de Fetos}

Também foram capturadas imagens de fetos in vivo dentro do útero materno em pacientes com vários períodos de gestação. Tais imagens foram adquiridas no equipamento de ultra-som ATL HDI 3500, presente no Hospital das Clínicas de Ribeirão Preto, no Departamento de Ginecologia e Obstetrícia.

As imagens têm como característica resolução espacial de 640x480 pixels que é a resolução máxima oferecida pelo aparelho de ultra-som. Uma fatia de um volume adquirido pode ser visualizado na Figura 5.14. O tamanho da imagem para reconstrução foi fixado em 256x256 pixels ou 512x512 pixels. Esse tamanho irá depender do tamanho da estrutura que será selecionada pelo operador do aparelho de ultra-som. O número de aquisições de imagens pode variar de um volume para outro por causa do tamanho do feto, da estrutura analisada ou do tempo de aquisição da seqüência de imagens, sendo que, em média foram capturadas em torno de 150 imagens por volume.

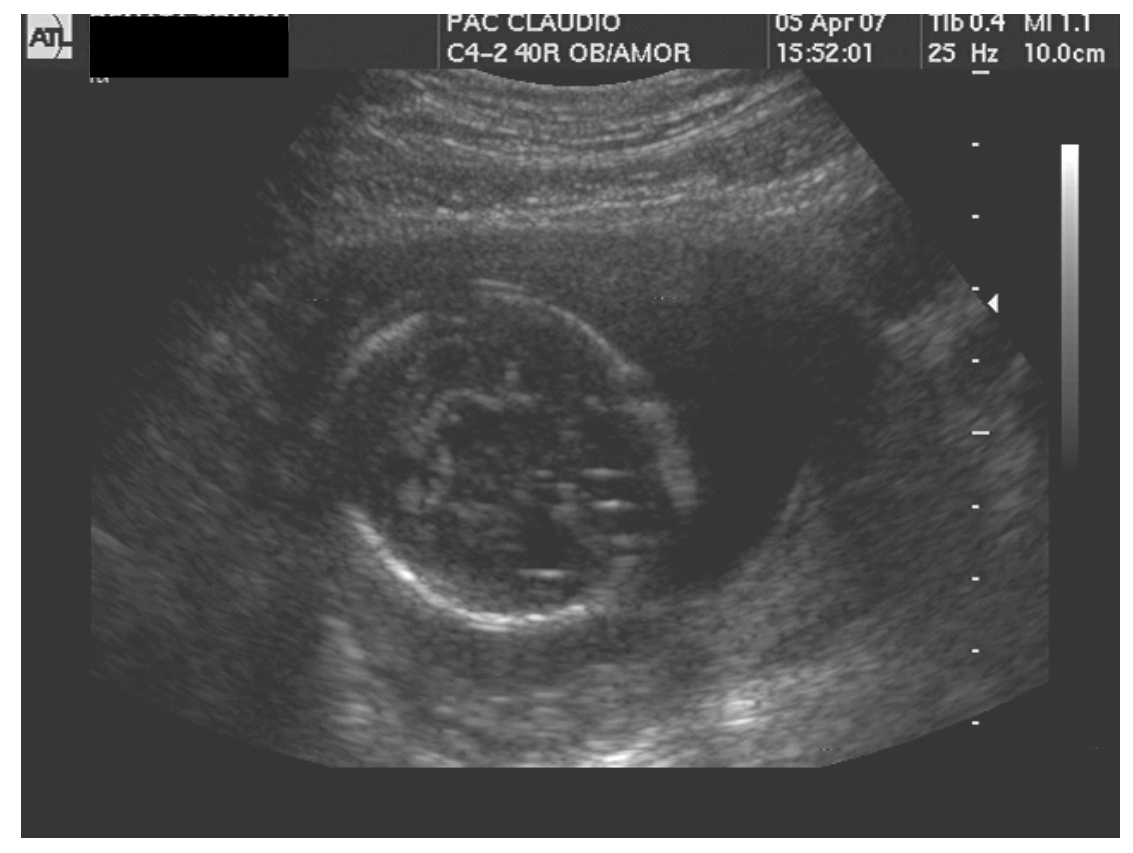

Figura 5.14 - Imagem de um feto de 18 semanas de uma fatia de uma seqüência de volume capturado. 
A resolução de contraste de cada imagem é de 8bits (256 tonalidades monocromáticas). Através de testes realizados no Hospital das Clínicas de Ribeirão Preto, no Departamento de Ginecologia e Obstetrícia, o tempo necessário para o operador do aparelho de ultra-som adquirir toda a seqüência de imagens no Modo-B de um feto de 18 semanas foi de aproximadamente 4s.

\subsection{Sistema USOTri}

O software desenvolvido neste trabalho para captura das imagens e reconstrução das imagens em 3D foi construído em linguagem de programação Java (HORSTMANN (2001)). Essa linguagem foi escolhida para a implementação devido a sua capacidade de ser executada em qualquer sistema operacional, não restringir o usuário a uma determinada arquitetura de hardware e a gratuidade da aplicação.

Para a elaboração deste trabalho foi desenvolvido um sistema para reconstrução 3D a partir de imagens 2D de ultra-som ao qual foi atribuído o nome de USOTri (Ultra-Som Obstétrico Tridimensional).

Na Figura 5.15 são apresentados os módulos pertencentes ao sistema USOTri. Todos os módulos funcionam dentro do sistema de forma integrada. 


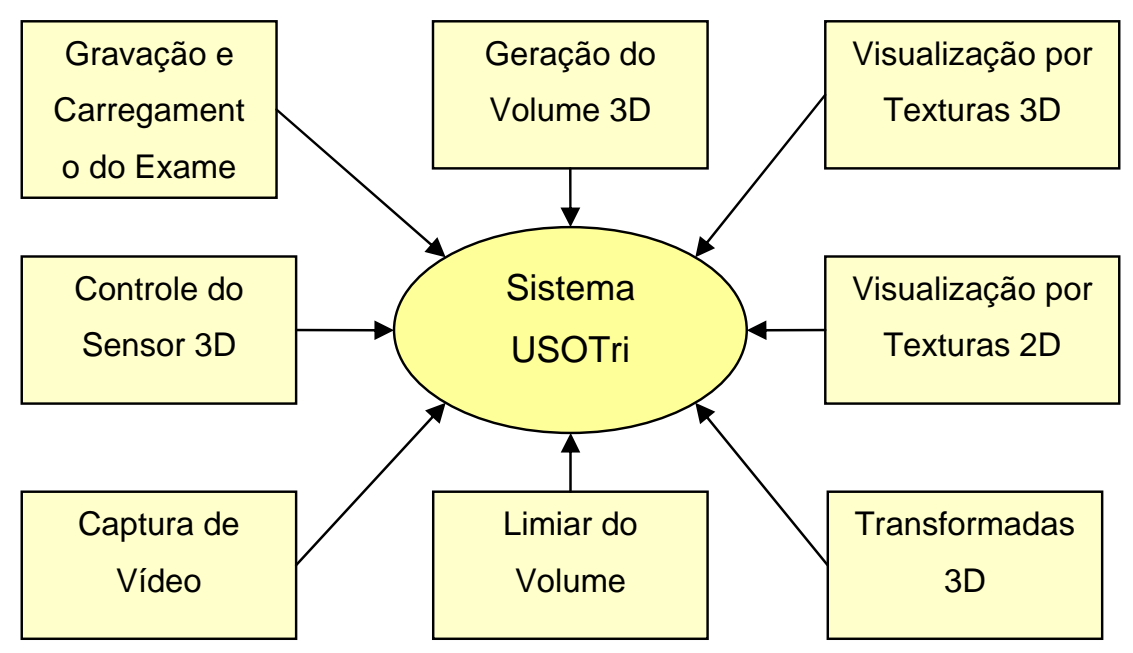

Figura 5.15 - Diagrama de módulos do sistema.

Os recursos de programação orientada a objetos foram utilizados para que cada módulo funcione como um objeto dentro do programa, tornando o código fonte do sistema muito mais compreensível e adaptado ao modelo moderno de desenvolvimento de software.

Cada objeto desenvolvido neste sistema foi construído tomando as devidas precauções para que ele possa ser reutilizado caso seja criado mais algum módulo que necessite das funcionalidades de algum objeto já existente. Isso evita a redundância dentro do código de programação e torna o código fonte do sistema mais enxuto e compreensível. Estas características também são úteis no caso mais algum módulo vir a fazer parte deste sistema futuramente.

\subsubsection{Diagrama de Fluxo de Funcionamento do Sistema USOTri}

O algoritmo de funcionamento deste sistema pode ser observado através do diagrama de fluxo da Figura 5.16 que tem início com a aquisição das imagens do ultra-som. 
O sistema USOTri possui suporte interno à captura e armazena as imagens de ultra-som através de uma placa de vídeo captura conectada com a saída de vídeo do aparelho de ultrasom. As seqüências de imagens são capturadas de acordo com a angulação e posicionamento do sensor de coordenadas 3D.

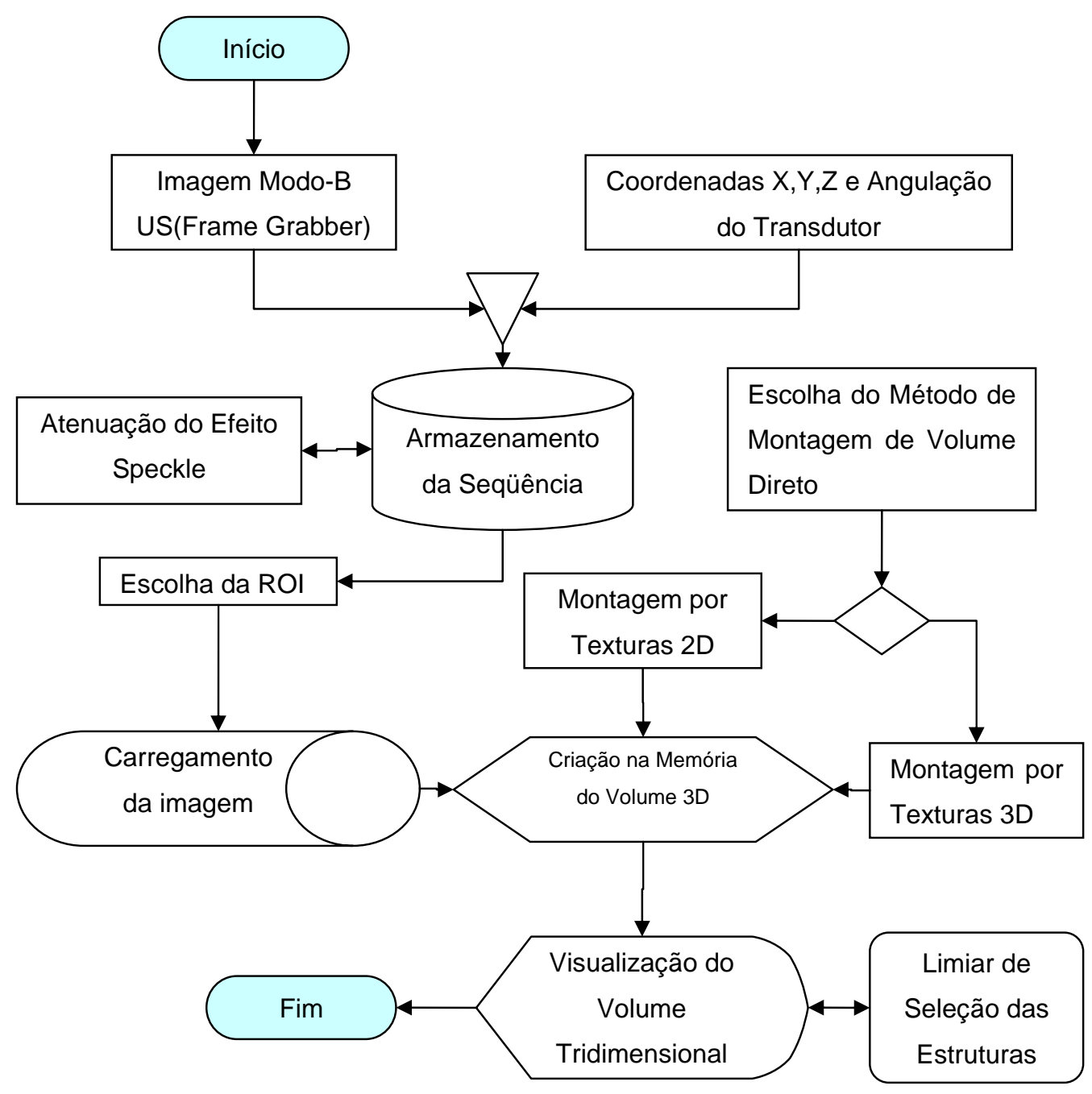

Figura 5.16 - Fluxograma do esquema de funcionamento do algoritmo para reconstrução de imagens de ultra-som.

O modelo e marca do equipamento utilizado para a captura de vídeo é a placa externa PixelView PlayTV USB 2.0. Ela possui como especificação técnica a captura de até 
30 imagens por segundo. O conector do tipo S-Video da placa deve ser ligado ao conector S-Video da saída do aparelho de ultra-som para que o sistema possa receber as imagens. O sistema recebe as imagens através do conector USB que é ligado a alguma porta USB disponível no computador.

O módulo de Captura de Vídeo presente no sistema USOTri foi desenvolvido utilizando o acesso a vídeo-captura diretamente pela programação em Java através da versão 2.1.1e da biblioteca JMF (Java Media Framework). Essa bilblioteca é uma API (Application Program Interface) que permite a manipulação de áudio, vídeo e outras mídias em aplicações Java como applications e applets. Com ela é possível capturar de áudio e vídeo e codificá-lo em diversos formatos como também a transmissão das mídias pelo padrão RTP (Real time Transport Protocol) para o desenvolvimento de aplicações que utilizem vídeo sob demanda (TERRAZAS et al. (2002)).

Essa biblioteca proporciona o controle de acesso à captura de vídeo diretamente pelo próprio sistema USOTri que controla todas as funcionalidades da placa de vídeo-captura.

No equipamento "Polhemus Patriot", existe um driver que possibilita todo o controle entre a aplicação desejada e a obtenção das coordenadas 3D através do hardware. Porém, este driver não pôde ser utilizado neste trabalho, pois ele foi desenvolvido para trabalhar apenas com aplicações desenvolvidas em linguagem de programação C e não em linguagem de programação Java, como o presente projeto. O fabricante não disponibiliza um driver para ser utilizado em linguagem Java e além disso não foi encontrada na literatura correlata qualquer menção sobre um driver desenvolvido para o seu controle utilizando essa linguagem.

Neste caso, o módulo de controle do hardware do sensor Patriot teve que ser desenvolvido aqui, sendo o primeiro e único até o momento que consegue interagir com sistemas desenvolvidos em Java. Toda a interface de controle do hardware do equipamento "Polhemus Patriot" necessitou programada em Java para que o sistema USOTri pudesse obter as coordenadas 3D diretamente do dispositivo sensor de posicionamento empregado. 
Para a criação dessa interface foi necessário utilizar algumas bibliotecas de controle de comunicação serial para a linguagem Java chamada de "Java Comm" (Java Communications) (PRESTON (2006)). A obtenção das coordenadas 3D ocorre quando um caractere ' $\mathrm{C}$ ' é enviado por meio da porta serial do computador conectada ao sensor Patriot. Após o recebimento deste caractere, o console do Patriot começa a enviar as informações das coordenadas $\mathrm{x}, \mathrm{y}, \mathrm{z}$, azimute, elevação e rolagem de volta para a porta serial do computador em formato binário a uma taxa de $60 \mathrm{~Hz}$. Esse formato binário é constituído por uma seqüência de 36 bytes, dos quais os 12 primeiros correspondem às informações da Tabela 5.7:

Tabela 5.7 - Cabeçalho da seqüência dos 12 primeiros bytes enviados pelo equipamento Patriot.

\begin{tabular}{|c|c|c|}
\hline Bytes & Indicador & Descrição \\
\hline 2 & Frame'Tag & $\begin{array}{l}\text { Indica a contagem de cada bloco de informações enviadas para } \\
\text { o computador. }\end{array}$ \\
\hline 2 & StationNumber & Indica qual sensor está enviando às coordenadas. \\
\hline 2 & $\begin{array}{l}\text { Initiating } \\
\text { Command }\end{array}$ & Comando de Inicialização. \\
\hline 2 & Error Indicator & Indica o código de algum erro reportado pelo console. \\
\hline 2 & Reserved & Informações reservadas que acaso possam ser enviadas. \\
\hline 2 & ResponseSize & $\begin{array}{l}\text { Indica quantos bytes serão enviados relativos às coordenadas } \\
\text { 3D. Esse número é } 24 \text { caso as configurações de fábrica do } \\
\text { equipamento não sejam alteradas. }\end{array}$ \\
\hline
\end{tabular}

Os próximos 24 bytes mostrados na Tabela 5.8 correspondem às informações relativas às coordenadas $3 \mathrm{D}$ de posicionamento do sensor em relação à fonte magnética. Cada seqüência de 4 bytes da Tabela 5.8 corresponde a uma numeração simples em ponto flutuante, definidos pela IEEE 754, que correspondem ao tipo primitivo de armazenamento de dados do tipo Float pertencente na Linguagem Java.

Tabela 5.8 - Seqüência de bytes relativos às coordenadas 3D do equipamento Patriot.

\begin{tabular}{|c|c|}
\hline Bytes & Descrição \\
\hline 4 & $\mathrm{X}$ \\
\hline 4 & $\mathrm{Y}$ \\
\hline 4 & $\mathrm{Z}$ \\
\hline 4 & Azimute \\
\hline 4 & Elevação \\
\hline 4 & Rolagem \\
\hline
\end{tabular}


Antes de efetuar a captura das imagens o usuário determina qual será a distância (em centímetros) das fatias e a angulação para que o sistema detecte se ocorreu uma movimentação do sensor e automaticamente capture a imagem.

Para que este sistema funcione, é necessário que o sensor de coordenadas 3D fique acoplado corretamente no transdutor de ultra-som. A Figura 5.17(a) mostra o acoplamento correto do sensor. Neste exemplo o sensor está afastado do transdutor cerca de $3 \mathrm{~cm}$ por meio da utilização de um bloco de plástico desta mesma medida. Este distanciamento é necessário, pois, pelo fato do sensor funcionar por campo magnético, peças de metal dentro do transdutor podem gerar distorções no momento da aquisição das coordenadas.

Na Figura 5.17(b) é mostrado o acoplamento errado, em que o sensor fica acoplado muito próximo do transdutor, o que faz com que haja distorções no momento de captura das coordenadas 3D por causa de peças de metal presentes no transdutor.
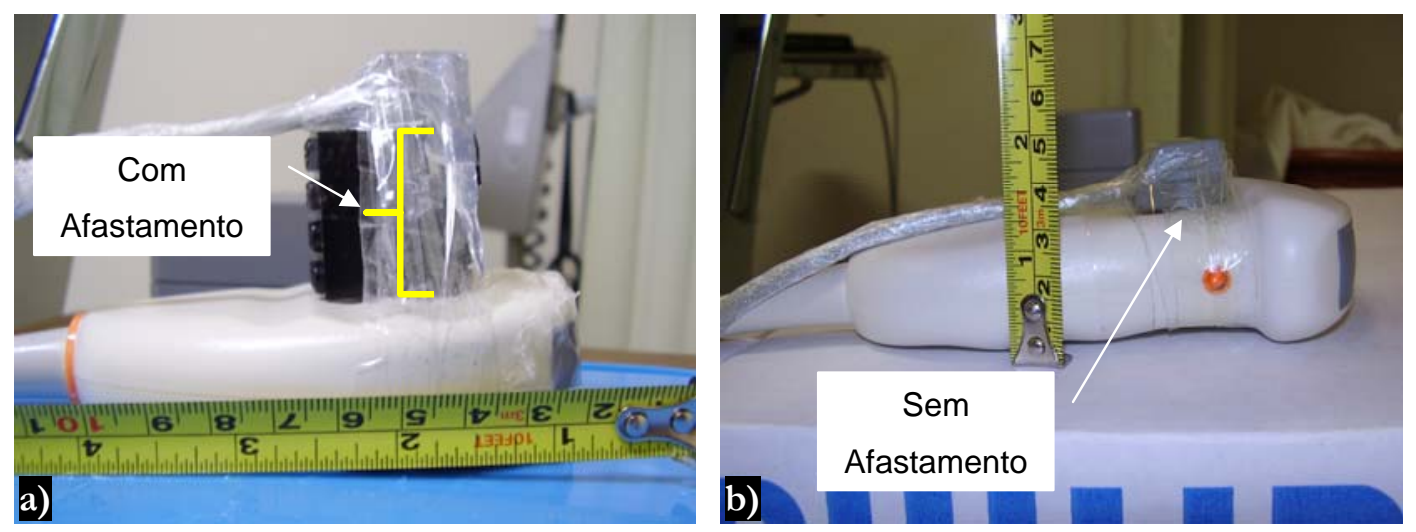

Figura 5.17 - Acoplamento do sensor no transdutor para a realização dos testes deste trabalho: a) Modo correto; b) Modo errado.

Para efeito de comprovação do comentário acima, a Figura 5.18 mostra a diferença de captura de um volume com o sensor afastado e com o sensor próximo do transdutor. Na Figura 5.18(a) o volume foi capturado corretamente pois o sensor estava afastado $3 \mathrm{~cm}$ do transdutor. A Figura 5.18(b) mostra uma distorção na captura da movimentação do 
transdutor, indicando um desvio que, na verdade, não ocorreu, pois o movimento do transdutor havia sido feito em linha reta.

Toda vez que o transdutor é movimentado acoplado ao sensor 3D é possível verificar seu posicionamento $\mathrm{x}, \mathrm{y}, \mathrm{z}$ juntamente com seu ângulo de inclinação no espaço tridimensional.
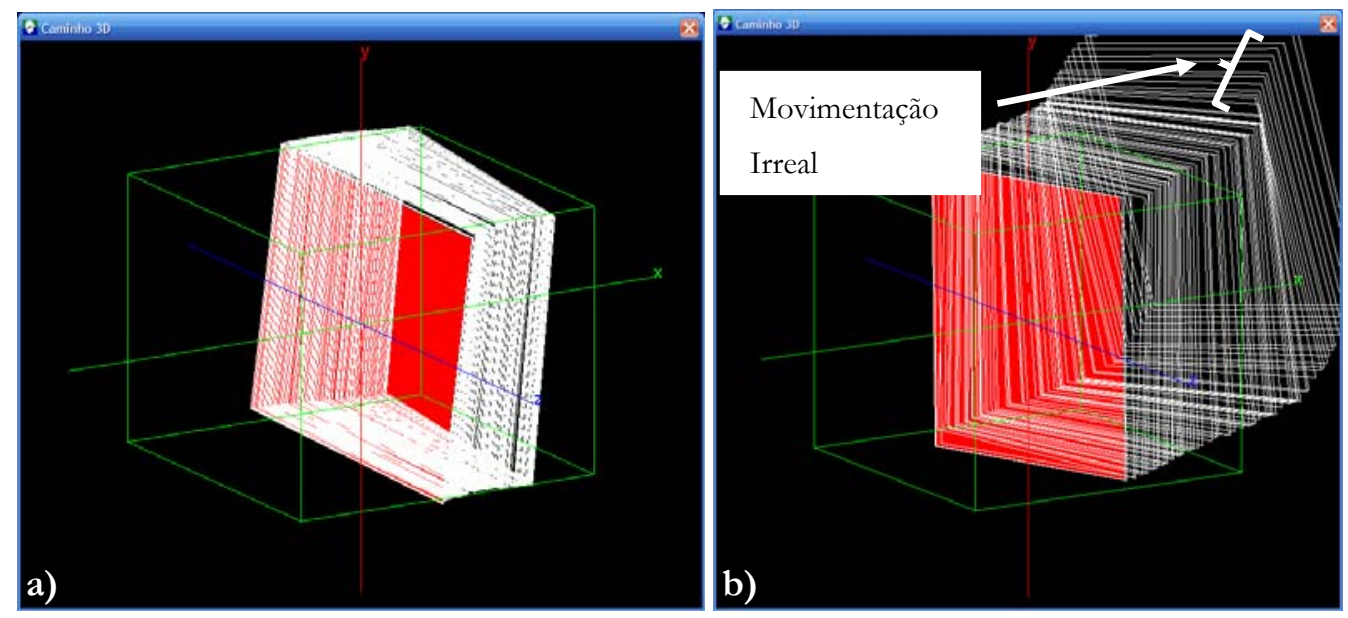

Figura 5.18 - Imagens mostrando a trajetória percorrida para capturar um volume tridimensional.

Os quadrados brancos representam a detecção do movimento do transdutor e representam a imagem capturada: a) Volume capturado com o sensor afastado do transdutor $3 \mathrm{~cm}$; b) Volume capturado com o sensor próximo do transdutor, caracterizando um desvio de trajetória na movimentação do transdutor que, na verdade, não ocorreu.

Toda vez que é detectada uma mudança na angulação ou no posicionamento do sensor Patriot, maior que um limiar definido pelo usuário, para a distância entre as fatias do volume, a imagem é capturada pela placa de vídeo-captura e é armazenada em formato de arquivo de imagem RAW. Na memória do computador ficam armazenados o relacionamento do número da seqüência da imagem RAW, seu posicionamento x,y,z e a angulação capturados pela porta serial.

O armazenamento de imagens no formato de arquivo RAW se caracteriza por não apresentar uma padronização da estrutura interna de armazenamento definida por órgãos 
de controle de padronização. Por esse motivo o formato de gravação dos dados binários é definido de acordo com a implementação de cada programador. Neste trabalho a estrutura interna do arquivo RAW é mostrada da Figura 5.19.

\begin{tabular}{|c|c|c|c|}
\hline Número de Colunas & Número de Linhas da & $\begin{array}{c}\text { Quantidade de } \\
\text { imagens presentes }\end{array}$ & $\begin{array}{c}\text { Bytes reservados } \\
\text { para a seqüência de } \\
\text { da Imagem (2 bytes). }\end{array}$ \\
Imagem (2 bytes) & no arquivo (2 bytes). & imagens. \\
\hline
\end{tabular}

Figura 5.19 - Estrutura interna do arquivo RAW utilizada neste trabalho.

O cabeçalho deste arquivo é composto por 6 bytes e é divido em 3 seqüências, cada uma contendo 2 bytes de informação, que são armazenadas no formato Big-Endian (byte mais significativo é o da esquerda). Nos primeiros 2 bytes é armazenado o número de colunas presentes nas imagens de Ultra-som. Os 2 próximos bytes especificam a quantidade de linhas da imagem. A próxima seqüência de 2 bytes especifica o número de imagens capturadas para o volume. Na seqüência seguinte, os bytes representados referemse aos valores de cada pixel presente em cada imagem.

A quantidade de bytes necessários para armazenar toda a imagem capturada varia de acordo com o número de colunas, linhas e número de fatias capturadas. O valor da quantidade de bytes para o armazenamento pode ser obtido pelo cálculo:

$$
\text { Quantidade_de_Bytes }=\text { Colunas } \times \text { Linhas } \times \text { Fatias }
$$

onde Colunas representa o número de colunas das imagens capturadas, Linhas é a quantidade de linhas presentes nas imagens e Quantidade é o número de imagens capturadas que serão armazenadas. A multiplicação destes 3 itens resulta na quantidade de bytes necessários para armazenar a seqüência de imagens no formato RAW. 
Antes do início do processo de visualização tridimensional, deve ser feito um préprocessamento para a diminuição do efeito speckle nas imagens (DANTAS et al. (2002)). O efeito speckle é caracterizado pela existência de um padrão granuloso que diminui consideravelmente o contraste e o formato de uma estrutura em uma imagem. A Figura 5.20 ilustra a diferença entre uma imagem original capturada utilizando o Modo-B e o resultado do processamento dessa imagem utilizando a técnica de filtro Gaussiano 3x3 pixels como uma técnica de redução do efeito speckle (HUANG et al. (2005)).
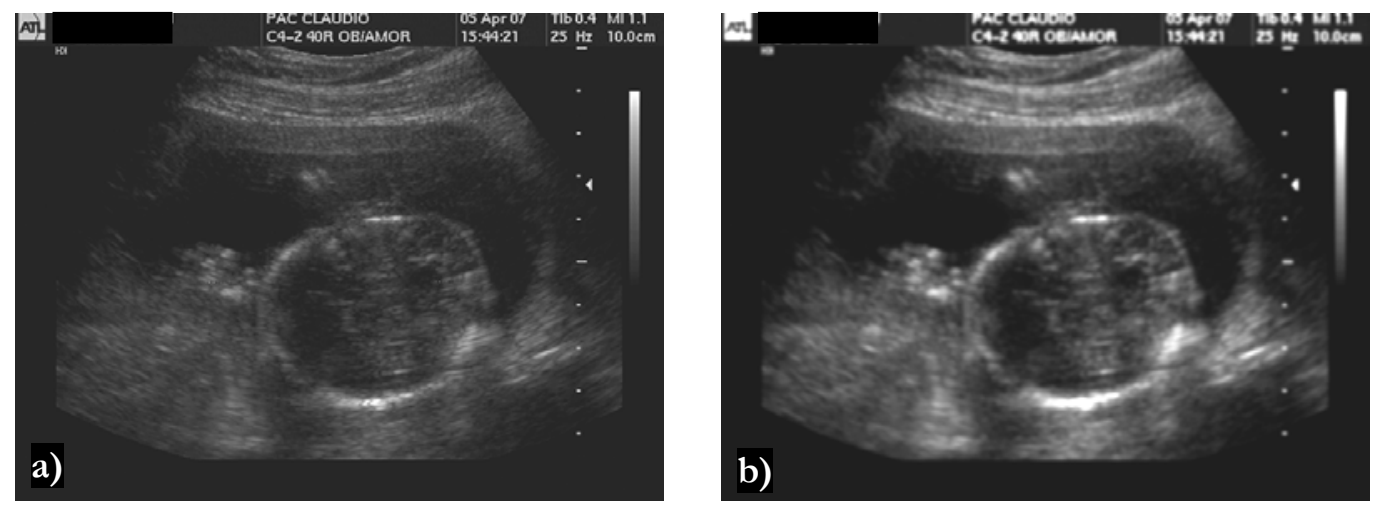

Figura 5.20 - a) Imagem original capturada utilizando o Modo-B; b) Aplicação da técnica de redução do efeito speckle na imagem original utilizando o método do filtro Gaussiano implementando neste trabalho.

Após o armazenamento das imagens, o filtro Gaussiano com tamanho de pixel de 3x3 é aplicado para a redução do efeito speckle.

Ao final da captura de imagens é necessário informar alguns parâmetros ao sistema para que o mesmo possa reconstruir o conjunto de imagens em um volume tridimensional (Figura 5.21). Em geral é necessária a inserção de 4 parâmetros para que a imagem possa ser reconstruída. 


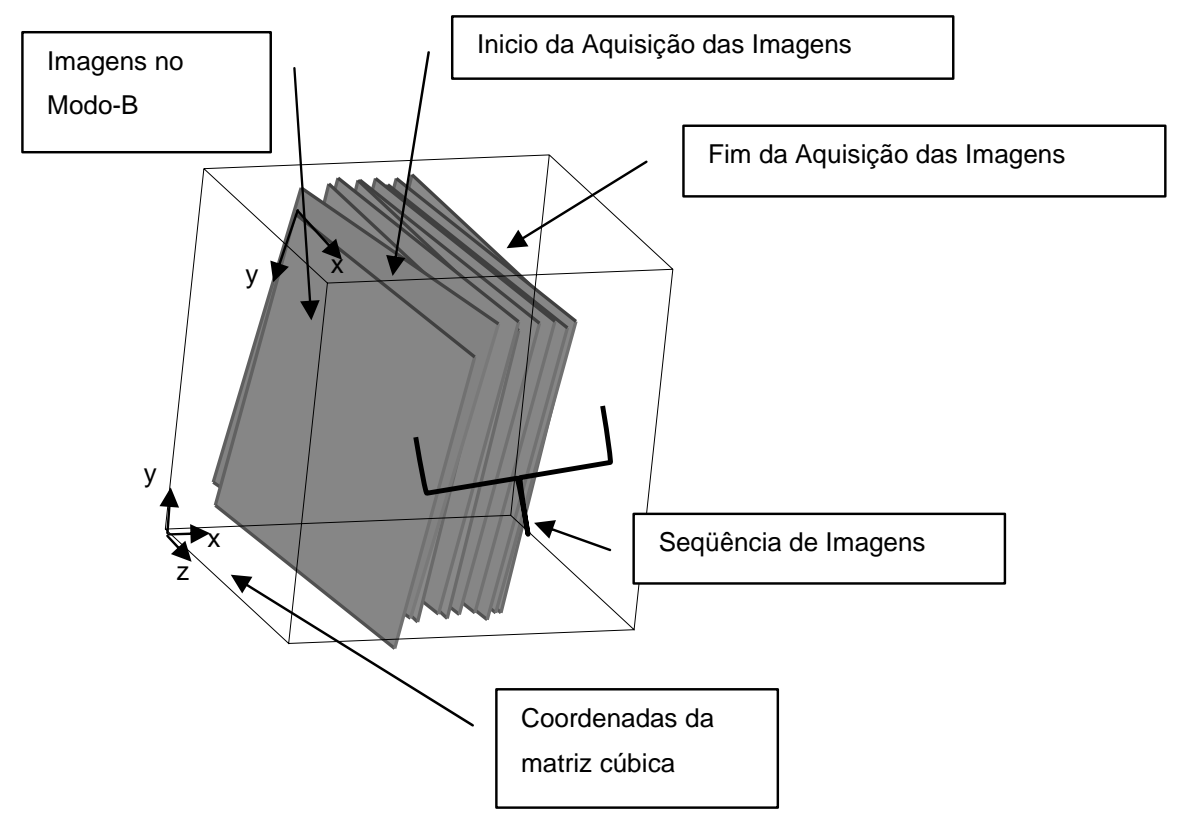

Figura 5.21 - Modelo de posicionamento das imagens dentro do cubo da matriz de pixels.

O primeiro parâmetro, mostrado na Figura 5.22(a), é a indicação do ponto de orientação da imagem. Esse ponto é uma marcação que é feita no topo superior central, utilizando o mouse. Esse ponto constitui a origem das ondas de ultra-som que geram as imagens no Modo-B. Essa marcação é necessária, pois todos os cálculos da matriz de transformação 3D são realizados tomando esse ponto como parâmetro.

O segundo parâmetro (Figura 5.22(b)) é a seleção da Região de Interesse (RI), a qual é selecionada para que somente essa parte da imagem seja reconstruída tridimensionalmente. A seleção dessa região é um ponto importante e define o que será reconstruído tridimensionalmente na tela. 


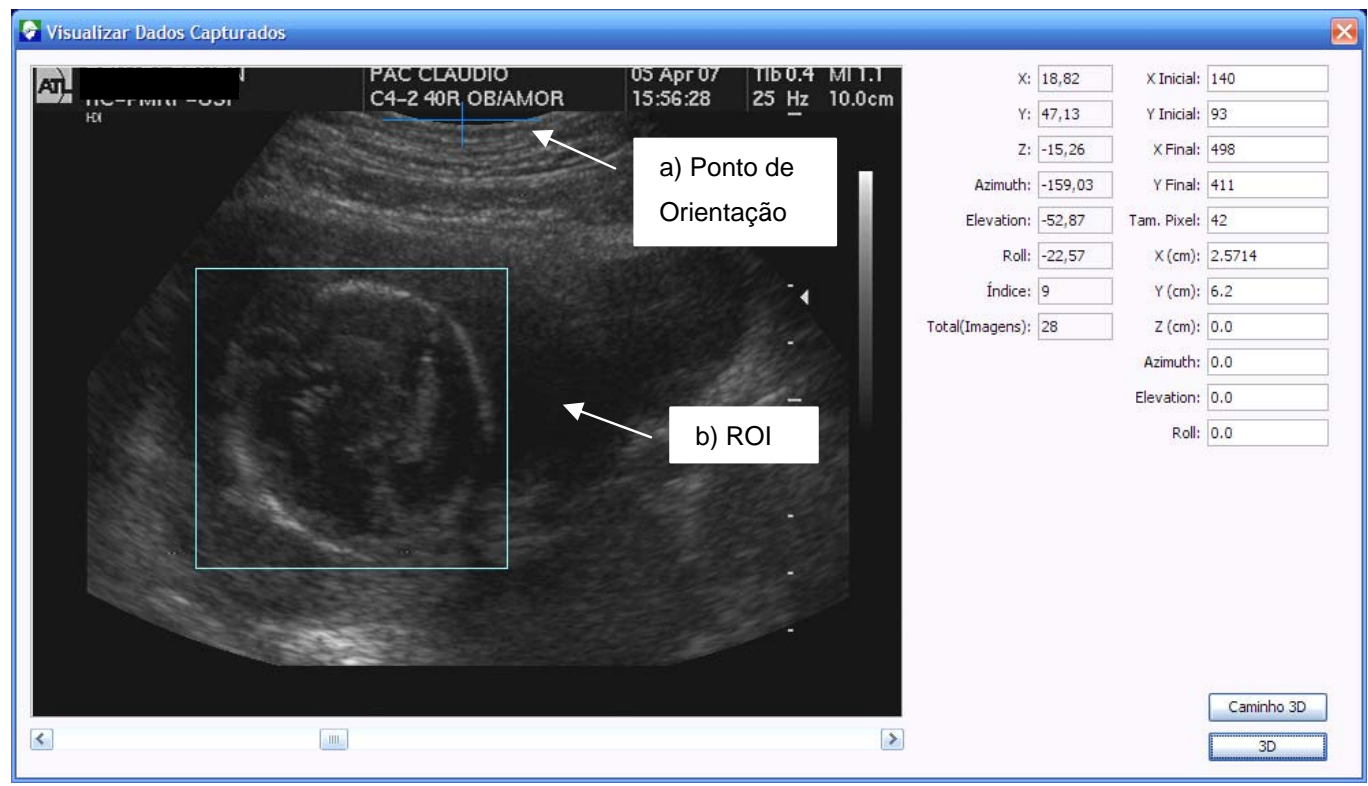

Figura 5.22 - Imagem mostrando a seleção da RI e do ponto de orientação do início da imagem.

O terceiro parâmetro indica a relação entre $1 \mathrm{~cm}$ e os pixels na imagem. A entrada desse valor é importante, pois as coordenadas 3D são capturadas tomando como base os movimentos do transdutor no mundo real, em centímetros. Para a reconstrução 3D, esses valores devem estar em número de pixels. A Figura 5.23 mostra a seleção que deve ser realizada com o mouse, marcando o intervalo de $1 \mathrm{~cm}$ da grade de medição que geralmente fica na parte direita em alguns aparelhos de ultra-som. 


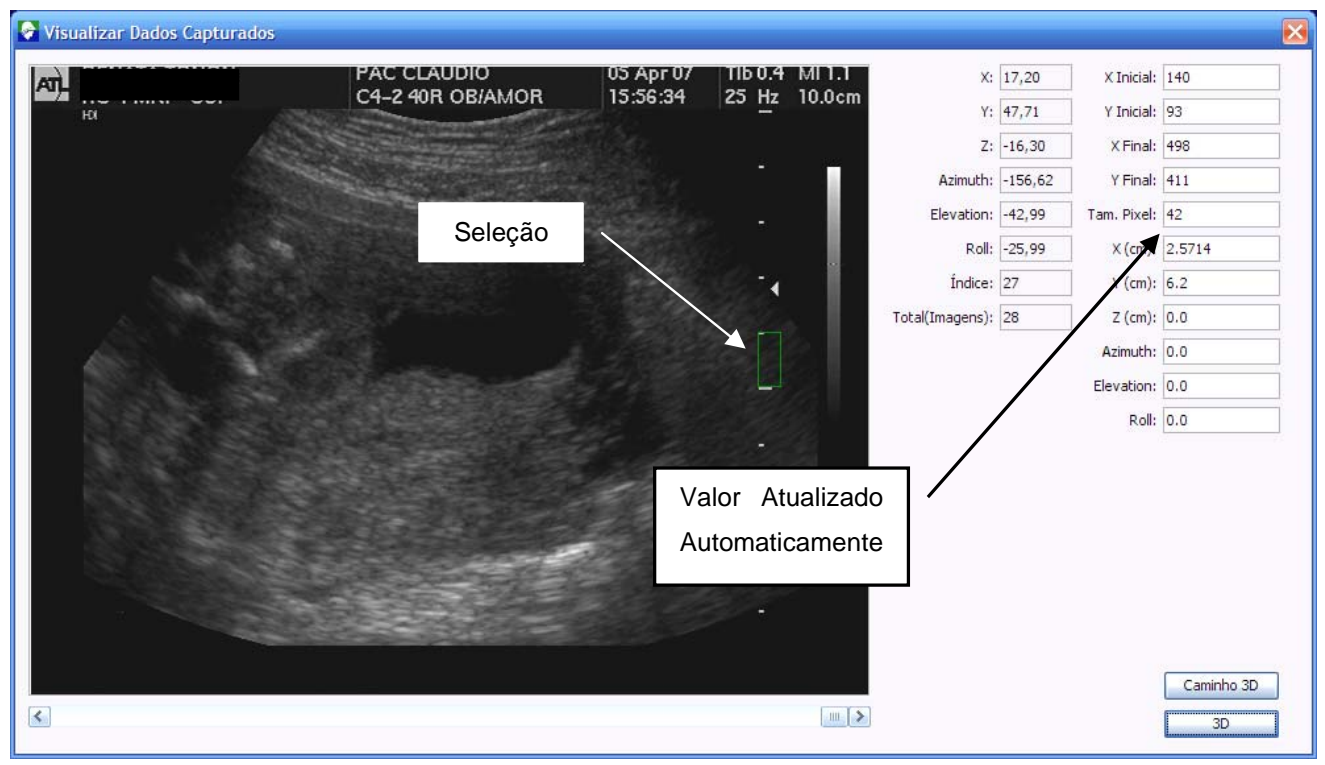

Figura 5.23 - Imagem contendo a seleção feita pelo usuário na grade da imagem utilizando um

mouse.

Como no aparelho de ultra-som, as imagens podem ser aproximadas ou afastadas utilizando o efeito zoom, e o computador onde é feita a reconstrução de imagens não reconhece automaticamente quando esse procedimento ocorre, por estar apenas recebendo as imagens através da entrada de vídeo. É necessário converter todas as coordenadas capturadas de centímetros para pixels. Essa conversão é realizada multiplicando o valor de 1 centímetro em pixels nas coordenadas 3D das imagens capturadas.

O quarto e último parâmetro indica a posição do deslocamento do sensor em relação ao transdutor. Toda a aquisição das coordenadas 3D é referência da posição relativa do sensor no espaço do mundo real, variando x, y e z em centímetros. O sensor é posicionado a uma distância de aproximadamente $3 \mathrm{~cm}$ do transdutor para que os componentes de metal do transdutor não interfiram no campo magnético entre o sensor e a fonte magnética. Por este motivo, como a posição de tomada das imagens é diferente em termos métricos do transdutor, considerado, na técnica de obtenção de imagens em Modo-B, como o ponto de orientação, mostrado anteriormente na Figura 5.22(a). 
Nesta parametrização, o usuário indica o afastamento de fixação onde o sensor está posicionado no transdutor (do centro do sensor em direção à ponta do transdutor onde são emitidas as ondas de ultra-som). Deve-se inserir no sistema os valores $\mathrm{x}, \mathrm{y}$ e $\mathrm{z}$ em centímetros e os valores do azimute, elevação e rolagem em graus.

Para a etapa inicial da reconstrução 3D, cada pixel pertencente à região selecionada da RI da imagem capturada no Modo-B precisa ser transformado dentro do volume tridimensional para sua respectiva posição dentro de uma matriz tridimensional criada na memória do computador. Como a posição entre o sensor e a fonte magnética não é fixa, é possível mover o transdutor por um quadrante de até $90 \mathrm{~cm}^{3}$, tomando como base a origem da fonte magnética.

Não é viável computacionalmente a criação de uma matriz cúbica que detenha toda a extensão da zona de funcionamento do sensor até a fonte, pois seria necessária a criação de uma matriz cúbica de $90 \mathrm{~cm}$; tomando-se como base que $1 \mathrm{~cm}$ equivale (dependendo do zoom da imagem adquirida no Modo-B pelo aparelho de ultra-som) a cerca de 28pixels, essa matriz teria o tamanho de 16.003.008.000 Bytes.

Para não ocorrer essa demanda excessiva de memória da construção da matriz tridimensional, é necessária a verificação do tamanho necessário para o armazenamento do volume. Isso é realizado vasculhando todas as coordenadas das imagens obtidas durante aquisição do volume 3D.

Primeiramente uma conversão é realizada multiplicando o tamanho do centímetro em pixels para cada posição X, Y e Z de cada coordenada capturada. Desta maneira os pontos das coordenadas em centímetros são convertidos em pixels.

A realização do ajuste do tamanho do volume é feito armazenado as menores coordenadas x, y e z para cada plano do volume. Também são armazenados as maiores coordenadas x, y e z para cada plano do cubo do volume. Neste esse cálculo, é vasculhada cada coordenada 3D da primeira até a última imagem capturada. Em cada RI é feita a 
transformação 3D da equação (5.2) conforme mostra a matriz de transformação utilizada para verificação dos pontos extremos da RI da imagem nas coordenadas x, y e z:

$$
\begin{aligned}
& {\left[\begin{array}{l}
x^{\prime} \\
y^{\prime} \\
z^{\prime} \\
1
\end{array}\right]=\left[\begin{array}{llll}
0 & 0 & 0 & t_{x} \\
0 & 0 & 0 & t_{y} \\
0 & 0 & 0 & t_{z} \\
0 & 0 & 0 & 1
\end{array}\right] \cdot\left[\begin{array}{cccc}
\cos \psi & 0 & \sin \psi & 0 \\
0 & 1 & 0 & 0 \\
-\sin \psi & 0 & \cos \psi & 0 \\
0 & 0 & 0 & 1
\end{array}\right] \cdot\left[\begin{array}{cccc}
\cos \theta & -\sin \theta & 0 & 0 \\
\sin \theta & \cos \theta & 0 & 0 \\
0 & 0 & 1 & 0 \\
0 & 0 & 0 & 1
\end{array}\right] .} \\
& \cdot\left[\begin{array}{cccc}
1 & 0 & 0 & 0 \\
0 & \cos \phi & -\sin \phi & 0 \\
0 & \sin \phi & \operatorname{con} \phi & 0 \\
0 & 0 & 0 & 1
\end{array}\right] \cdot\left[\begin{array}{cccc}
0 & 0 & 0 & -t_{x} \\
0 & 0 & 0 & -t_{y} \\
0 & 0 & 0 & -t_{z} \\
0 & 0 & 0 & 1
\end{array}\right] \cdot\left[\begin{array}{c}
x \\
y \\
z \\
1
\end{array}\right]
\end{aligned}
$$

onde, $x, y$ e z são os pontos extremos relativos de cada RI das imagens capturadas que serão submetidas à matriz de transformação. A seqüência de transformações realizadas é uma translação para a origem, uma rotação no eixo x, seguida de outra rotação no eixo z, outra rotação no eixo y, finalizando a translação do ponto para a origem.

Para os quatro pontos extremos na imagem, ou seja, para os pontos $\mathrm{x}_{\mathrm{i}}$, $\mathrm{y}_{\mathrm{i}}$, onde $i$ assume os valores da coluna inicial ou coluna final para $\mathrm{x}$, e os valores da linha inicial ou linha final para y, considerando cada RI selecionada.

Subtraindo a diferença entre o maior e o menor ponto x, y e $z$, tem-se de forma simples qual o tamanho mínimo necessário para o armazenamento da RI em uma matriz cúbica conforme a equação (5.3).

$$
\begin{aligned}
s m X & =\operatorname{Max} X-\operatorname{Min} X \\
s m Y & =\operatorname{Max} Y-\operatorname{Min} Y \\
s m Z & =\operatorname{Max} Z-M i n Z
\end{aligned}
$$


onde $s m X, s m Y$ e $s m Z$ representam o tamanho necessário para se criar uma matriz cúbica para o armazenamento da transformação 3D de cada ponto da RI.

Para cada ponto capturado nas coordenadas 3D é feita a compensação por causa do afastamento do sensor em relação ao ponto médio de captura marcado na imagem de acordo com a matriz de transformação da equação (5.3); o que leva á:

$$
\begin{aligned}
& {\left[\begin{array}{l}
x^{\prime} \\
y^{\prime} \\
z^{\prime} \\
1
\end{array}\right]=\left[\begin{array}{llll}
0 & 0 & 0 & t_{x} \\
0 & 0 & 0 & t_{y} \\
0 & 0 & 0 & t_{z} \\
0 & 0 & 0 & 1
\end{array}\right] \cdot\left[\begin{array}{cccc}
\cos \psi & 0 & \sin \psi & 0 \\
0 & 1 & 0 & 0 \\
-\sin \psi & 0 & \cos \psi & 0 \\
0 & 0 & 0 & 1
\end{array}\right] \cdot\left[\begin{array}{cccc}
\cos \theta & -\sin \theta & 0 & 0 \\
\sin \theta & \cos \theta & 0 & 0 \\
0 & 0 & 1 & 0 \\
0 & 0 & 0 & 1
\end{array}\right] \cdot} \\
& \cdot\left[\begin{array}{cccc}
1 & 0 & 0 & 0 \\
0 & \cos \phi & -\sin \phi & 0 \\
0 & \sin \phi & \operatorname{con} \phi & 0 \\
0 & 0 & 0 & 1
\end{array}\right] \cdot\left[\begin{array}{cccc}
0 & 0 & 0 & -t_{x} \\
0 & 0 & 0 & -t_{y} \\
0 & 0 & 0 & -t_{z} \\
0 & 0 & 0 & 1
\end{array}\right] \cdot\left[\begin{array}{cccc}
0 & 0 & 0 & -s m X \\
0 & 0 & 0 & -s m Y \\
0 & 0 & 0 & -s m Z \\
0 & 0 & 0 & 1
\end{array}\right] \cdot\left[\begin{array}{c}
x \\
y \\
z \\
1
\end{array}\right]
\end{aligned}
$$

Com este último procedimento mostrado na matriz de transformação utilizada para o posicionamento da imagem no volume da equação (5.4), os pontos são ajustados em uma matriz com o menor tamanho possível para o acondicionamento do volume de imagens das RI selecionadas.

Desta maneira, a quantidade de memória necessária para o armazenamento, ajustando o tamanho da matriz de acordo com a quantidade de imagens geralmente não passa de 16.000.000 Bytes, tomando como base a seleção de uma RI de 256x256 pixels e com 256 imagens capturadas. Ao final do processo de ajuste as imagens são armazenadas no formato RAW.

A partir do ajuste realizado para gravação, o usuário pode selecionar a região de interesse desejada por meio da interface mostrada na Figura 5.24. A seleção foi implementada de forma semelhante àquela que ocorre nos sistemas de ultra-som 3D comerciais disponíveis atualmente. A seleção da RI permite que seja determinada uma seqüência de determinados valores de voxels que ficarão presentes no volume. Este tipo de 
recurso permite que determinados tipos de estruturas, que geralmente possuem valores de voxels semelhantes, fiquem presentes ou sejam excluídos do volume, melhorando a visualização.

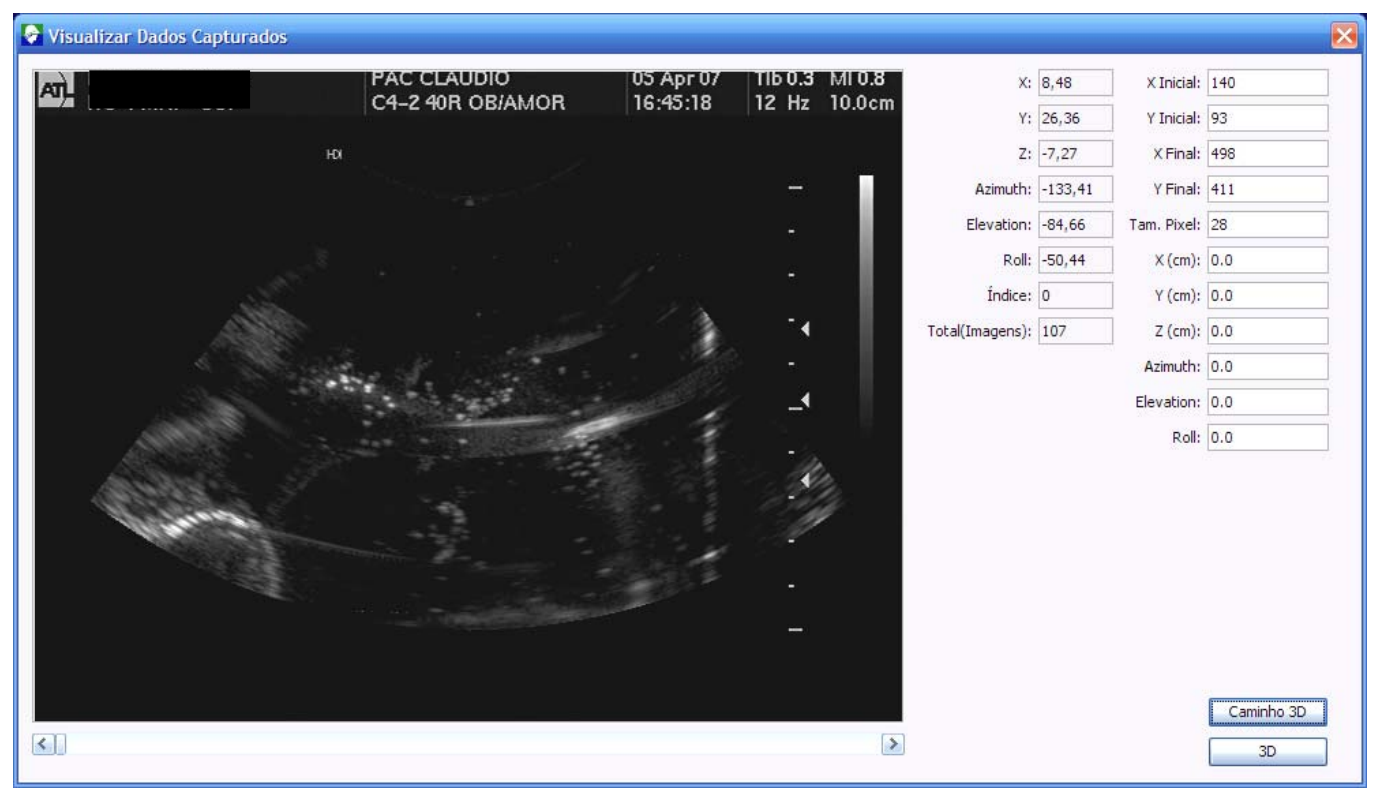

Figura 5.24 - Interface para montagem do volume.

A visualização da direção e a quantidade de imagens do volume adquirido pode ser visualizado graficamente, na Figura 5.25. Cada Fatia da imagem adquirida é representada como sendo um quadrado em branco.

Para a montagem das imagens como texturas é requerido se será utilizado o modelo de visualização por Texturas 2D ou Texturas 3D no OpenGL.

A visualização do Volume Direto baseado no modelo de Texturas 2D é feito pela aplicação de funções glTexImage2D do OpenGL. O método por Texturas 3D é realizado pela aplicação de funções glTexImage3D do OpenGL. 


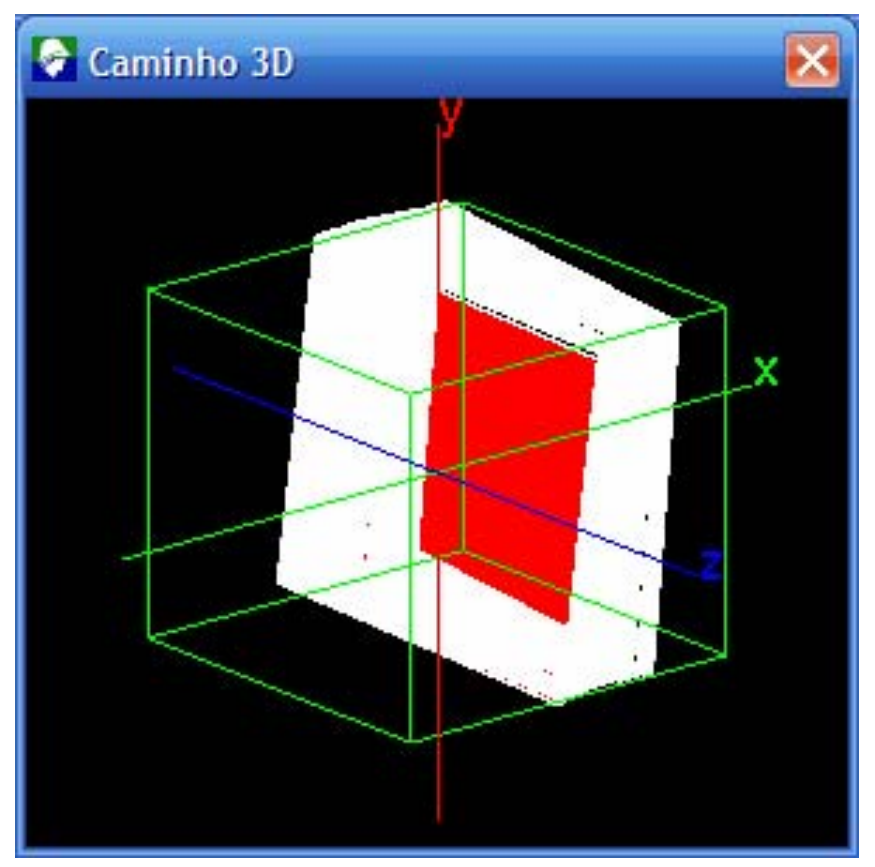

Figura 5.25 - Caminho percorrido pelo transdutor para a captura de imagens. Os quadrados brancos representam cada imagem capturada.

No instante da visualização, é possível selecionar uma seqüência de determinados valores de voxels presentes no volume. Esses valores servem como um limiar para que, de acordo com a escolha, eles possam ou não estar presentes naquele volume. Este tipo de recurso permite que determinados tipos de estruturas, que geralmente possuem valores de voxels semelhantes, permaneçam presentes ou sejam excluídos do volume.

Para a visualização do volume tridimensional, o usuário seleciona o conjunto de imagens capturadas no Modo-B e o sistema monta o volume tridimensional sem nenhum tipo de auxílio de intervenção do usuário. É necessário apenas selecionar o método de montagem do volume na mesma interface da Figura 5.24.

Para a melhoria da manipulação da visualização do volume tridimensional na programação, foram utilizados comandos de acesso a bibliotecas gráficas OpenGL que aumentam a performance do volume tridimensional (WRIGHT (1996)). 
Métodos de visualização volumétrica (DREBIN et al. (1988); ELVINS (1992)) como Ray-casting e Ray-tracing demandam um longo tempo computacional para a montagem do volume para a visualização. Por este motivo deve ser utilizado o método de Visualização de Volume por Texturas (EBERT et al. (1994)). Neste processo, a montagem do volume 3D é feita a partir das imagens bidimensionais por meio da montagem de cada imagem como uma textura, sobrepondo uma textura sobre a outra.

A visualização por texturas (Figura 5.26) é uma técnica de visualização de Volume Direto. Esse método também pode produzir uma imagem do interior do volume como a técnica por Ray-casting (HALL et al. (1991)) embora seja mais limitada.

No método Ray-casting, cada pixel da imagem 3D é formado por cada raio que atravessa todo o volume da imagem. O método de reconstrução 3D por texturas carrega cada imagem adquirida pelo transdutor como uma textura usando as bibliotecas OpenGL e utiliza a projeção em paralelo das imagens ao ângulo da visualização para o efeito 3D. A textura é utilizada como uma memória auxiliar de voxels (pixel de uma imagem 3D) processando todos os raios simultaneamente, de cada imagem 2D por vez.

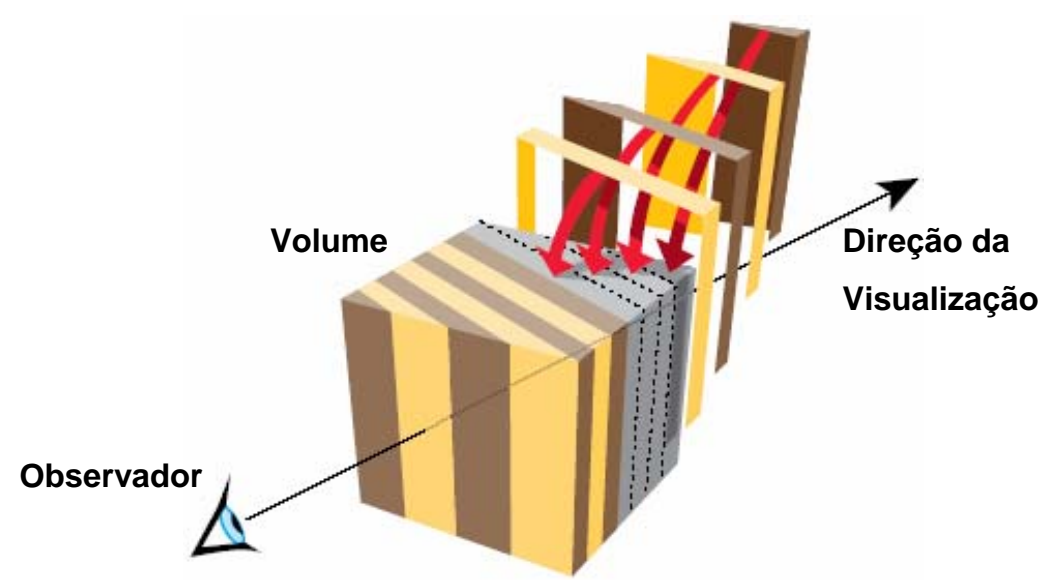

Figura 5.26 - Esquema de visualização direta de dados por texturas em OpenGL (MCREYNOLDS et al. (1998)). 
Este algoritmo é muito mais rápido (desde que a placa de vídeo do computador tenha suporte de aceleração por hardware do OpenGL) que a técnica de Ray-casting.

Nos testes deste projeto foi utilizado um computador PC de $1800 \mathrm{MHz}$ com $256 \mathrm{MB}$ de memória RAM e placa de vídeo NVIDIA GeForce 4 MX440. Também foi utilizado um notebook de $3.2 \mathrm{GHz}$ com 512MB de memória RAM e placa de vídeo GeForce FX 5700. Para os testes de portabilidade (capacidade de o programa ser executado em várias plataformas e sistemas computacionais diferentes sem a necessidade de modificação no código fonte), este programa foi utilizado nos sistemas operacionais Linux e Windows, conforme exemplificam a Figura 5.27 e a Figura 5.28.

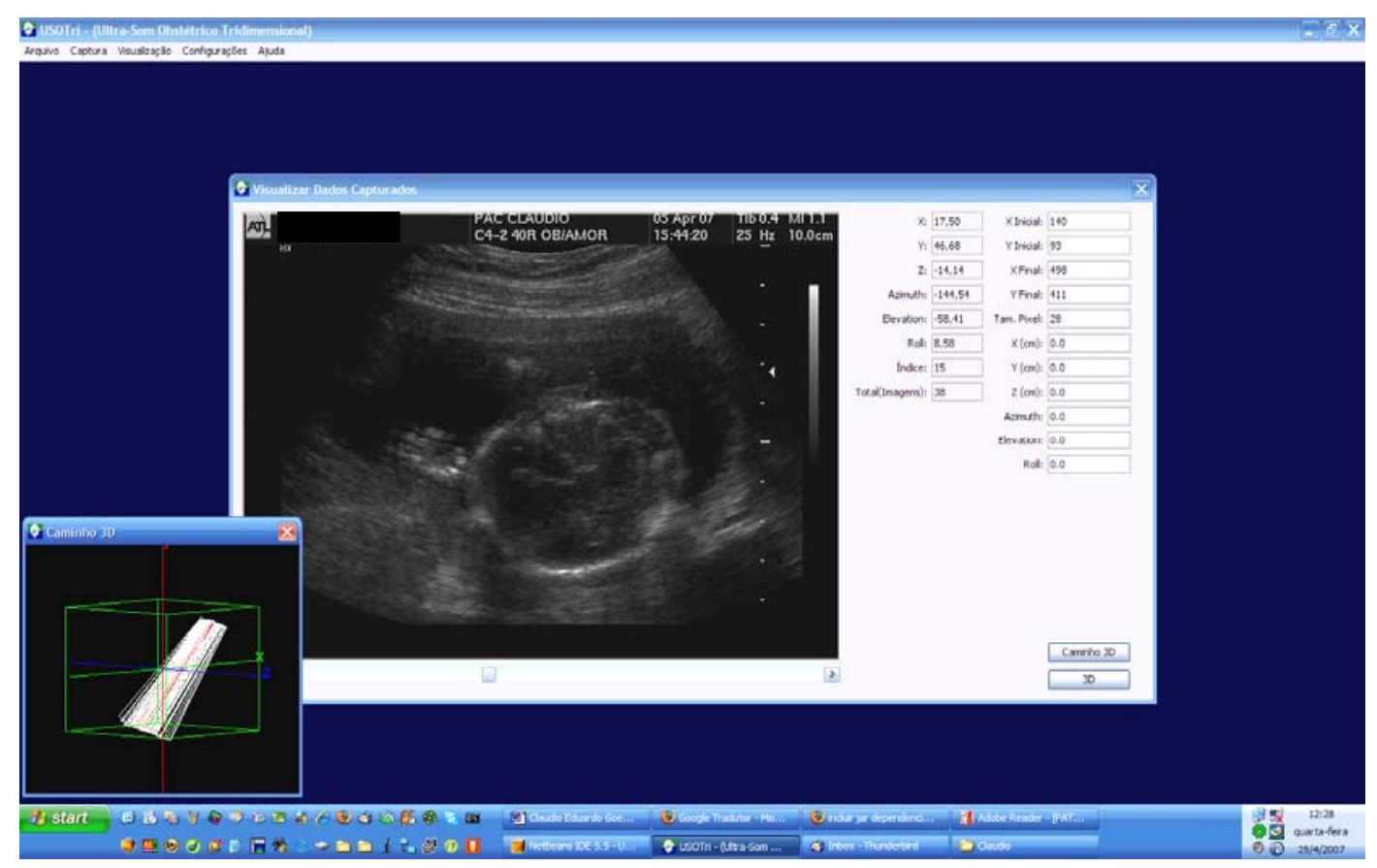

Figura 5.27 - Sistema funcionando na plataforma Windows com o sistema operacional Windows XP. 
$X$ USOTri - (Utra-Som obstétrico Tridimensional)

Arquivo Captura Visualizaçäo Configuraçöes Ajuda
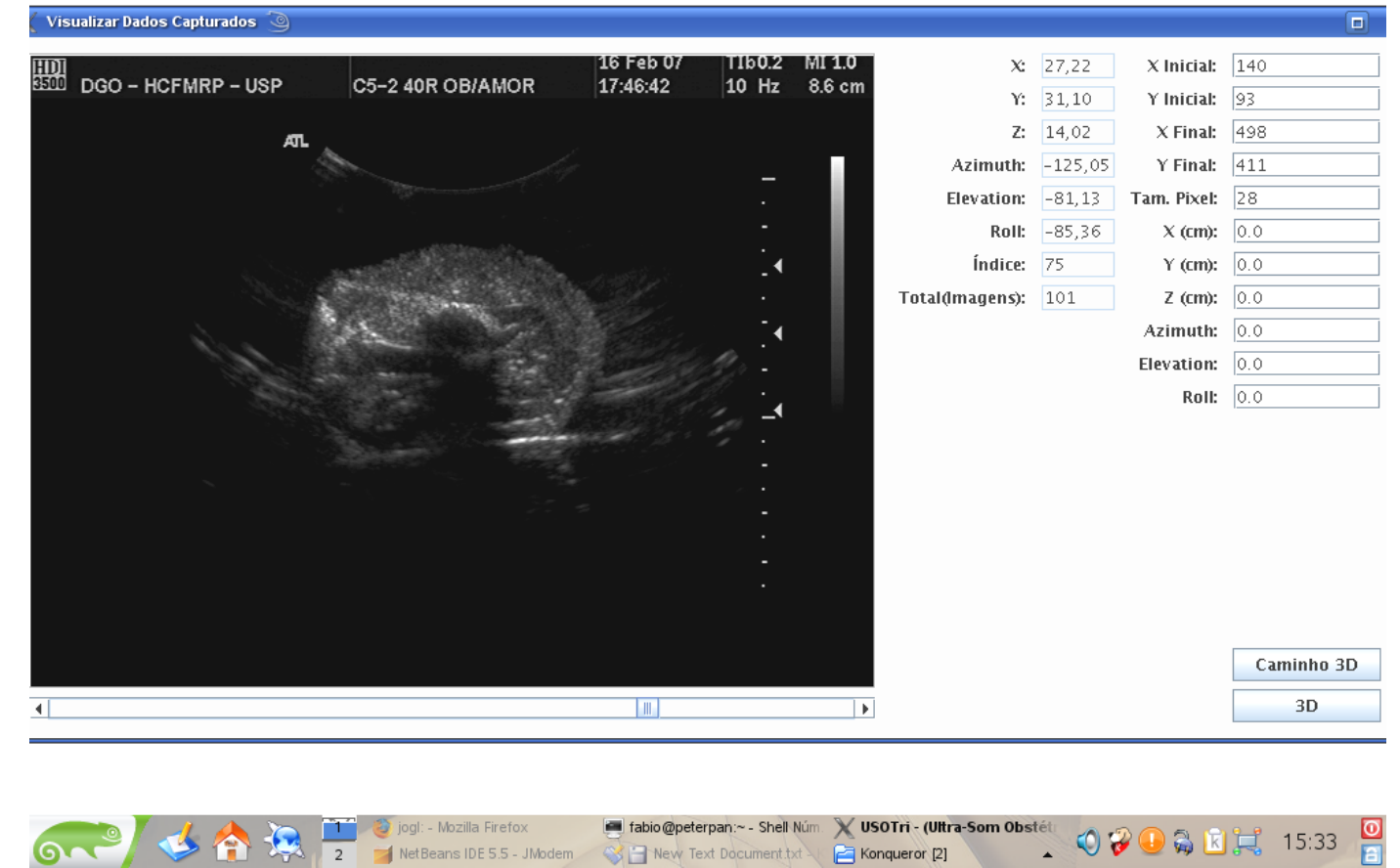

Figura 5.28 - Sistema funcionando na plataforma Linux na distribuição Suse versão 10.2.

Embora a linguagem computacional Java não possua suporte direto para acesso das API's (Application Program Interface) OpenGL no seu kit padrão de desenvolvimento de aplicações, atualmente existem várias bibliotecas disponíveis que fazem a ligação do OpenGL ao Java. Na realização deste procedimento de ligação foi utilizado a API do projeto JOGL. Este projeto é desenvolvido e mantido pela empresa Sun Microsystems (CHEN et al. (2006).

O processo de montagem do volume tridimensional é feito a partir das imagens bidimensionais por meio da montagem de cada imagem como uma textura (EBERT et al. (1994)) à outra. Este método de reconstrução é chamado de reconstrução por Texturas 3D. 
$\mathrm{Na}$ visualização de volumes, a utilização do método de interpolação é necessário. A interpolação ocorre quando em determinadas circunstâncias é necessário fazer a amostragem entre voxels para se obter um voxel intermediário.

Neste sistema foi utilizada a interpolação das fatias empregando o núcleo linear (MAELAND et al. (1988)). Nos testes desta ferramenta foi utilizado um PC de 32bits com um processador de $1500 \mathrm{Mhz}, 256 \mathrm{MB}$ de memória RAM e uma placa de vídeo com suporte aceleração 3D NVIDIA GeForce 4 MX440. Para os testes de portabilidade, este software foi utilizado nos sistemas operacionais Linux (Distribuição Suse versão 10.2) e Microsoft Windows XP.

Testes de visualização tridimensional de imagem de phantoms computacionais neste trabalho serviram como base para o desenvolvimento do esquema de visualização tridimensional de imagens de ultra-som tomando como base o modelo de SACKMAN et al. (1994). Tais imagens e os processos de sua obtenção serão apresentados no próximo capítulo. Já imagens de pacientes reais são adquiridas pelo operador do aparelho ultrasonográfico no Modo-B, direcionando o transdutor do aparelho em qualquer orientação desde que todo o volume do objeto em estudo seja percorrido pelo transdutor conforme ilustrado na Figura 5.29. Segundo STEINER et al. (1994) e RANKIN et al. (1993), este é o tipo de modalidade de construção do volume tridimensional denominado de freehand. 


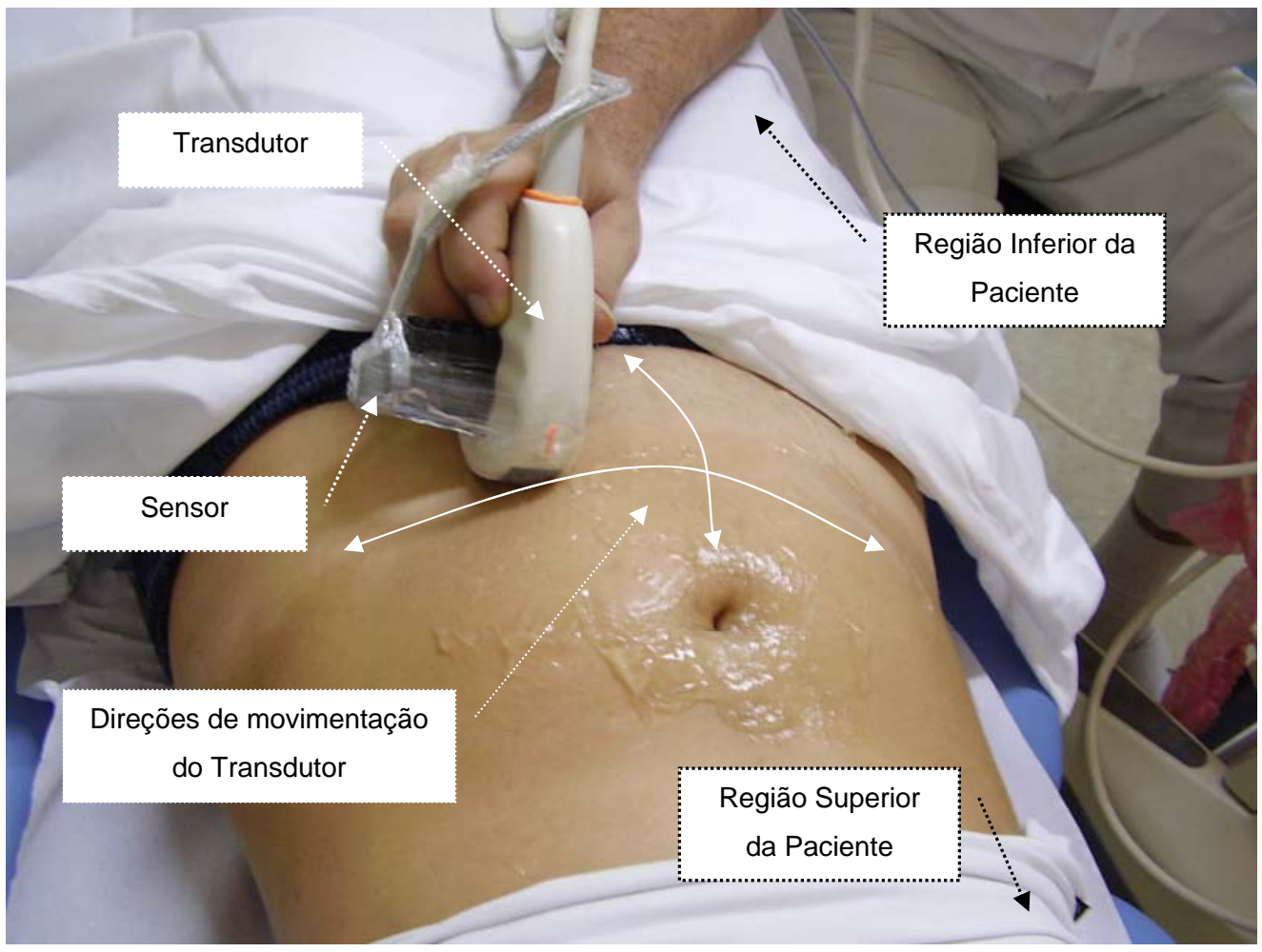

Figura 5.29 - Zona de ação de captura de imagens utilizando o transdutor em uma gestante. 


\section{CAPÍTULO 6}

\section{Resultados}

\subsection{Introdução}

Para o desenvolvimento dessa pesquisa foi necessária a geração de alguns phantoms computacionais. Objetos deste tipo são importantes para testes, pois como o formato do objeto de estudo é conhecido, a avaliação da estrutura resultante formada pelo sistema pode ser feita com mais precisão. Na primeira etapa de testes de desenvolvimento, foram criadas imagens geométricas de um Cubo, uma Esfera e um Cone. Esses formatos foram escolhidos, pois, como se tratam de figuras que possuem facilidade em termos de percepção de sua forma e definição, torna-se fácil a avaliação da geração do volume tridimensional.

O sistema desenvolvido neste trabalho também foi submetido a um teste prático onde foram capturadas imagens de phantoms reais em sala de exames do Hospital das 
Clínicas de Ribeirão Preto utilizando o sensor de posicionamento Patriot. Imagens reais de um feto in vivo também foram obtidas neste mesmo lugar.

\subsection{Phantom Computacional}

As imagens das figuras geométricas criadas para funcionar como phantoms computacionais tinham resolução espacial de 256x256 pixels e de 512x512 pixels. Estas dimensões foram escolhidas, pois, em situação clínica prática, corresponde à resolução espacial da captura das imagens de pacientes. A resolução de contraste de cada imagem foi de 8 bits (256 tonalidades de cinza). O volume de cada objeto geométrico foi dividido em 150 seções transversais.

Uma seção transversal do meio da seqüência de imagens de cada objeto gerado para a elaboração do phantom computacional pode ser observada na Figura 6.1(a,b,c). Embora esse primeiro conjunto de imagens funcione para os testes de visualização do sistema, as imagens não se assemelham com imagens reais de ultra-som que, na prática, possuem o padrão de ruído chamado de efeito speckle.

Desta forma, o passo seguinte, foi a inserção do ruído speckle, para tornar os phantoms mais semelhantes às imagens reais. Essas novas imagens foram geradas através da aplicação do processamento do método descrito em JENSEN (1996), o qual funciona aplicando uma linha dispersa padrão em uma Gaussiana aleatória para efetuar a dispersão. O relacionamento entre a imagem em níveis de cinza e a dispersão da amplitude é dada por:

$$
a=10 * \exp \left(\operatorname{img}\left(\overrightarrow{r_{k}}\right) / 100\right)
$$

onde, img é a imagem em escala de cinza com os valores variando de 0 até 255 e $\vec{r}_{k}$ é a posição dispersa. Esta operação foi aplicada sobre cada imagem dos objetos geométricos originais. A Figura 6.1(d,e,f) mostra a imagem resultante da adição do ruído speckle nesses objetos. 


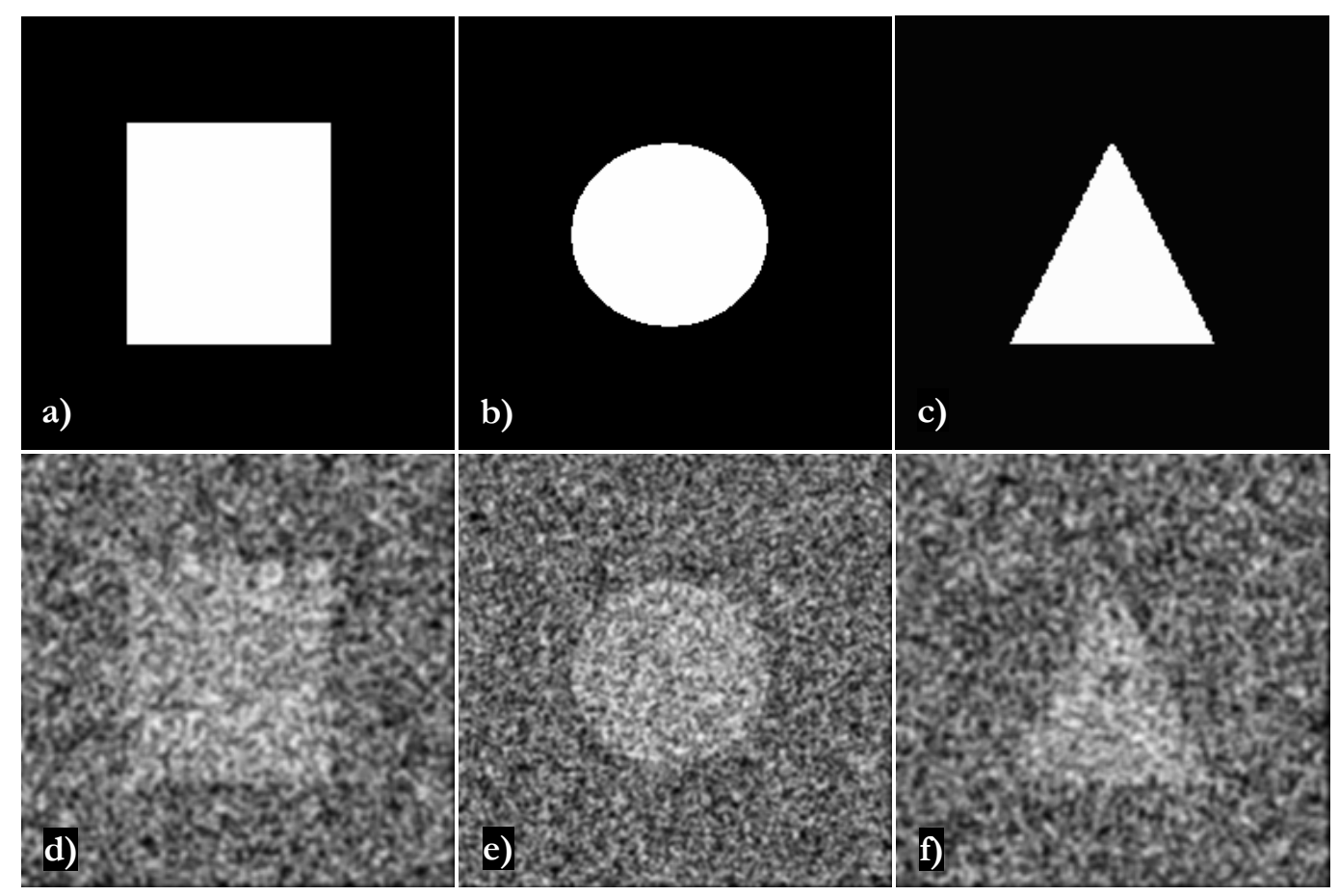

Figura 6.1 - Seção transversal das estruturas geométricas originais criadas para a geração do volume 3d: a) Cubo; b) Esfera; c) Cone; Inserção do ruído speckle nas imagens originais: d) Cubo; e) Esfera; f) Cone.

Como os phantoms computacionais criados anteriormente são apenas de objetos geométricos de tons binários, foi criado um outro phantom utilizando vários polígonos com diferentes níveis de tonalidades (Figura 6.2). A idéia era verificar o resultado da reconstrução 3D de um objeto com diferentes tipos de interfaces na mesma imagem. 

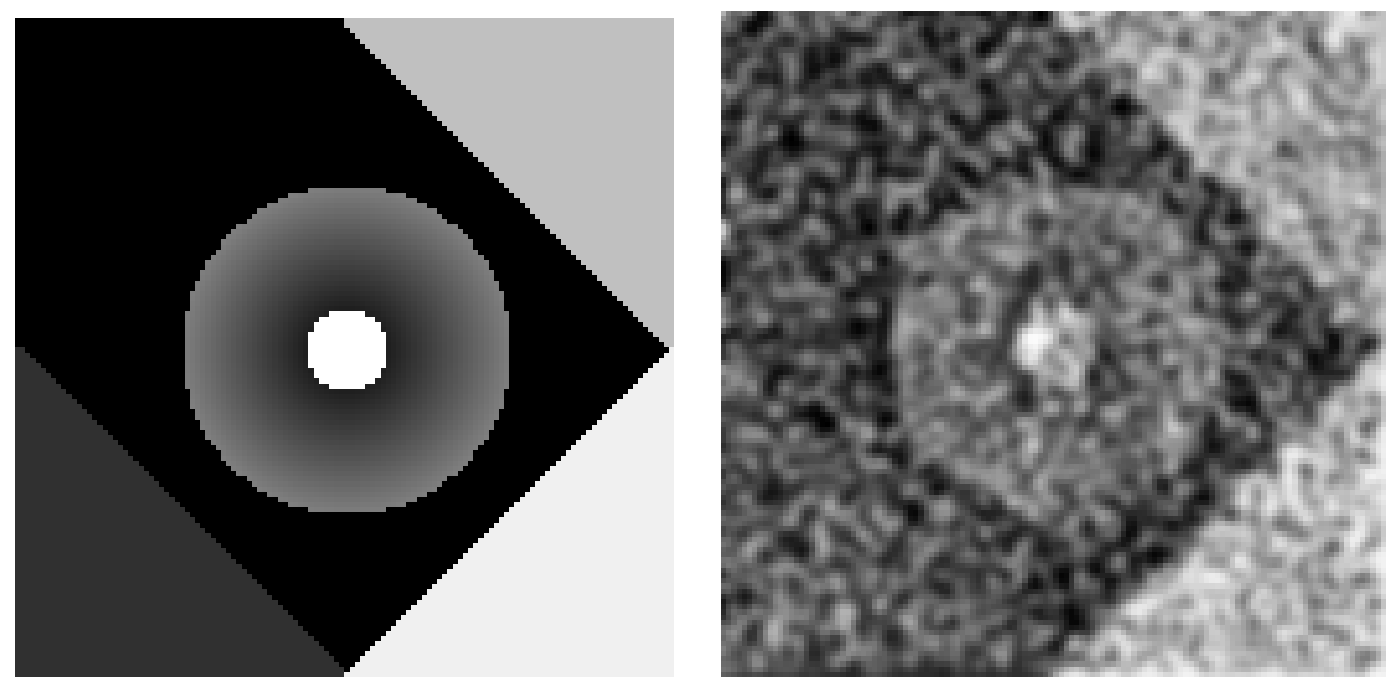

Figura 6.2 - Seção transversal do Phantom mesclado com várias imagens geométricas: a) Sem adição do efeito speckle; b) Com adição do efeito speckle.

Para a visualização do volume tridimensional das imagens simuladas do phantom computacional, o usuário deve selecionar primeiramente o conjunto de fatias das imagens para que o sistema monte o volume tridimensional sem nenhum tipo de intervenção do usuário.

Para a melhoria da manipulação da visualização do volume tridimensional na programação, foram utilizados comandos de acesso a bibliotecas gráficas OpenGL. Essa biblioteca gráfica foi utilizada pelo fato de que a performance da manipulação do volume tridimensional aumenta consideravelmente com a utilização do suporte ao acesso por aceleração através do hardware das placas de vídeo. Atualmente, as placas de vídeo com suporte a essa tecnologia possuem baixo custo e estão presentes na maioria dos computadores que manipulam imagens em 3D.

Como resultados da utilização do sistema completo desenvolvido neste trabalho, a Figura 6.3 ilustra a visualização dos volumes 3D reconstruídos através das seções transversais de cada fatia das imagens dos phantoms computacionais criados. A Figura 6.3(a,b,c) mostra os volumes reconstruídos das imagens originais do Cubo, Esfera e Cone. 
Já a Figura 6.3(d,e,f) ilustra os volumes das imagens do Cubo, Esfera e Cone adicionadas do efeito speckle para a simulação mais próxima do ultra-som 3D.

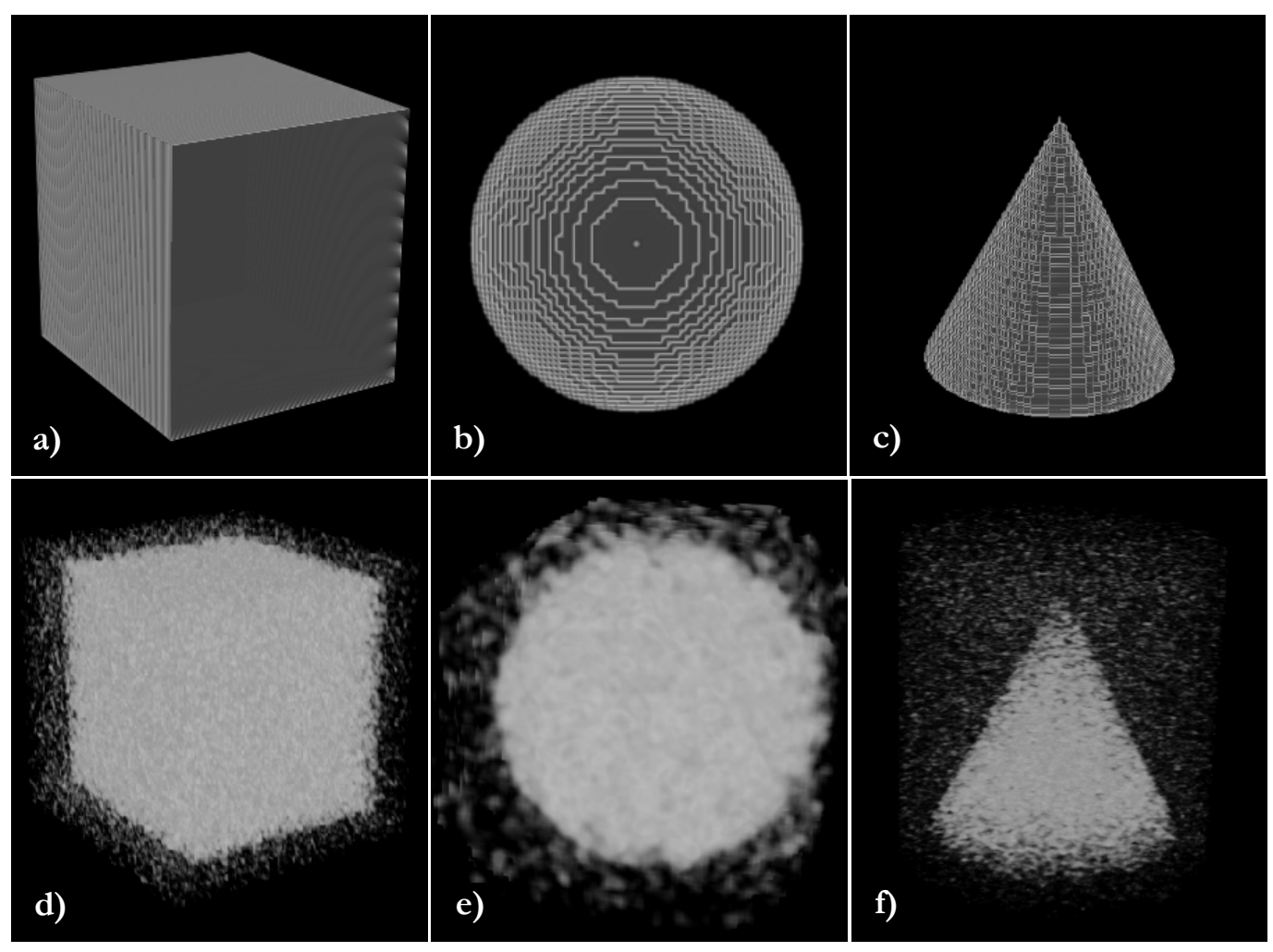

Figura 6.3 - Imagem da reconstrução de volume nos phantom's computacionais gerados neste trabalho: Imagens dos objetos originais: a) Cubo; b) Esfera; c) Cone; Imagens dos objetos processados com o efeito speckle: d) Cubo; e) Esfera; f) Cone.

Na Figura 6.4 é apresentado o resultado da reconstrução do phantom computacional que possui vários objetos geométricos em seu interior. Na Figura 6.4(a) o modelo está sem a adição do efeito speckle, já na Figura 6.4(b) o mesmo modelo pode ser visto, mas com a adição do efeito speckle. 

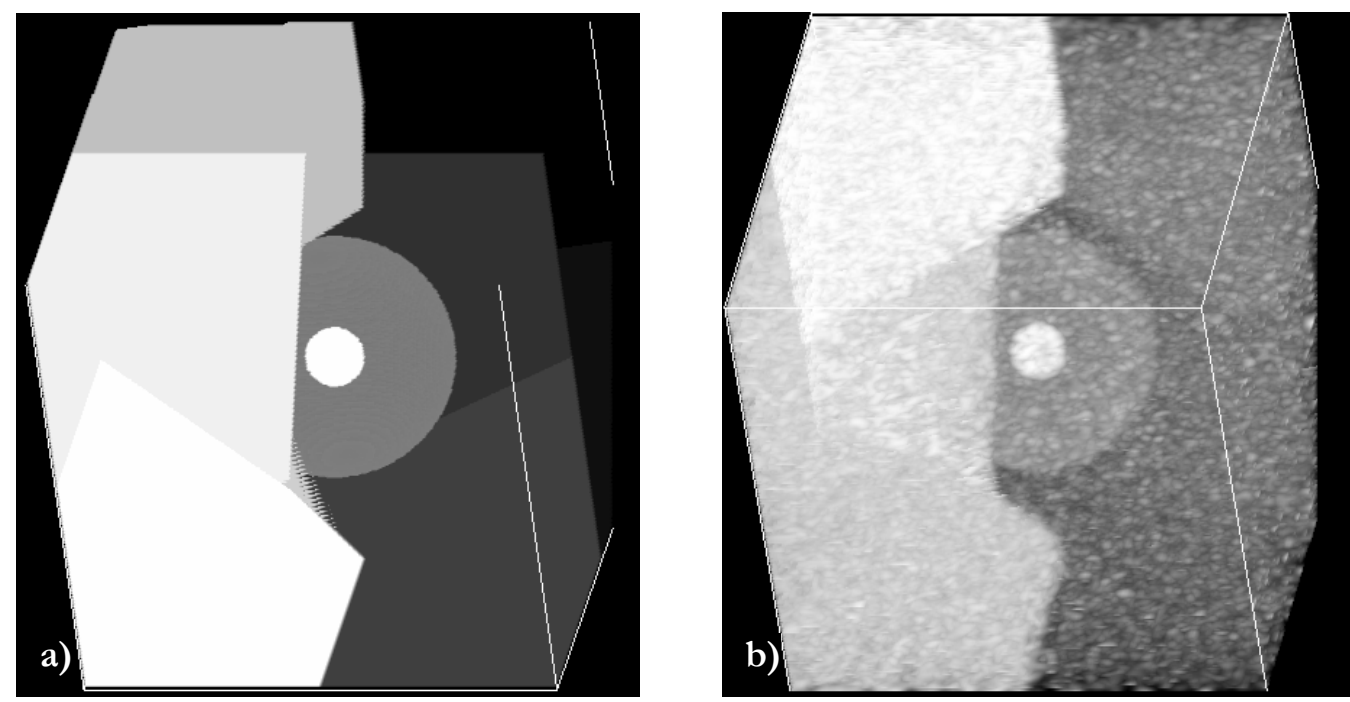

Figura 6.4 - Imagem da reconstrução do modelo de phantom computacional composto por várias figuras geométricas: a) Sem adição do efeito speckle; b) Com adição do efeito speckle.

\subsection{Testes Práticos com Phantoms Físicos}

Os testes práticos com phantoms físicos foram realizados também no Hospital das Clínicas de Ribeirão Preto. Todos os phantoms foram submetidos à mesma bateria de captura de imagens. A inserção dos phantoms no Pote C foi feita sempre da mesma maneira, sendo colocados no fundo do pote. Alguns phantoms, como o preservativo e a luva cirúrgica, necessitaram ser fixados com fita adesiva para permanecerem no fundo. Uma imagem mostrando a seqüência de tomada de imagens do phantom da Figura 5.11(e) pode ser observada na Figura 6.5. Deve-se ter a devida atenção em relação ao sensor na Figura 6.5, pois o mesmo encontra-se sem o espaçamento necessário para a anulação da interferência eletromagnética. A captura dessa seqüência foi realizada corrigindo o espaçamento, através da inserção de um bloco de plástico de $3 \mathrm{~cm}$ entre o transdutor e o sensor.

A Figura 6.6 mostra como foi feita a captura da seqüência de imagens da boneca. Esta imagem já mostra a correção do espaçamento entre o sensor e o transdutor. 


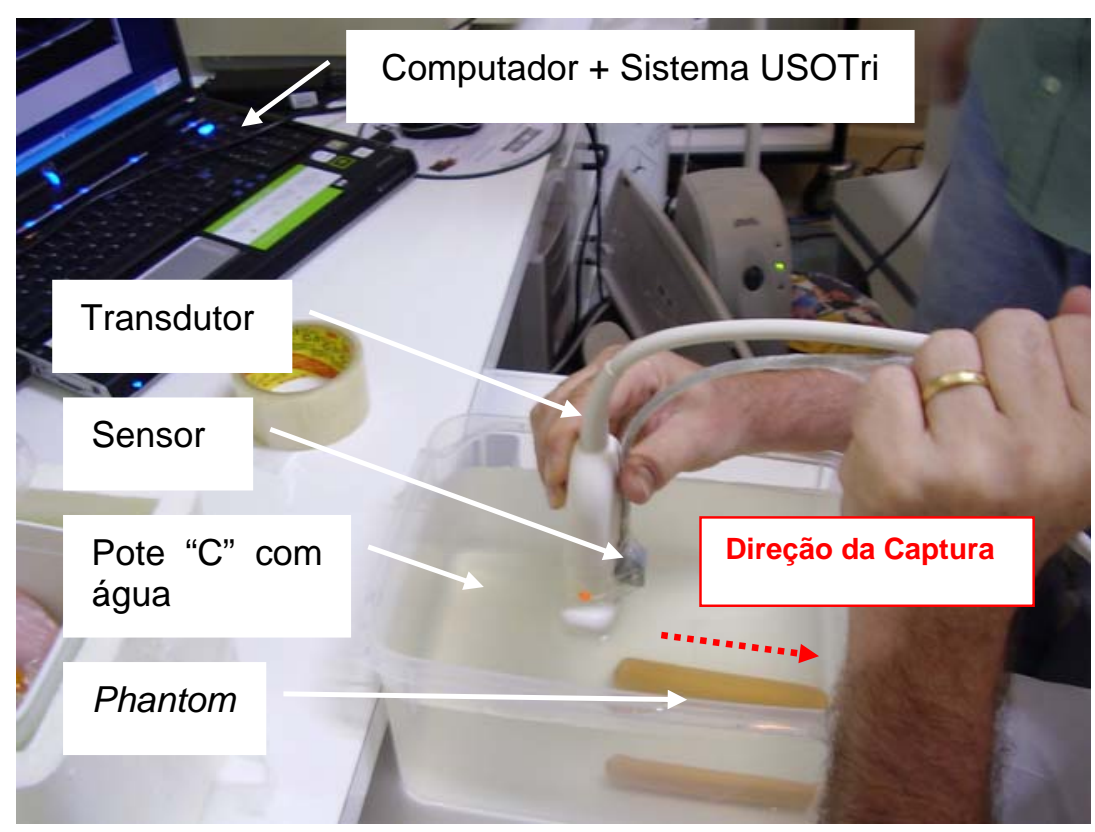

Figura 6.5 - Imagem de exemplo mostrando como foram feitas as aquisições das seqüências de imagens dos phantoms, neste caso a lingüiça de porco.

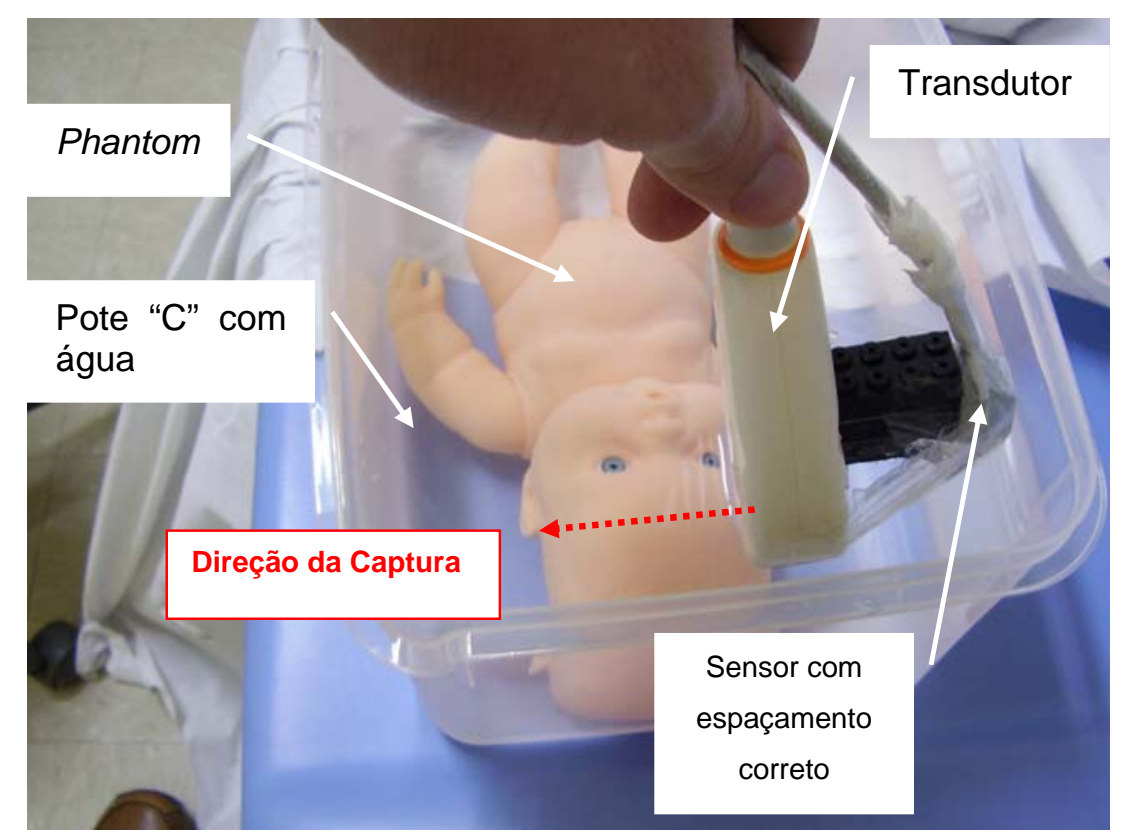

Figura 6.6 - Imagem mostrando a realização da captura da seqüência de imagens do phantom boneca de brinquedo. 
O modelo de phantom utilizado para aferição do formato morfológico do feto pode ser conferido na Figura 6.7, onde é possível observar a imagem de ultra-som da cabeça de uma boneca reconstruído tridimensionalmente.

A imagem da luva cirúrgica, também utilizada como phantom, pode ser observada na Figura 6.8, onde é possível notar todos os dedos da luva com o formato condizente ao esperado. Também é possível observar que a parte superior da luva na Figura 6.8(b) não apareceu na reconstrução. Ocorreu que o limiar de segmentação extraiu essa região e, pelo fato da luva ser muito fina e estar cheia d'água, essa região superior não foi reconstruída corretamente.

A Figura 6.9 mostra a imagem reconstruída do preservativo utilizado nos testes. Pode-se observar que o formato é condizente com a imagem do phantom original.

Na imagem da Figura 6.10(b) foi feita a reconstrução tridimensional da lingüiça de porco. Nesta imagem também verifica-se a eficácia do sistema montando a imagem 3D a partir de sua série de fatias. Uma das fatias em imagem de ultra-som pode ser visualizado na Figura 6.10(a).

A Figura 6.11(a) mostra outro phantom correspondendo a uma mini-salsicha de carne de porco. Na Figura 6.11(b) pode ser conferida a reconstrução 3D das seqüências do volume adquirido. Pode ser observado claramente que o formato condiz com a imagem verdadeira deste phantom.

Outra imagem de phantom reconstruída tridimensionalmente a partir de sua seqüência de imagens (Figura 6.12(a)), pode ser comprovada na Figura 6.12(b). Essa imagem 3D também se assemelha à imagem real deste phantom.

Além da visualização tridimensional, este programa possui uma interface básica para manipular o volume, sendo possível para o operador visualizá-lo em todos os ângulos através da interação com um mouse, movendo-se sobre a janela da imagem 3D reconstruída. 

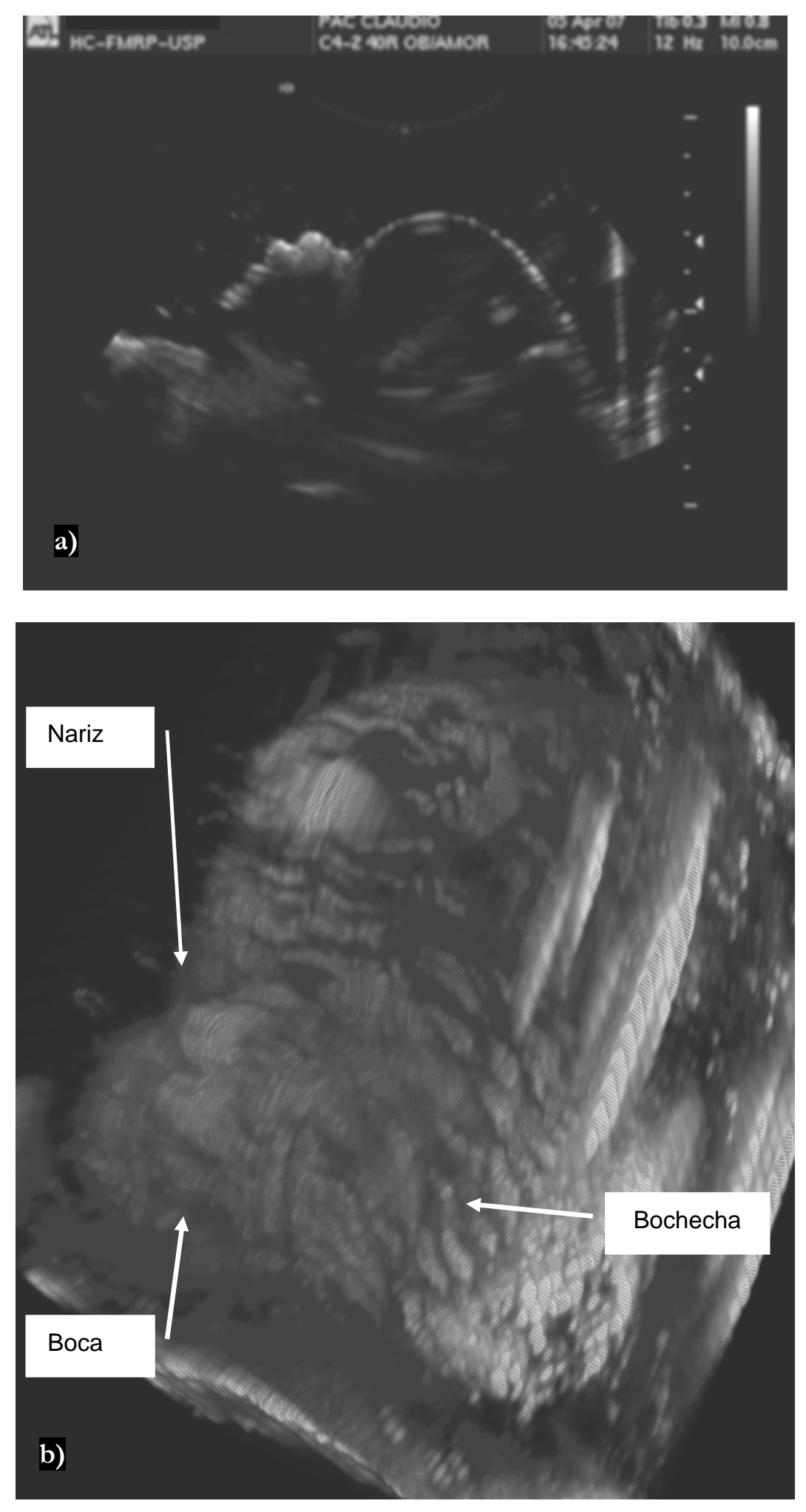

Figura 6.7 - Imagem reconstruída da boneca de brinquedo: a) Fatia 2D do volume capturado; b) Reconstrução 3D. 

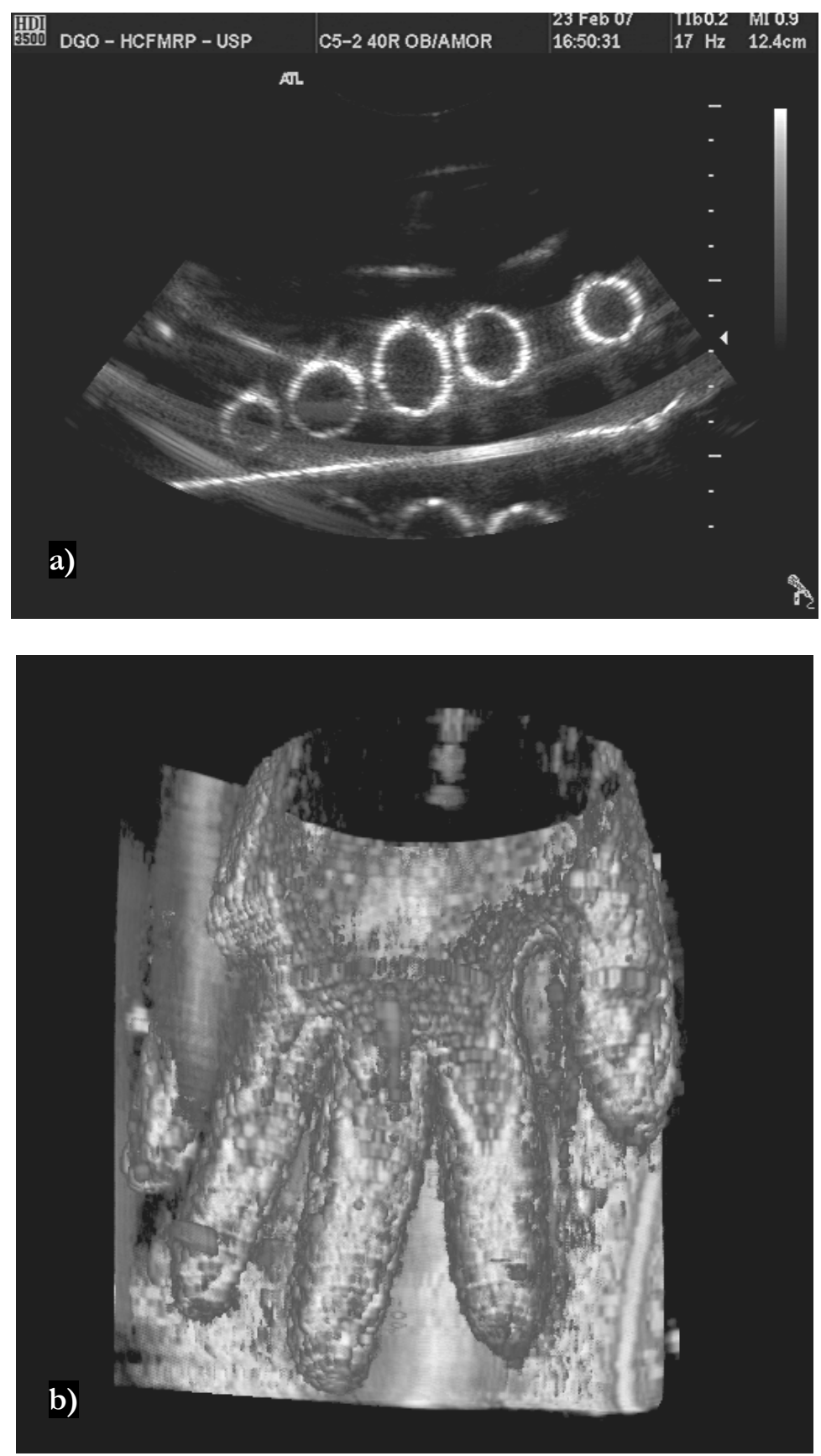

Figura 6.8 - Imagem reconstruída da luva cirúrgica: a) Fatia 2D do volume capturado; b)

Reconstrução 3D. 

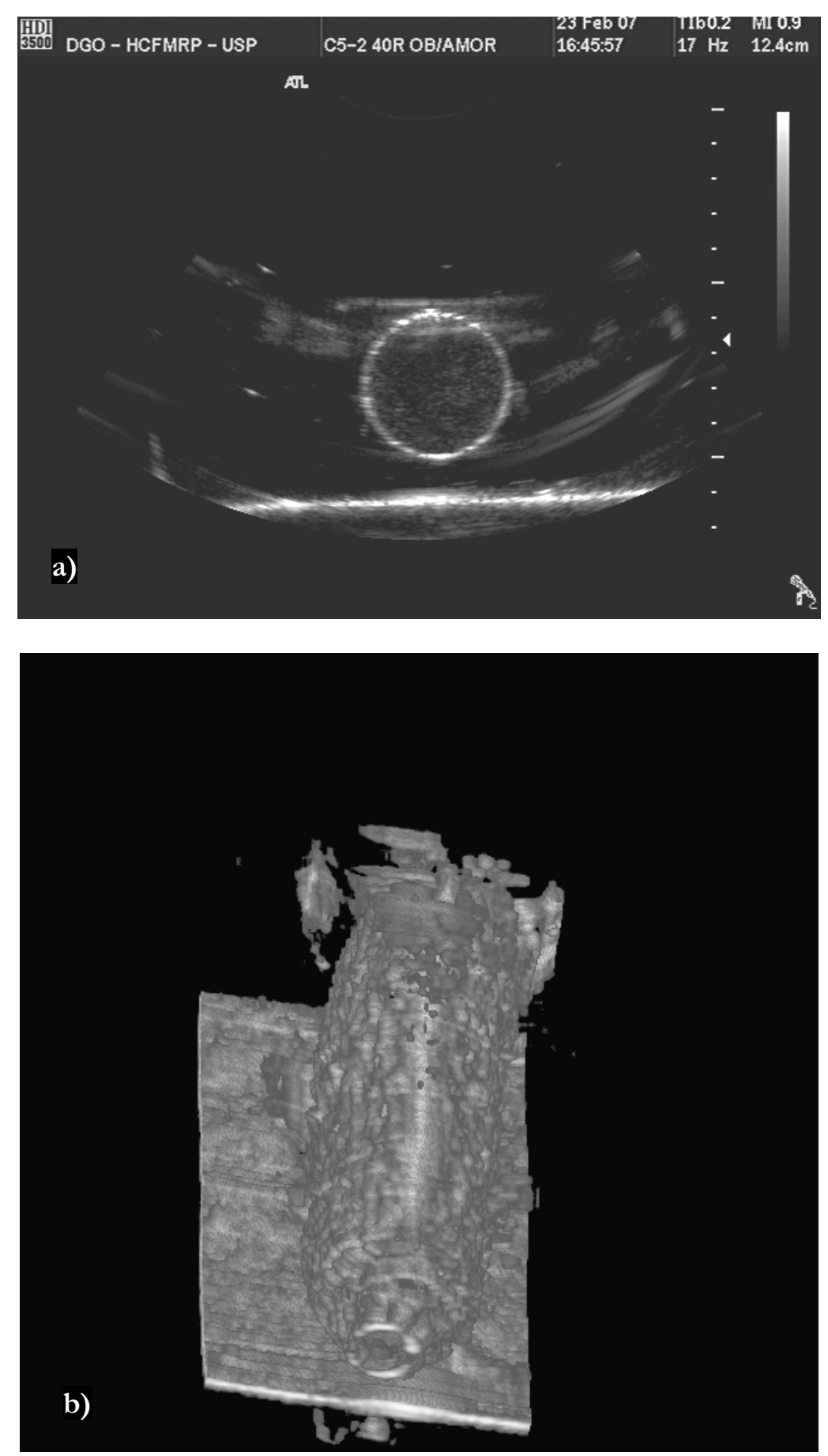

Figura 6.9 - Imagem reconstruída do preservativo: a)Fatia 2D do volume capturado; b) Reconstrução 3D. 

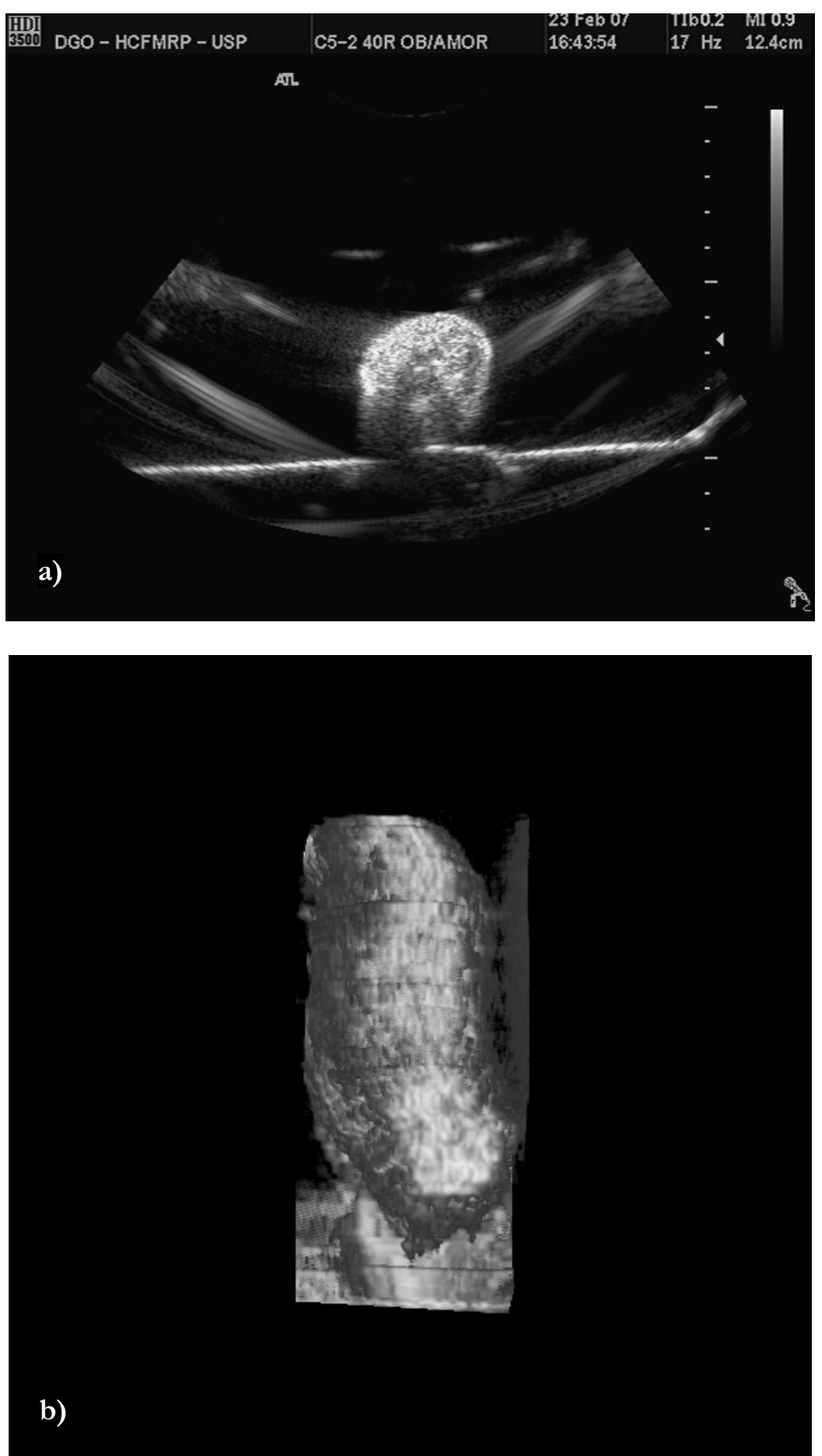

Figura 6.10 - Imagem reconstruída da lingüiça de porco: a) Fatia 2D do volume capturado; b)

Reconstrução 3D. 

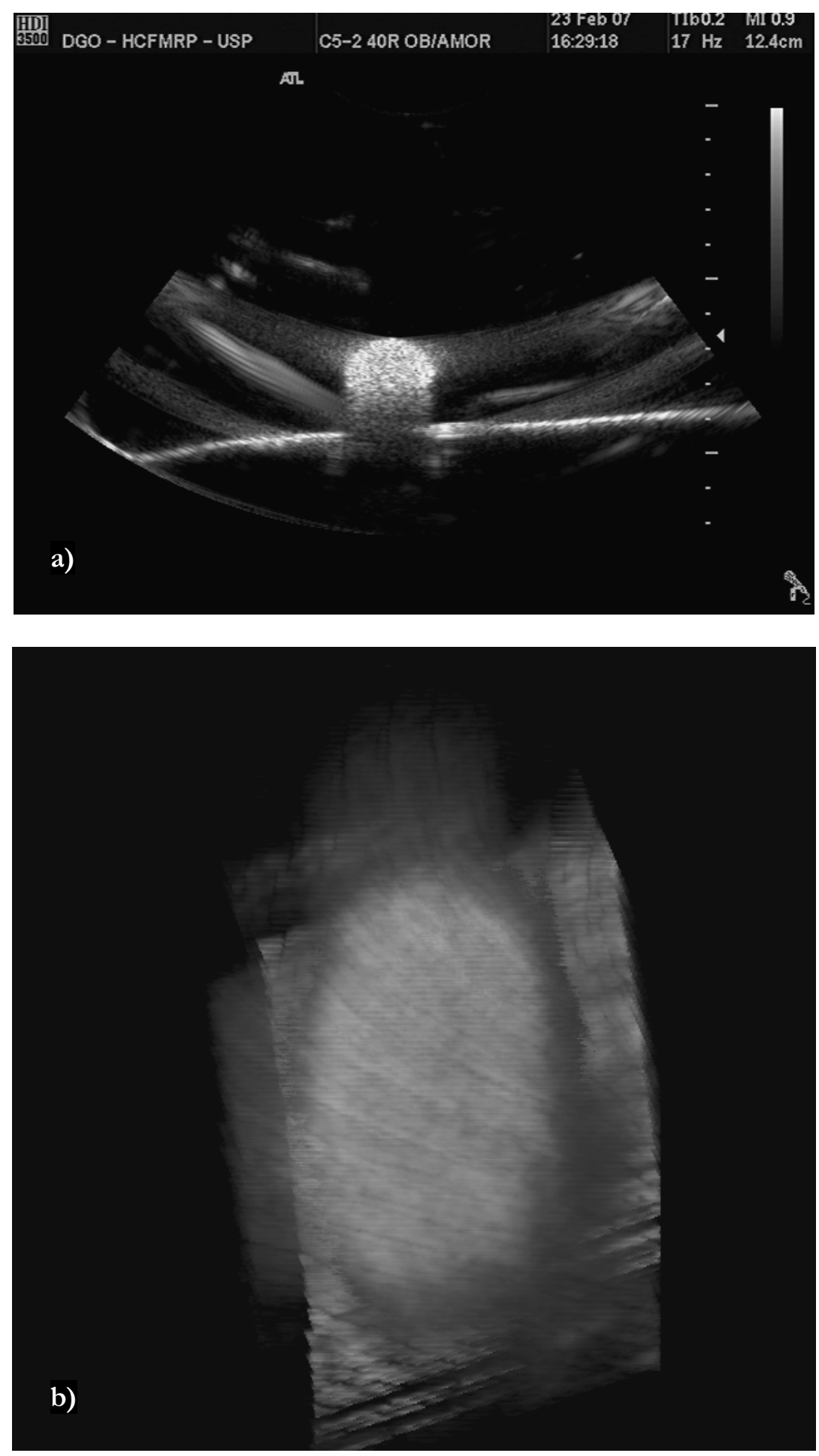

Figura 6.11 - Imagem reconstruída da mini-salsicha: a) Fatia 2D do volume capturado; b)

Reconstrução 3D. 

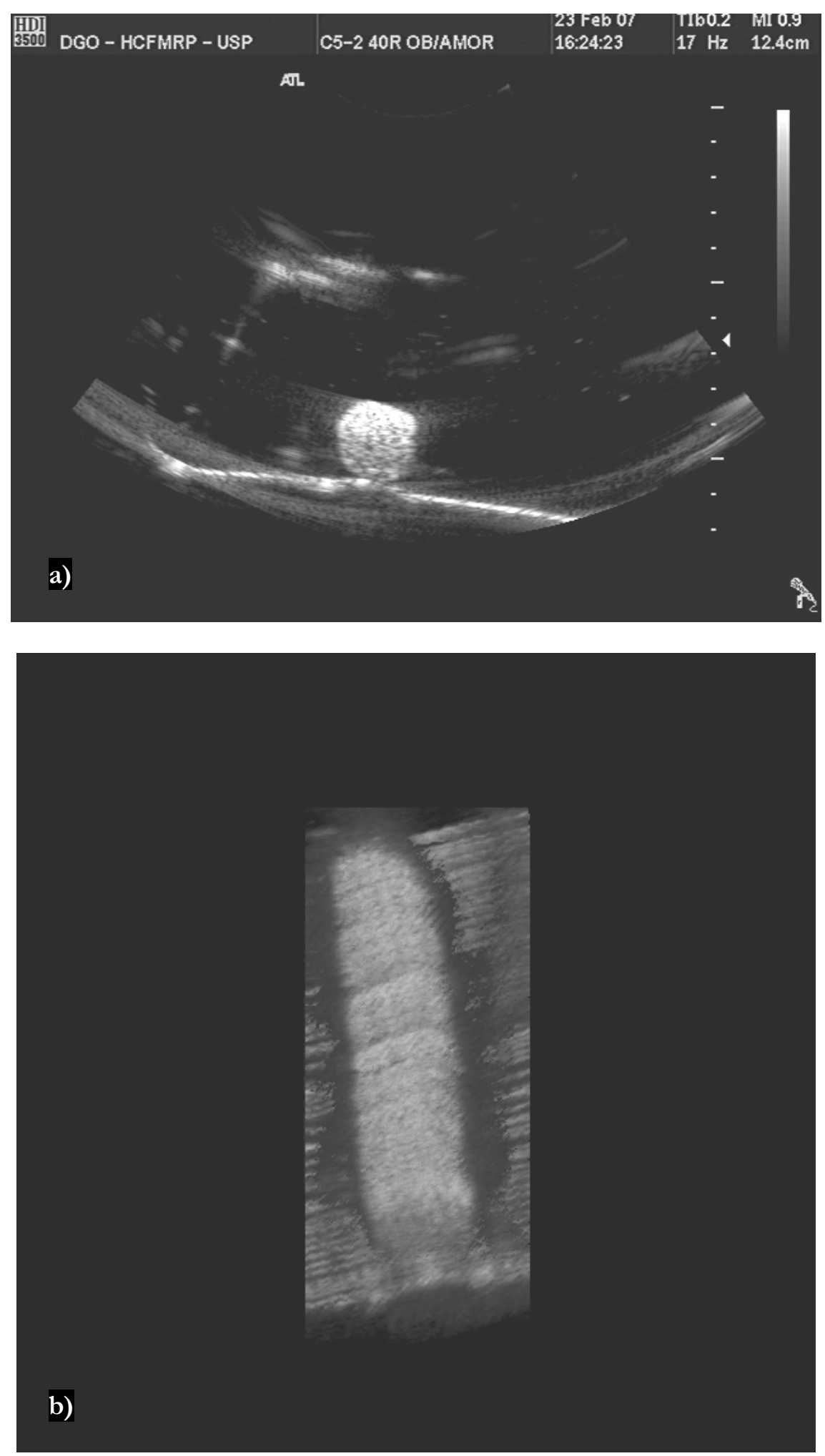

Figura 6.12 - Imagem reconstruída da salsicha de porco: a) Fatia 2D do volume capturado; b)

Reconstrução 3D. 


\subsection{Testes com Imagens Reais de Feto in vivo}

Para a avaliação do adequado funcionamento do presente sistema, foi necessária também a realização de testes com imagens reais, pois, diferentemente das imagens de phantoms, nas imagens in vivo o feto costuma movimentar-se constantemente e, por esse motivo, algumas imagens foram obtidas de algumas pacientes para verificar o efeito desse aspecto na reconstrução das imagens.

Assim imagem desse tipo pode ser observada na Figura 6.14, que corresponde a um feto com idade gestacionária de 34 semanas.

A Figura 6.14 mostra uma imagem da RI dentro do volume adquirido para a posterior reconstrução 3D do feto in vivo. Essa imagem foi adquirida através dos testes com uma paciente do Hospital das Clínicas de Ribeirão Preto, utilizando novamente o mesmo equipamento ATL HDI 3500. A imagem mostra a face do feto na qual é possível observar a boca aberta e os olhos fechados. Infelizmente, devido à demora na aquisição da captura desse conjunto de imagens, o feto moveu-se e sua mão aparece com um efeito do tipo "arrasto".

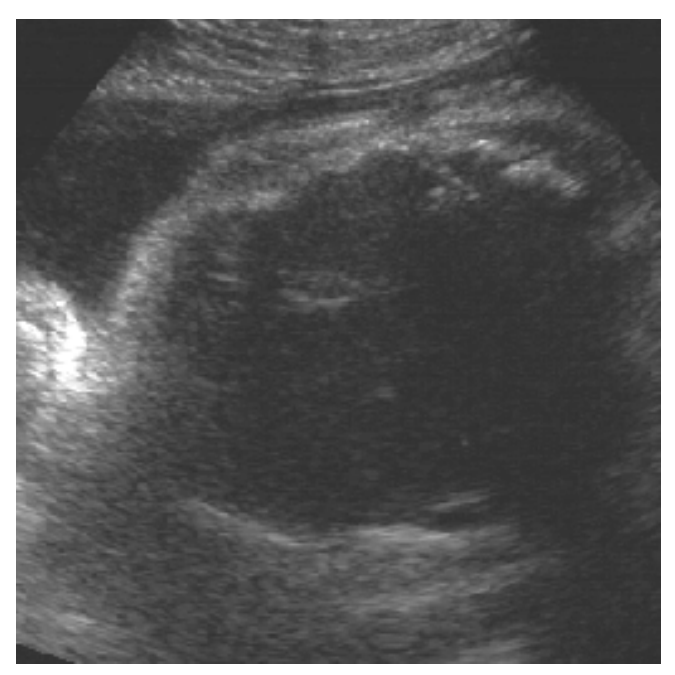

Figura 6.13 - Imagem da RI do volume do feto in vivo. 

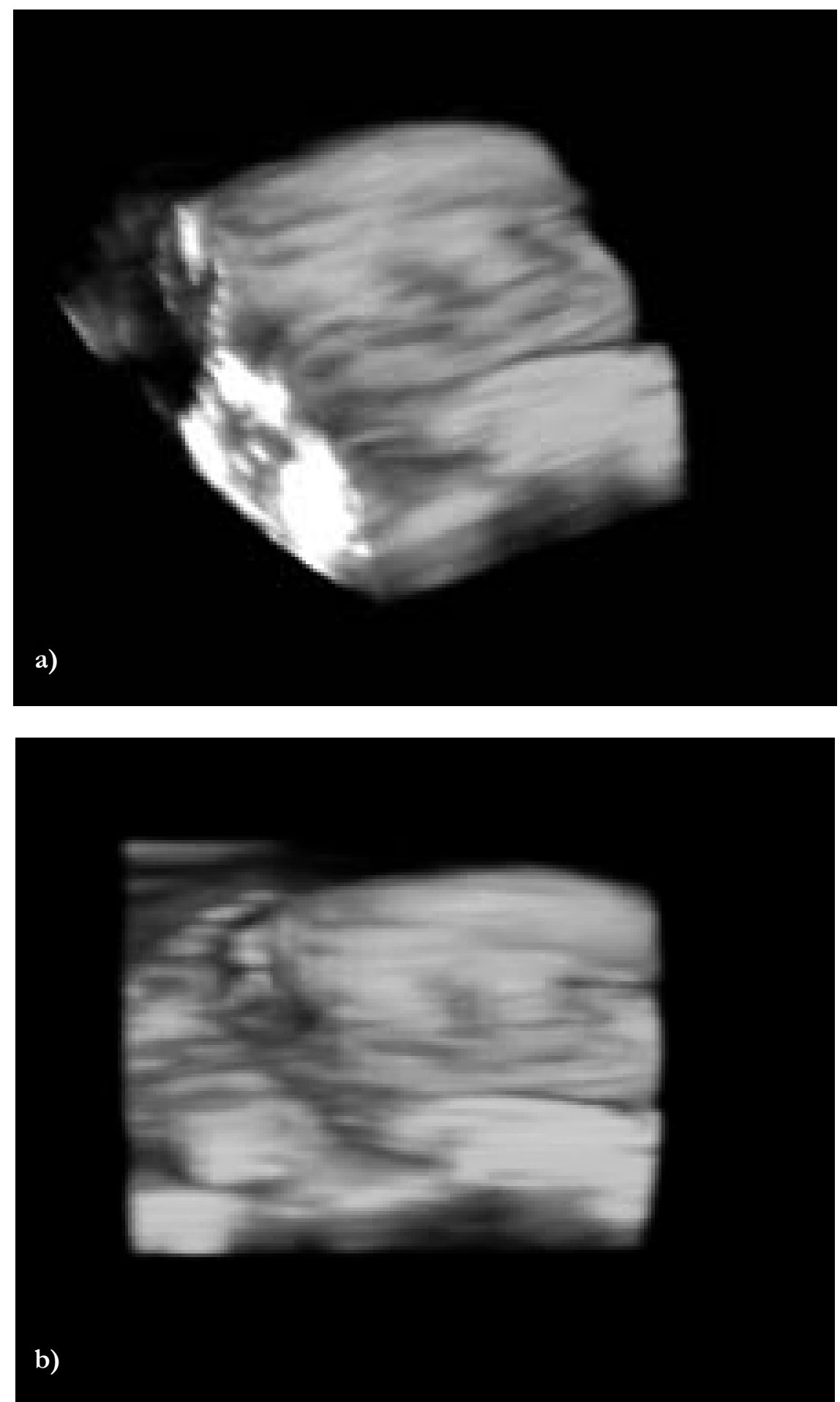

Figura 6.14 - Imagens de fetos reais geradas neste sistema: a) Reconstrução 3D; b) Reconstrução 3D de um ângulo frontal. 


\section{CAPÍTULO 7}

\section{Discussão e conclusões}

\subsection{Introdução}

O ultra-som freehand em relação a outros métodos de captura 3D em aparelhos de ultra-som possui as vantagens de baixo custo, pode ser adaptado a qualquer aparelho de qualquer marca de ultra-som, desde que gere imagens no Modo-B, e permite definir o número de fatias de aquisição do volume 3D.

Como desvantagem, o tempo requerido para capturar um volume é tipicamente mais longo se comparado a equipamentos comerciais com transdutores em matriz ou com direcionadores de feixes para a captura de imagens em 3D. Ele é determinado pelo tempo que o médico demora para fazer a varredura com o ultra-som no corpo do paciente.

Um fator positivo do sistema USOTri desenvolvido nesta pesquisa é que, como ele pode ser utilizado através da Internet, o médico pode executar o programa em qualquer 
computador desde que possua uma conexão com a Internet. Na Figura 7.1 é apresentado o sistema USOTri funcionando dentro de um browser (Navegador de páginas de Internet). Neste exemplo foi utilizado o Firefox, mas qualquer outro browser com suporte a linguagem Java pode ser utilizado, como o Microsoft Internet Explorer, Opera, Mozilla entre outros.

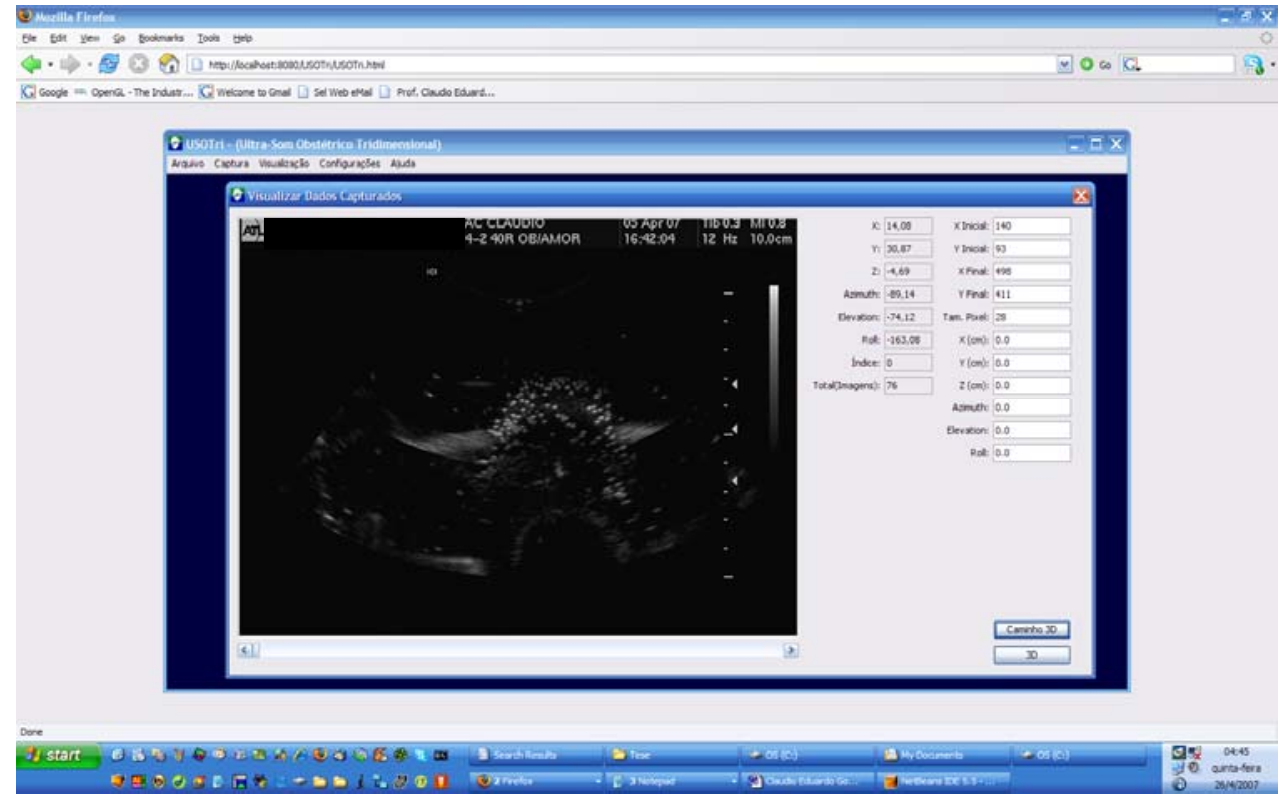

Figura 7.1 - Imagem do sistema USOTri funcionando como uma applet dentro do browser FireFox versão 1.5.0.11

Os recursos providos quando o sistema é executado como uma applet dentro de um browser ou como um aplicativo comum carregado no sistema operacional, são os mesmos.

No sistema funcionando pelo browser da Internet, é possível fazer a visualização dos dados de um volume já capturado e sua reconstrução 3D, além de possibilitar a conexão do sensor Patriot a uma placa de vídeo-captura ligada com o aparelho de ultra-som no computador.

Desta forma o sistema em applet que foi carregado da Internet irá possuir as mesmas funcionalidades do sistema que funciona como aplicativo. 
Neste trabalho a utilização deste sistema não é restrita, ao contrário dos sistemas providos pelos fabricantes de equipamentos de ultra-som 3D que restringem o número de licenças para a utilização do software integrado com o aparelho de ultra-som.

\subsection{Manipulação da Informação do Volume 3D}

Deve ser dada atenção em relação à manipulação do volume quanto à memória do computador. Em um volume com resolução espacial de 256x256x256 voxels, a quantidade de Bytes necessária para sua alocação na memória é de 16,384 MBytes. Caso o computador utilizado possua 512MB de memória RAM, isso significa um consumo dos recursos de memória do computador de 3,13\%. Por outro lado, no caso da utilização de um volume com resolução espacial de 512x512x512 voxels, a quantidade de Bytes para alocação na memória é de 131,072 MBytes que pode representar 25,04\% da ocupação da memória de um computador com 512 MB de memória RAM.

Assim, a utilização da matriz de voxels de 512x512x512 pixels tem o dobro da resolução espacial se for comparada à de uma matriz de voxels da ordem de 256x256x256, mas, em relação ao consumo dos recursos de memória RAM, a matriz cúbica de voxels de 512 requer 8 vezes mais memória em relação à matriz cúbica de voxels da ordem de 256 como pode ser observado na Figura 7.2.

Do ponto de vista prático, o melhor tamanho de matriz a ser trabalhado é a de 256 , pois a quantidade de memória é bem menor do que a de 512 e através da manipulação das RI é possível selecionar partes do volume que se deseja ser visualizado que geralmente correspondem ao objeto inteiro de estudo. 


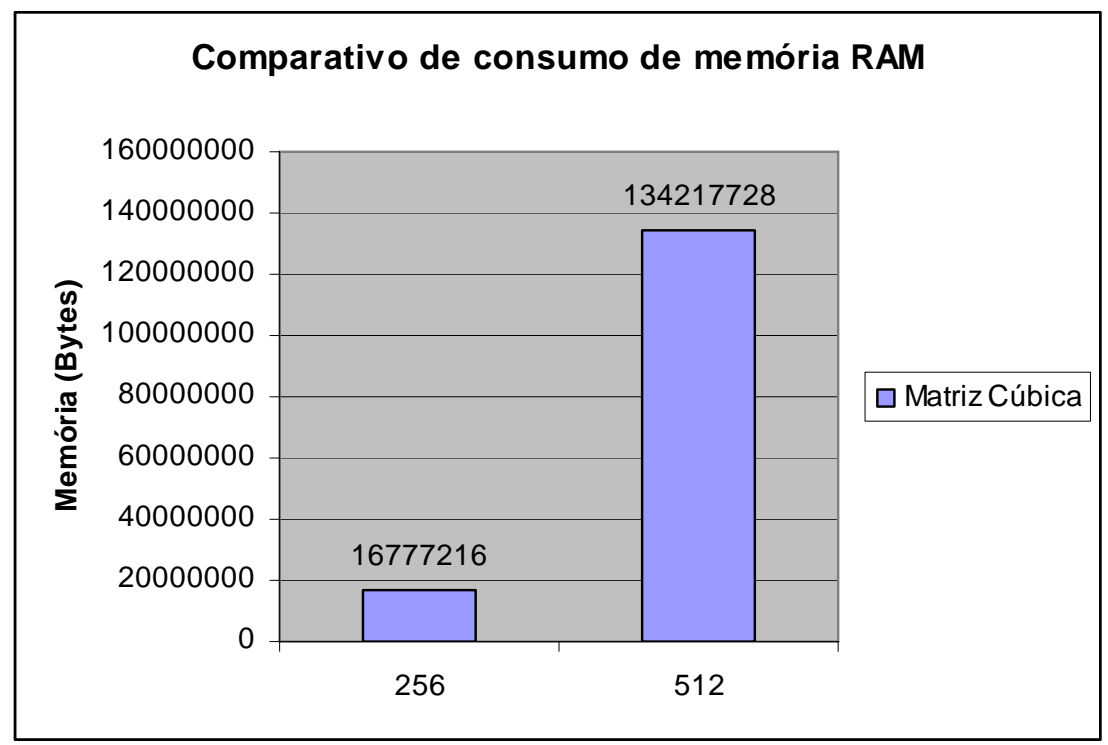

Figura 7.2 - Gráfico comparativo, mostrando o consumo de memória RAM entre uma matriz cúbica da ordem de 256 por outra de 512.

\subsection{Calibração do Sistema}

Em algumas referências bibliográficas (GILJA et al. (1998);PRAGER et al (1998) e DETMER et al. (1994)) é descrita a necessidade de implementação de uma correção de distorções presentes nas coordenadas geradas pelo sensor 3D.

Esse tipo de calibração é feito utilizando um phantom composto de arames dispostos geometricamente em uma caixa com água. É realizada a captura dessas imagens utilizando o transdutor e o sensor 3D e é gerada uma matriz de transformação para efeito de alinhamento do sensor. Esse tipo e procedimento torna-se necessário quando o sensor é acoplado muito próximo do transdutor e o campo magnético do sensor é afetado pela proximidade dos componentes de metal presentes no transdutor.

Na Figura 7.3 é mostrada uma imagem típica destes trabalhos onde o sensor 3D é acoplado muito próximo do transdutor do ultra-som. Nestes trabalhos é dito que toda vez que o sensor é acoplado ao transdutor é necessária a realização de testes de correções de 
distorções das coordenadas 3D. Este tipo de fato pode inviabilizar a implementação do sistema, pois toda vez que o sensor é acoplado ao transdutor, é necessária a realização destes testes de correção.

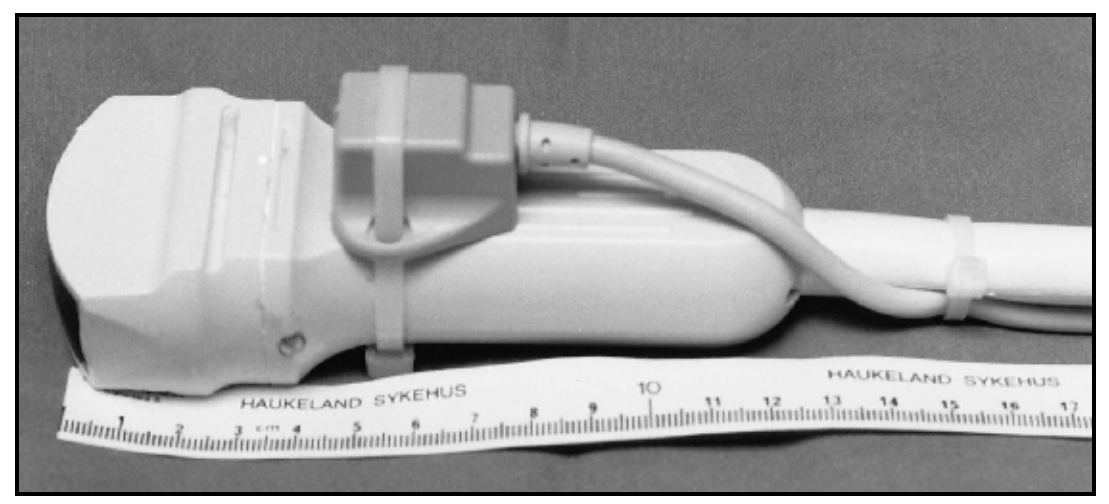

Figura 7.3 - Imagem ilustrando o esquema de acoplamento do sensor do trabalho de GILJA et al. (1998).

Diferentemente de outras propostas da literatura, neste trabalho não foi necessária a criação de um módulo para corrigir esse tipo de distorção, pois os dados devem ser adquiridos com o sensor acoplado a uma distância de aproximadamente $3 \mathrm{~cm}$ do transdutor. O simples fato de acoplar o sensor dessa forma faz com que não sejam geradas distorções grosseiras nas aquisições das coordenadas 3D, nem que seja necessário realizar testes de calibração do sistema toda a vez que o sensor for acoplado ao transdutor.

\subsection{Conclusões Finais Sobre o Sistema USOTri}

A vantagem da presente proposta de adaptação dos aparelhos de ultra-som é que, com a utilização do sistema aqui desenvolvido, é possível gerar imagens tridimensionais em qualquer desses aparelhos, desde que ofereça o Modo-B de visualização de imagens, reduzindo muito o custo quando comparado com a aquisição de um aparelho de ultra-som $3 \mathrm{D}$. 
Infelizmente, para este tipo de adaptação dos aparelhos de ultra-som convencionais para a geração de imagens 3D, é imprescindível ainda a utilização de um sensor de coordenadas 3D, que custa aproximadamente US $\$ 3.000,00$.

Várias dificuldades também foram encontradas utilizando o sensor em relação ao espaço físico da sala de exame obstétrico. Geralmente, salas deste tipo apresentam uma grande quantidade de equipamentos presentes, e em sua maioria grandes equipamentos ou suportes feitos de metal, que podem influenciar na distorção do campo magnético entre o sensor e a fonte. Como exemplo, é possível apresentar a Figura 7.4 que ilustra uma cadeira onde são realizados os exames obstétricos, a qual é toda de metal. Por isso, cuidados especiais foram tomados para que tanto o sensor quanto a fonte magnética não fossem muito aproximados dela, ainda que fosse o local de apoio da paciente.

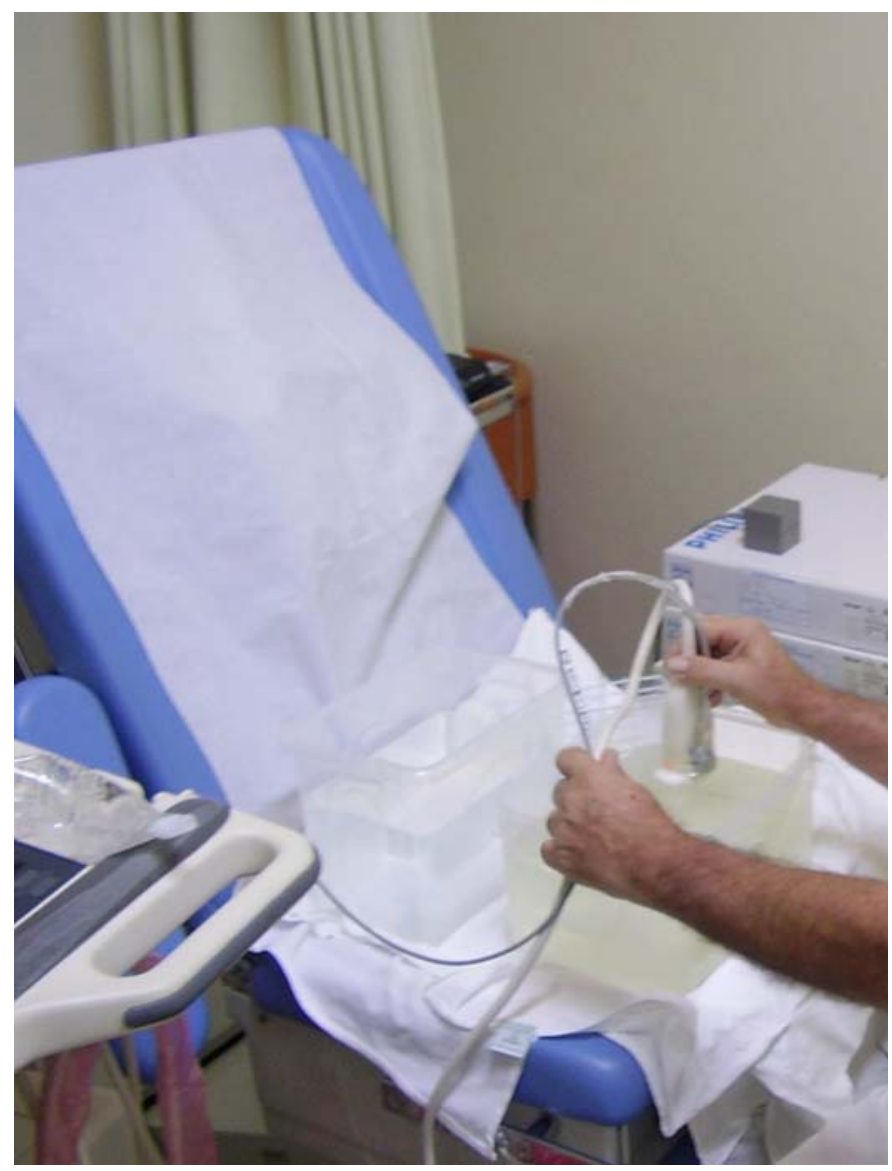

Figura 7.4 - Cadeira para exames obstétricos feita de metal. 
Diferente dos sistemas propostos até aqui, um aspecto inédito deste projeto está na sua capacidade para funcionar em qualquer arquitetura e sistema operacional. Após a captura das imagens, também é possível a visualização 3D através da Internet.

A interface do software com o usuário do sistema é um fator importante. Por esse motivo, ela deve ser bem estruturada, oferecendo as ferramentas de manipulação e processamento do volume 3D, sem aumentar o nível de complexidade da utilização do sistema, para que o usuário possa interagir de acordo com as suas necessidades, extraindo desta forma maior proveito das ferramentas que são disponíveis.

É importante em um exame clínico que os resultados sejam imediatos. Por esse motivo, este sistema apresenta a reconstrução do volume no menor tempo possível para que o operador do aparelho possa avaliar os resultados do volume capturado. Este processo não consome mais que alguns segundos, de acordo com o que foi apurado nos testes de campo.

O fator negativo é que as imagens não podem ser geradas no Modo 4D, que consiste em imagens 3D em movimento, pois neste esquema é necessário primeiramente fazer a varredura das imagens bidimensionais no aparelho de ultra-som para depois fazer a reconstrução tridimensional no computador. Isso, entretanto, não é necessariamente uma desvantagem, já que a obtenção da imagem tridimensional é rápida e é possível ainda durante o tempo de realização do exame, ou seja, enquanto a paciente ainda se encontra na sala.

Cuidados adicionais devem ser levados em consideração no momento da captura do volume tridimensional no exame, pois o sensor magnético é suscetível à interferência magnética que pode ocorrer pela presença de peças de metal que porventura estejam próximas dele, as quais devem ser afastadas para que a aquisição das coordenadas de posicionamento do sensor não seja afetada. 
Para este trabalho, foi de fundamental importância a aquisição do sensor de coordenadas 3D para ser acoplado juntamente com o transdutor, para que, juntamente com as imagens capturadas, seja armazenada a posição, a direção e a angulação do transdutor para cada uma, sendo possível, desta forma, distribuir melhor as imagens no volume 3D, produzindo um retrato mais fiel da estrutura em estudo.

Futuramente pretende-se desenvolver um encaixe para o transdutor destes aparelhos convencionais de modo que, a partir de componentes internos de um mouse como o sensor de movimento, possa ser utilizado para controlar a movimentação do transdutor que ficará nele conectado, buscando descartar o sensor Patriot.

Um mini-motor pode ser acoplado também neste esquema, descartando a movimentação manual do operador para a aquisição do volume, o que proporcionaria também a capacidade desse sistema conseguir gerar as imagens 3D em movimento (Modo 4D). A vantagem disso é que esse aparato pode ser montado com peças de mouse, cujo custo é extremamente baixo. Uma outra vantagem seria que, diferentemente do sensor magnético, o sensor de posição do mouse não é afetado por peças de metal que podem estar presentes em uma sala de exames, e por esse motivo, acaba sendo uma melhor opção do que o sensor magnético.

\subsection{Acesso à Tecnologia}

Muitas vezes, os pais estão presentes durante os exames pré-natais e, por dificuldade na compreensão das fatias transversais geradas nas imagens de ultra-som do feto em imagens bidimensionais, não conseguem constituir uma imagem do futuro bebê em suas mentes.

Existe um grande desnível social em países do $3^{\circ}$ mundo, como no caso do Brasil, onde algumas pacientes podem pagar por um acompanhamento de médicos particulares, 
que possuem em suas clínicas aparelhos mais modernos como o ultra-som 3D comercial e por esse motivo têm o privilégio de poder acompanhar a feição de seu filho mesmo ainda com idade gestacionária.

Por outro lado, as pacientes mais humildes dispõem apenas de acompanhamento em ambulatórios da rede pública de saúde, onde a presença de aparelhos 3D comerciais de última geração ainda não é realidade. A expectativa desse projeto é que essas pacientes poderiam ser beneficiadas dos resultados desse trabalho, a partir da adaptação dos aparelhos convencionais para a geração de imagens em 3D.

Este sistema foi desenvolvido tomando como base as mais novas tecnologias disponíveis na linguagem Java. Todos os módulos, desde a comunicação com o sensor 3D, passando pela captura de vídeo do aparelho de ultra-som até a visualização tridimensional, foram desenvolvidas tomando como base o princípio fundamental desta linguagem, que é a portabilidade, ou seja, em qualquer tipo de computador, indiferente do sistema operacional em utilização, é possível a utilização do programa. Outro fato importante é que este sistema pode ser facilmente utilizado através da Internet, o que é possível graças às características presentes em sistemas desenvolvidos na linguagem Java.

\subsection{Conclusão Final}

Esse trabalho apresentou uma nova metodologia para permitir a reconstrução tridimensional de imagens de ultra-som a partir de um aparelho convencional que gera imagens no Modo-B.

A grande vantagem desse sistema é permitir a qualquer hospital ou clínica de

diagnóstico por imagem uma "adaptação" do aparelho convencional de ultra-som já existente em um sistema 3D de baixo custo. Essa "adaptação" necessita de um sensor 
Polhemus Patriot e uma placa de vídeo-captura, além de um microcomputador, a um custo muito inferior se comparado a um aparelho de ultra-som 3D comercial.

Atualmente os equipamentos 3D comerciais possuem um custo proibitivo para a aquisição na maioria dos Hospitais e Ambulatórios públicos no Brasil, e este trabalho apresenta-se como uma alternativa para a geração de imagens a um custo muito mais baixo e eficaz.

Além disso, o sistema proposto pode ser utilizado através da Internet, o que permite que sua ampla difusão. Futuramente os custos podem ser ainda mais reduzidos com a utilização de outra tecnologia mais barata que o sensor Patriot.

\subsection{Sugestões para trabalhos futuros}

Elaboração de um estudo com técnicas de HCI (Human Computer Interaction) para a criação de uma interface mais intuitiva e amigável para o usuário.

Adaptação de um módulo para a realização de cálculos e medições volumétricos, baseados nas imagens em 3D.

Desenvolvimento de um estudo comparativo com técnicas de redução de efeito speckle com baixo custo computacional para o aumento da qualidade visual na utilização em volumes de imagens 3D.

Adaptação de um mini motor elétrico para movimentar o transdutor convencional, eliminando desta forma a movimentação manual e a necessidade da utilização dos sensores de rastreamento 3D, para a captura das imagens e possibilitando a obtenção do efeito 4D (Imagem 3D em movimento). 


\section{Referências Bibliográficas}

BABA, K. et al. (1999). Fetal abnormalities; evaluation with real-time-processible three-dimensional USpreliminary report. Radiology. May; 211 (2) 441-6, 1999.

BEGA, G.; LEV-TOAFF, A.; KUHLMAN, K.; KURTZ, A.; GOLDBERG, B.; WAPNER, R. (2001). Three-dimensional ultrasonographic imaging in obstetrics - Present and future applications. Journal of Ultrasound in Medicine. 20 (4): 391-408 Apr, 2001.

BLUTH, E.I.; BENSON, C.B.;ARGER, P.H. (1999). Ultrasound in obstetrics and gynecology: A Pratical approach. Thieme Medical Publishers. 1999.

BREDTHAUER, G.R.; VON RAMM, O.T. (2004) Interactive Rendering of Real Time Volumetric Ultrasound Images. IEEE International Symposium on Biomedical Imaging: From Nano to Micro, Arlington, Virginia, April 15-18, 2004. 
CAMPBELL, S. (2002). 4D, or not 4D: that is the question. Ultrasound in Obstetrics and Gynecology. 19: 1-4, 2002.

CANDIANI, F. (1998). The latest in ultrasound: three-dimensional imaging. Part 1 European Journal of Radiology. 27: S179-S182 Suppl. 2 May, 1998.

CARR, J.J.; BROWN, J.M. (1998). Introduction to biomedical equipment technology. Upper Saddle River, N.J.: Prentice Hall, 1998.

CHEN, J.X.; WEGMAN E.J. (2006). Foundations of 3D Graphics Programming Using JOGL and Java3D. Springer, 2006.

CHMAIT, R. et al. (2002). Prenatal evaluation of facial clefts with two-dimensional and adjunctive three-dimensional ultrasonography: a prospective trial. Am J Obstet Gynecol Oct; 187 (4): 946-9, 2002.

DANTAS, R.G.; LEEMAN, S.; EDUARDO, T.C. (2002). Redução de Interferências Destrutivas em Imagens Ultra-Sônicas Utilizando Novas Variações do Método de Diversidade de Freqüências: Resultados Preliminares. CBEB' 2002. XVIII Congresso Brasileiro de Engenharia Biomédica. p. 261-266, 2002.

DEITEL H.M.; DEITEL P.J. (2005). Java como programar. Pearson Prentice Hall, 2005.

DETMER, P.R.; BASHEIN, G.; HODGES, T. (1994). 3-D ultrasonic image feature localization based on magnetic scanhead tracking: in vitro calibration and validation. Ultrasound Med. Biol. 20:923-936, 1994. 
DREBIN, R.A.; CARPENTER L.; HANRAHAN P. (1988) Volume rendering. In John Dill, editor, Computer Graphics (SIGGRAPH '88 Proceedings), volume 22, pages 65-74, August, 1988.

DYSON, R.L. et al. (2000). Three-dimensional ultrasound in the evaluation of fetal anomalies. Ultrasound Obstet Gynecol September; 16(4):321-8, 2000.

EBERT, D.; MUSGRAVE, K.; PEACHEY, D.; PERLIN, K. (1994). Texturing and Modeling: A Procedural Approach. Academic Press, October, 1994.

ELVINS, T.T. (1992). A Survey of Algorithms for Volume Visualization. Computer Graphics. vol 26 (3), pp. 194-201, 1992.

FOLEY, J.; VAN DAM, A.; FEINER, S.; HUGHES, J. (1990). Computer Graphics: Principles and Practice. Addison-Wesley, 1990.

GEISER, E.A; ARIET, M.; CONETTA, D.A.; LUPKIEWIEZ, S.M.; CHRISTIE, L.G.Jr.; CONTI, C.R. (1982a). Dynamic three-dimensional echocardiographic reconstruction of the intact buman left ventricle: Technique and initial observations in patients. American Heart Journal 103:1056-1065, 1982.

GEISER E.A.; CHRISTIE, L.G.Jr.; CONETTA, D.A.; CONTI, C.R.; GOSSMAN, G.S. (1982b). A mechanical arm for spatial registration of two-dimensional echocardiopraphic sections. Catheterization and Cardiovascular Diagnosis 8:89-101, 1982. 
GHI, T. et al. (2002). Two-dimensional ultrasound is accurate in the diagnosis of fetal craniofacial malformation. Ultrasound Obstet Gynecol. Jun; 19 (6): 543-51, 2002.

GILJA, O.H.; HAUSKEN, T.; OLAFSSON, S.; MATRE K.; ODEGAARD, S. (1998). In Vitro Evaluation of Three-Dimensional Ultrasonography Based on Magnetic Scanbead Tracking. Ultrasound in Med. \& Biol., Vol. 24, No. 8, pp. 1161-1167, 1998.

HALL, P.M.; WATT, A.H. (1991). Rapid volume rendering using a boundary-fill guided ray cast algorithm. In N. M. Patrikalakis, editor, Scientific Visualization of Physical Phenomena (Proceedings of CG International '91), pages 235-249. Springer-Verlag, 1991.

HE, T.; HONG, L.; KAUFMAN, A.; PFISTER, H. (1996). Generation of Transfer Functions with Stochastic Search Techniques. Proceedings IEEE Visualization 1996, pp. 227-234. IEEE Computer Society Press, October 1996.

HEDRICK, W.R.; DAVID, L.H.; STARCHMAN, D.E. (1995). Ultrasound physics and instrumentation. St. Louis : Mosby, c1995. $3^{\text {rd }}$ ed., 1995.

HORSTMANN, C.S.; CORNELL, G. (2001). Core Java 2; tradução de João Eduardo Nóbrega Tortello. São Paulo : Pearson Education do Brasil, 2001.

HUANG, Q.H.; ZHENG, Y.P.; LU, M.H.; CHI, Z.R. (2005). Development of a portable 3D ultrasound imaging system for musculoskeletal tissues. UltraSonics. 43: 153-163, 2005.

HUGHES, S.W.; D’ARCY T.J.; MAXWELL, D.J.; CHIU, W.; MILNER, A.; SAUNDERS, J.E.; SHEPPARD, R.J. (1996). Volume Estimation from Multiplanar 2D 
Ultrasound Images Using a Remote Electromagnet Position and Orientation Sensor. Ultrasound in Med. \& Biol., Vol. 22, No. 5, pp. 561-572, 1996.

JENSEN, J.A. (1996). Field: A Program for Simulating Ultrasound Systems. 10th Nordic-Baltic Conference on Biomedical Imaging Published in Medical \& Biological Engineering \& Computing, pp. 351-353, Volume 34, Supplement 1, Part 1, 1996.

KELLEY, I.M.; GARDENER, J.E.; BRETT, A.D.; RICHARDS, R.; LEES, W.R. (1994). Three-dimensional US of the fetus - work in progress. Radiology. 192:253-259, 1994.

LEVOY, M. (1987). Rendering of Surfaces from Volumetric Data. Tech. Report 87-016, Computer Science Dept., Univ. of North Carolina, Chapel Hill, 1987.

LEVOY, M. (1988a). Direct Visualization of Surfaces from Computed Tomography Data. SPIE Medical Imaging II Conf. Proc. Newport Beach, Calif., Feb. 1988.

LEVOY, M. (1988b). Display of Surfaces from Volume Data. IEEE Computer Graphics and Applications, Vol. 8, No. 3, pp. 29-37, May 1988

LICHTENBELT, B.; CRANE, R.; NAQVI, S. (1998) Introduction to Volume Rendering. Prentice Hall PTR, 1998.

LORENSEN, W.E.; CLINE, H.E. Marching Cubes: A High Resolution 3D Surface Construction Algorithm. Computer Graphics (Proc. SIGGRAPH), pp. 163-169, July 1987. 
MAELAND, E. (1988). On the Comparation of Interpolation Methods. IEE Transactions on Medical Imaging, 7(3):213-217, September 1988.

MARKS, J.; ANDALMAN B.; BEARDSLEY P.A.; FREEMAN, W.; GIBSON, S.; HODGINS, J. KANG, T.; MIRTICH, B.; PFISTER, H.; RUML, W.; RYALL, K.; SEIMS, J.; SHIEBER, S. Design Galleries: A General Approach to Setting Parameters for Computer Graphics and Animation. Proceedings of SIGGRAPH '97, pp. 389-400. ACM SIGGRAPH, New York, August 1997.

MEINEL, K. et al. (1998). Transparent 3-D ultrasound in fetal abnormalities. Ultraschall Med, Jun;19(3) 120-5, 1998.

MERZ, E. et al. (1995). Three-dimensional ultrasonography in prenatal diagnosis. J Perinatat Med. 23 (3): 213-22, 1995

MCREYNOLDS, T.; BLYTHE, D. (1998). Advanced Graphics Programming Techniques Using OpenGL. SIGGRAPH ‘98 Course, 1998.

PRAGER, R.W.; ROHLING, R.N.; GEE, A.H.; BERMAN L. (1998). Rapid Calibration for 3-D Freehand Ultrasound. Ultrasound in Med. \& Bio, Vol 24, No 6, pp. 855-869, 1998.

PRESTON, S. (2006). The Definitive Guide to Building Java Robots. Apress, 2006.

RAICHLEN, J.S.; TRIVEDI, S.S.; HERMAN, G.T.; St. JONH SUTTON, M.G.; REICHEK, N. (1986). Dynamic three-dimensional reconstruction of the left ventricle from twodimensional echocardiograms. Journal of American College Cardiology. 8:364-370, 1986. 
RANKIN, R.N.; FENSTER, A.; DOWNEY, D.B.; et al. (1993). Tree-dimensional sonographic reconstruction: techniques and diagnostic applications. Am J. Roentgenol. 161:695-702, 1993.

RICKEY, D.W.; PICOT, P.A.; CHISTOPHER, D.C.; FENSTER, A. (1995). A wall-less vessel phantom for Doppler ultrasound studies. Ultrasound Med Biol 21:1163-1175, 1995.

SACKMAN, M.; PAULETZKI, J.; ZWIEBEL, F.; HOLL, J. (1994) Three-Dimensional Ultrasonography in Hepatobiliary and Pancreatic Diseases. Bildgebung. 61:104-9, 1994.

SAKAS, G.; WALTER, S. (1995) Extracting Surfaces from Fuz:y 3D-Ultrasound Data. ACM Press. Proceedings of SIGGRAPH 465-474, 1995.

SAWADA, H.; FUJII, J.; KATO K.; ONOE, M.; KUNO, Y. (1983). Three dimensional reconstruction of the left ventricle from multiple cross sectional echocardiograms, V alue for measuring left ventricular volume. Br Heart Journal 50:438-442, 1983.

SHEIKH, K.; SMITH, S.; et al. (1991). Real-Time, Three Dimensional Echocardiography: Feasibility and Initial Use. Echocardiography 8(1): 119-125, 1991.

SMITH, S.W., HENRY, J.; PAVY, G.; et al. (1991). High-speed ultrasound volumetric imaging system - Part I: Transducer design and beam steering. IEEE Transactions on Ultrasonics, Ferroelectrics, and Frequency Control 38(2): 100-108.

SMITH, S.W.; PAVY, H.G.; et al. (1992). Improved real-time volumetric ultrasonic imaging. Ultrasonic Imaging 14: 186-211, 1992. 
STEINER, H.; SAUDACH, A.; SPITZER, D.; SCHAFFER, H. (1994). Tree-dimensional ultrasound in obstetrics and gynecology: technique, possibilities and limitations. Hum Reprod. 9:1773-1778, 1994.

STETTEN, G. D.; PIZER, S.M. (1999). Medial-Node Models to Identify and Measure Objects in Real-Time 3-D Echocardiography. IEEE TRANSACTIONS ON MEDICAL IMAGING, VOL. 18, NO. 10, OCTOBER 1999.

TERRAZAS A.; OSTUNI J.; BARLOW M. Java ${ }^{\mathrm{TM}}$ Media APIs: Cross-Platform Imaging, Media, and Visualization. Sams Publishing. November 26, 2002

VON RAMM, O.T.; SMITH, S.W.; et al. (1991). High-speed ultrasound volumetric imaging system - Part II: Parallel processing and image display. IEEE Transactions on Ultrasonics, Ferroelectrics, and Frequency Control 38(2): 109-115, 1991.

VON RAMM, O.T. (2003) Real-time three dimensional echo for clinical echocardiology, Ultrasound in Medicine \& Biology, Volume 29, Issue 5, Supplement 1, Pages S118-S119, May 2003.

WOO, M. et al. (1999). OpenGL programming guide: the official guide to learning OpenGL, version 1.2 / OpenGL Architecture Review Board. Addison-Wesley, 1999.

WRIGHT, R.S. (1996). OpenGL Superbible: the complete guide to OpenGL programming for Windows NT and Windows 95. Richard S. Wright, Jr. and Michael Sweet, 1996. 
